\title{
FIELD STRENGTH MEASUREMENTS OF SPEED MEASURING RADAR UNITS
}

\author{
R. C. Baird \\ R. L. Lewis \\ D. P. Kremer \\ S. B. Kilgore
}

National Bureau of Standards

U.S. Department of Commerce

Washington, D.C. 20234

Contract No. DOT HS-7-01697

Contract Amt. $\$ 75,900$

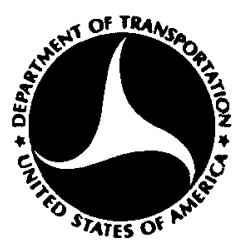

\section{JUNE 1981 \\ INTERIM REPORT}

\author{
This document is available to the U.S. public through the \\ National Technical Information Service, \\ Springfield, Virginia 22161
}

Prepared for

U.S. DEPARTMENT OF TRANSPORTATION

National Highway Traffic Safety Administration

Washington, D.C. 20590 
This document is disseminated under the sponsorship of the Department of Transportation in the interest of Information exchange. The United States Government assumes no liability for its contents or use thereof. 
Technical Report Documentation Page

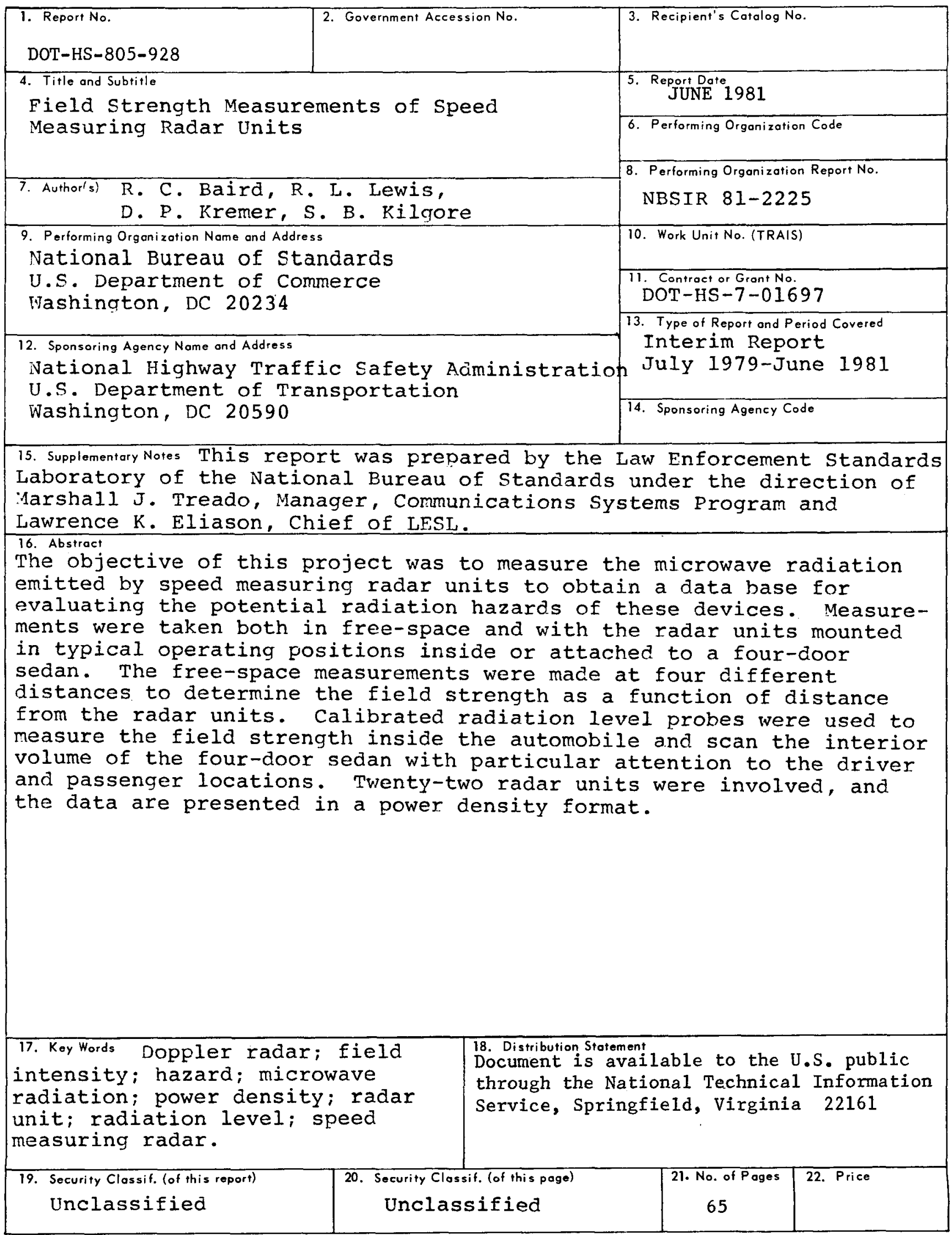

Form DOT F $1700.7(8-72) \quad$ Reproduction of completed page authorized 
Methic CONVERSION factors

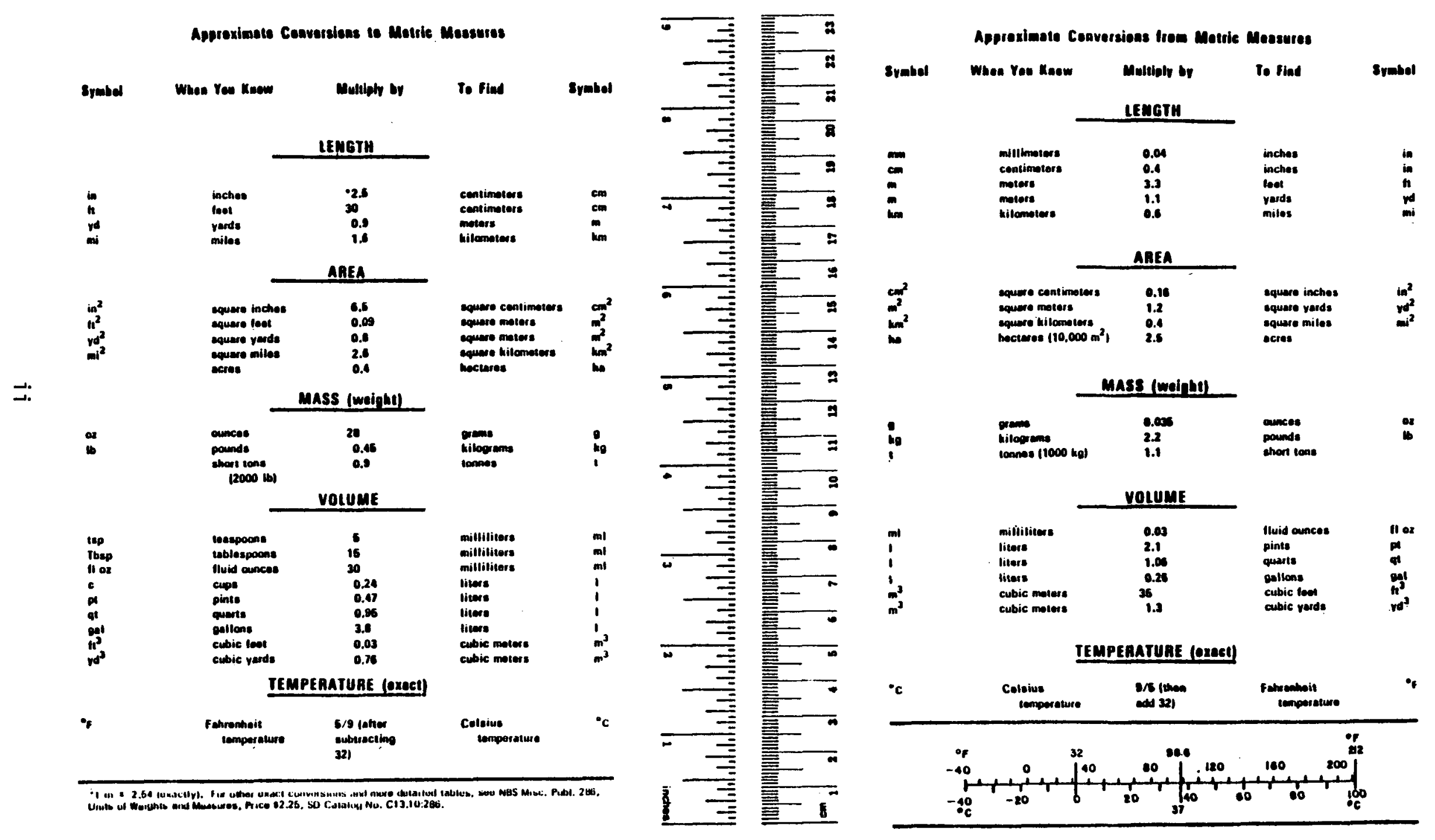




\section{ACKNOWLEDGMENTS}

This report was prepared by the Law Enforcement Standards Laboratory of the National Bureau of Standards under the direction of Marshall J. Treado, Manager, Communications Systems Program and Lawrence K. Eliason, Chief of LESI. Dr. R. C. Baird directed the experimental measurement program which was carried out by $R$. L. Lewis and D. P. Kremer during the task I free-space measurement portion, and S. B. Kilgore during the task 2 vehicular measurement portion. A. C. Newell also assisted in the development of the measurement techniques. This project was sponsored by the National Highway Traffic Safety Administration, Department of Transportation, under Interagency Agreement DOT-HS-7-01697. The assistance of Ronald Engle and Dr. James Frank, NHTSA Contract Technical Monitors, is gratefully acknowledged. 
The National Highway Traffic Safety Administration (NHTSA) is engaged in a continuing effort to fulfill the objectives of the Highway safety Act of 1968. Accordingly, NHTSA has a particular interest in devices used for measuring vehicle speeds for law enforcement purposes. In August 1977 the NHTSA entered into an interagency agreement, DOT-HS-7-01697, with the National Bureau of Standards (NBS) for the purpose of developing performance standards and a qualified product list of speed measuring devices used for law enforcement purposes.

Modification 7 to the interagency agreement, initiated in July 1979, provided for the measurement of the strength of microwave fields surrounding typical speed measuring radar devices, both in free space and in a typical working environment. This research and testing has been performed by the personnel of the Electromagnetic Fields Division under the cognizance of the Law Enforcement Standards Laboratory (LESL) of IJBS. The results are included in this document.

Among the tasks performed by the LESL for the NHTSA is the preparation of technical reports on the results of research and testing. This document is one such report. Technical comments and suggestions are invited from interested parties. They may be addressed to the authors, or to the undersigned at the National Bureau of Standards, washington, DC 20234.

Lawrence K. Eliason, Chief

Law Enforcement Standards Laboratory 
Foreword . . . . . . . . . . . . . . . . . . . . . . . . iv

1. Introduction . . . . . . . . . . . . . . . . . . . . . . . . . . . 1

2. Task 1 Measurements . . . . . . . . . . . . . . . . . . . . . . . 2

2.1 General Approach . . . . . . . . . . . . . . . . . . . . . . 2

2.2 Description of Measurement . . . . . . . . . . . . . . . . . . 3

2.3 Calibration of Measurement System . . . . . . . . . . . . . . . 4

2.4 Measurement Procedures and Results . . . . . . . . . . . . . . 7

3. Task 2 Measurements . . . . . . . . . . . . . . . . . . . . . . . . 9

3.1 General Approach . . . . . . . . . . . . . . . . . . . . . . . 9

3.2 Probes Used for the Vehicular Measurements . . . . . . . . . . 9

3.3 Measurement Procedures and Results . . . . . . . . . . . . . . . . . 11

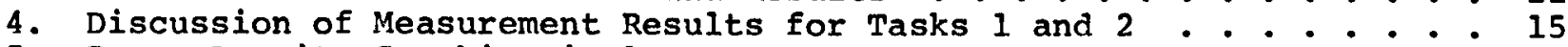

5. Power Density Graphic Displays . . . . . . . . . . . . . . . . . . . 16

Appendix A--References . . . . . . . . . . . . . . . . . . . . . . . . . . 


\author{
R. C. Baird, R. K. Lewis, D. P. Kremer, S. B. Kilgore* \\ National Bureau of Standards \\ Washington, DC 20234
}

\begin{abstract}
The objective of this project was to measure the microwave radiation emitted by speed measuring radar units to obtain a data base for evaluating the potential radiation hazards of these devices. Measurements were taken both in free-space and with the radar units mounted in typical operating positions inside or attached to a four-door sedan. The free-space measurements were made at four different distances to determine the field strength as a function of distance from the radar units. Calibrated radiation level probes were used to measure the field strength inside the automobile and scan the interior volume of the four-door sedan with particular attention to the driver and passenger locations. Twenty-two radar units were involved, and the data are presented in a power density format.
\end{abstract}

Key words: Doppler radar; field intensity; hazard; microwave radiation; power density; radar unit; radiation level; speed measuring radar.

\title{
1. INTRODUCTION
}

The objective of this project was to accurately measure the microwave radiation emitted by speed measuring radar units in order to obtain a data base for evaluating the potential radiation hazards of such devices. To meet this objective, the following two measurement tasks were undertaken.

Task 1. Free-Space Measurements: Direct measurements of the field strength levels surrounding 20 different radar units were made in the laboratory under approximate free-space conditions. In order to obtain data in the side- and back-lobe regions as well as in the direction of the main beam, measurements were made at selected points on an imaginary spherical surface centered at the aperture of the radar unit. Further, measurements were made at several distances in order to determine the field strength as a function of distance from the radar units.

Task 2. Vehicular Measurements: The radar units were mounted inside or attached to a four-door sedan in normal operational configurations. Calibrated radiation level probes were used to measure the field strength inside the automobile and to scan the entire interior volume of the vehicle, with particular attention to the driver and passenger locations. This task provided data on field strengths inside the automobile under simulated operating conditions.

*Electromagnetic Fields Division, Center for Electronics and Electrical Engineering. 


\section{TASK 1 MEASUREMENTS}

\subsection{General Approach}

The purpose of this task was to measure the field intensity in the region surrounding each radar unit and to determine and display the power density as a function of direction and distance from the radar. The measurements were performed at the National Bureau of Standards (NBS) nearfield scanning facility employing standard antenna measurement techniques.

The experimental arrangement and coordinate system are shown in figure 1. The radar was mounted on a model mount aimed at a small receiving antenna (probe), and aligned so that the aperture was in the $x-y$ plane and the direction of the main beam was along the z-axis which coincided with the axis of the receiving probe. The radar was then rotated (scanned) a full $360^{\circ}$ about the $y$-axis ( $\theta$ rotation) and the received signal was recorded at $5^{\circ}$ intervals in $\theta$. Next, the radar was rotated by $10^{\circ}$ about its own axis ( $\phi$ rotation) and the $\theta$ scan was repeated. (Note that, as shown in figure 1 , the $\phi$-rotation axis coincides with the $z$ axis for $\theta=0$.$) This process of$ stepping in $\phi$ and scanning in $\theta$ was repeated until data had been obtained over the entire measurement sphere enclosing the radar. The complete process was repeated for several separation distances, d.

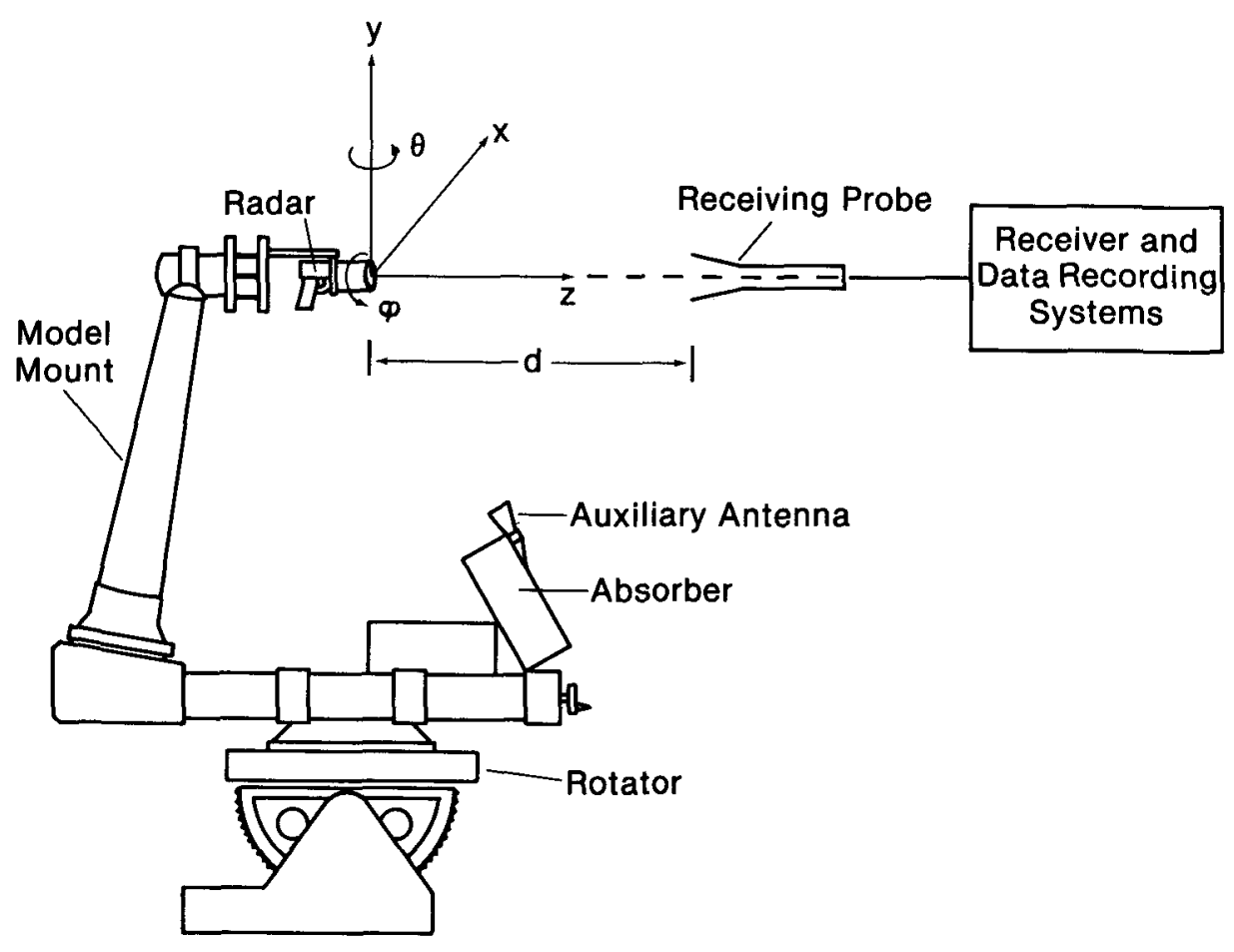

Figure 1. Experimental setup used for measuring electromagneric field strength in the vicinity of speed radar units. 
The received power, $P_{R^{\prime}}$ picked up by the probe was determined by means of a calibrated receiving system. The power density, $W$, incident on the receiving probe, was determined from the relation

$$
W=\frac{4 \pi P_{R}}{\lambda^{2} G}
$$

In this equation, $G$ is the gain of the probe and $\lambda$ is the free-space wavelength of the energy emitted by the radar unit [1] ${ }^{1}$.

\subsection{Description of Measurement System}

The measurement system is shown schematically in figure 2 as connected for power-density measurements. The signal generator, rotary-vane attenuator (RVA), thermistor, and power meter were only used in the calibration process to be described later. The rest of the system functioned as follows. The electromagnetic (EM) field emitted by the radar was sampled by a small probe antenna. The probe output signal was detected in the mixer and amplified and measured in the receiver. Finally, the amplitude was digitized and recorded on magnetic tape for later computer processing. A coaxial mixer was used for the $X$-Band measurements and a waveguide mixer was used at $\mathrm{K}$-Band. The receiver used was a calibrated, three-channel, wide-band, phase-amplitude model.

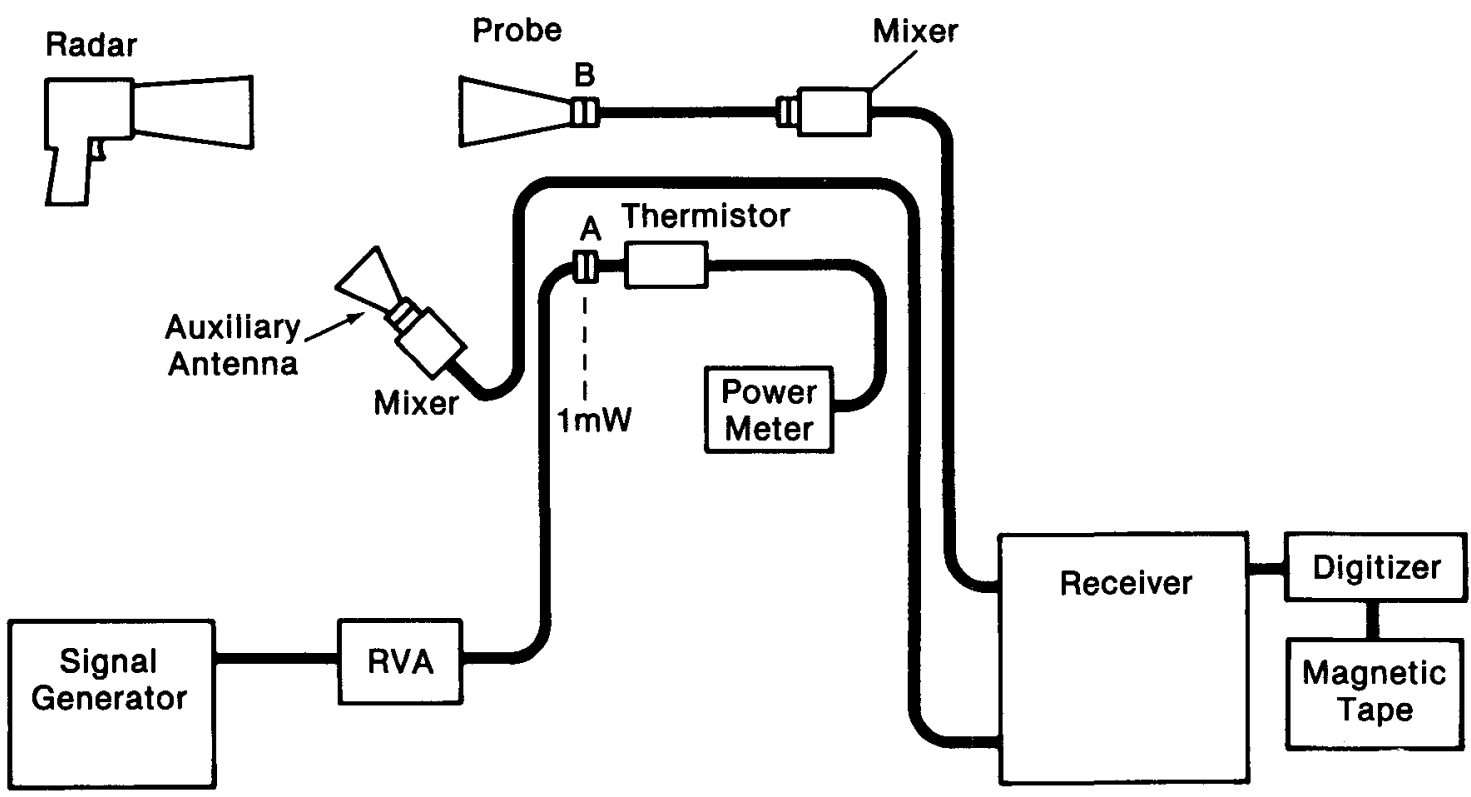

Figure 2. Schematic diagram of measurement system used to determine power density. As shown here, the system is connected for measuring the probe output produced by an incident electromagnetic field. The auxiliary antenna and circuit provide a stable reference signal to which the receiver is phase locked. A $1 \mathrm{~mW}$ calibrating signal is established at point $A$ by means of the calibrated thermistor, power meter, and rotary-vane attenuator (RVA).

\footnotetext{
${ }^{1}$ Numbers in brackets refer to references in appendix $\mathrm{A}$.
} 
In order for the receiver to have sufficient sensitivity to detect the weak signals existing in the side- and back-lobe regions, it must be phase locked to the radar. Since it was not feasible to connect a cable to the radar, the phase-lock signal was provided by means of an auxiliary antenna and mixer which responded to the side-lobe energy radiated by the radar and provided a constant signal for phase locking the receiver. Note that the auxiliary antenna and mixer were mounted on the rotator ( $f i g .1$ ) so that, as the radar was rotated in azimuth $(\theta)$, the relative positions of the radar and auxiliary antenna remained unchanged and the phase-lock signal remained constant within $+1.0 \mathrm{~dB}$. As the radar was rotated in $\phi$, changes of as much as $+3 \mathrm{~dB}$ in the amplitude of the phase-lock signals were observed, due mainIy to the change in polarization. However, the receiver remained locked during these changes and, since the data were recorded only during $\theta$ scans with constant $\phi$, these changes of amplitude in the locking signal were of no consequence. The auxiliary antenna was mounted below the probe and well out of the main beam, so there was no significant interaction between them; that is, the auxiliary antenna did not noticeably perturb the field measured by the probe.

The auxiliary antenna used for the $\mathrm{X}$-Band measurements was a broadband conical spiral with Type $N$ connector and it was connected to a coaxial mixer. The $\mathrm{k}$-Band auxiliary system consisted of a standard gain horn and waveguide mixer.

\subsection{Calibration of Measurement System}

\subsubsection{Calibration Procedure}

Absolute calibration of the power density measurement equipment was accomplished by means of the signal generator, attenuator, thermistor, and power meter of figure 2. The signal generator provided a calibrating signal of constant amplitude and frequency. The power of this signal at point A was measured by the calibrated thermistor and power meter combination, and accurate changes in this power level were accomplished by means of the RVA. The procedure for carrying out the calibration was as follows.

The radar was set at $\theta=0$ and $\phi=0$, in which case the probe measures the power in the main beam and the probe output signal was near a maximum for that distance. Under these conditions the receiver amplitude was set at $00.00 \mathrm{~dB}$. Next, the signal generator frequency was set equal to the radar frequency and, with the RVA set at $0 \mathrm{~dB}$, the signal generator amplitude was adjusted so that the power meter indicated $1 \mathrm{~mW}$. This means that $1 \mathrm{~mW}$ of power was available at $A$ if the thermistor and power meter had been calibrated correctly and all mismatch effects taken into consideration.

The next step was to disconnect the auxiliary mixer from the auxiliary antenna and connect the mixer to the signal generator as shown in figure 3 . This link provided the required phase-lock signal for the receiver. The transmission line connecting the RVA to the thermistor was disconnected at $A$ and connected to the primary mixer at $B$ in place of the probe (see fig. 3 ). Following these connections, the RVA was adjusted until the receiver again read approximately $00.00 \mathrm{~dB}$. The attenuator reading was noted, along with the offset from zero on the receiver. Finally, the circuits were reconnected as in figure 2 to make sure that no significant drift occurred during the calibration.

The above procedure determined the output power from the probe at $B$ with respect to $1 \mathrm{~mW}$. In other words, if the final RVA setting was $K d B$ and the receiver offset was $L$ dB, then the probe output signal would be $(K+L) d B$ below $1 \mathrm{mw}$. Eq (1) can then be used to calculate the incident on-axis power density, and the power densities at all other points are known since they were measured with respect to the on-axis value. 


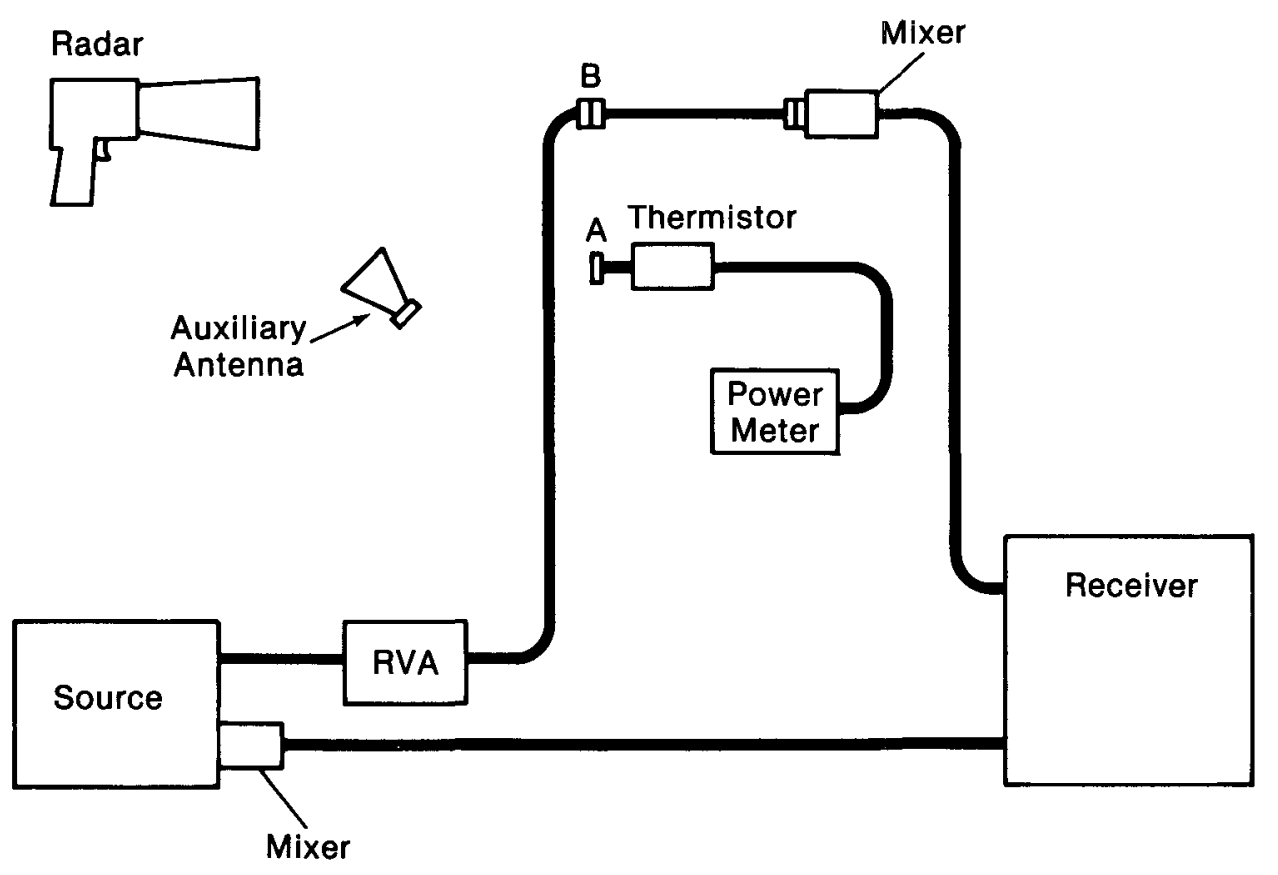

Figure 3. Schematic diagram of measurement system as it is connected for calibrating the probe output signal. The $1 \mathrm{~mW}$ calibrating signal is inserted at $B$ and compared with the signal produced by the probe antenna (see sec. 2.3.1 for details).

This calibration procedure was repeated at every measurement distance used for each radar.

\subsubsection{Estimated Measurement Accuracy}

According to eq (1), the accuracy of the measured power density depends on how accurately the received power is determined by the calibration procedure of the preceding section, and on how well $G_{P}$, the gain of the probe, is known. The accuracy of the $\mathrm{P}_{\mathrm{R}}$ calibration depends, in turn, on the accuracies of the attenuator, thermistor, power meter, and receiver. An additional factor is the degree of repeatability associated with the disconnection and connection of the transmission lines and probe at points $A$ and $B$ of figures 2 and 3 . Any amplitude drifts in system components or in the radar itself will also affect the repeatability.

The RVA is a calibrated, precision laboratory standard with an uncertainty of less than $+0.02 \mathrm{~dB}$ over the range 0 to $20 \mathrm{~dB}$ used for these measurements. The thermistor mounts were calibrated to account for mismatch effects, loss due to absorption within the mount but not in the thermistor elements, and the dc-to-microwave substitution error. The estimated uncertainty associated with the thermistor mount is $+0.06 \mathrm{~dB}$, and the uncertainty of the power meter used with the thermistor mount is $\pm 0.13 \mathrm{~dB}$. The uncertainty due to non-linearity of the receiver is $\pm 0.04 \mathrm{~dB}$.

The repeatability error was determined by repeating the procedure of section 2.3 .1 and observing any variations in the attenuator setting and receiver readings, The final receiver reading, following reconnection of the probe, was especially significant for indicating drift and flange 
connection errors. The uncertainty due to non-repeatability was estimated to be $\pm 0.20 \mathrm{~dB}$.

The theoretical gain value of each probe at the frequency of interest was used. These values are:

$$
\begin{array}{lr}
\mathrm{X} \text {-Band }(10.53 \mathrm{GHz}) & 16.7 \mathrm{~dB} \pm 0.3 \mathrm{~dB} \\
\mathrm{~K} \text {-Band }(24.15 \mathrm{GHz}) & 6.7 \mathrm{~dB} \pm 0.3 \mathrm{~dB}
\end{array}
$$

These gains could have been determined to within +0.1 ab by careful calibration, but it was not considered worth the added effort and expense in view of the other errors associated with the measurement. In addition, there is undoubtedly some variation in the output of different radar units of the same model, so there is not much to be gained by testing a particular radar to such accuracy. A near-zone gain correction for the $\mathrm{X}$-Band probe was required at the closest separation distance and has been included in the calculations.

The errors associated with these measurements are summarized below:

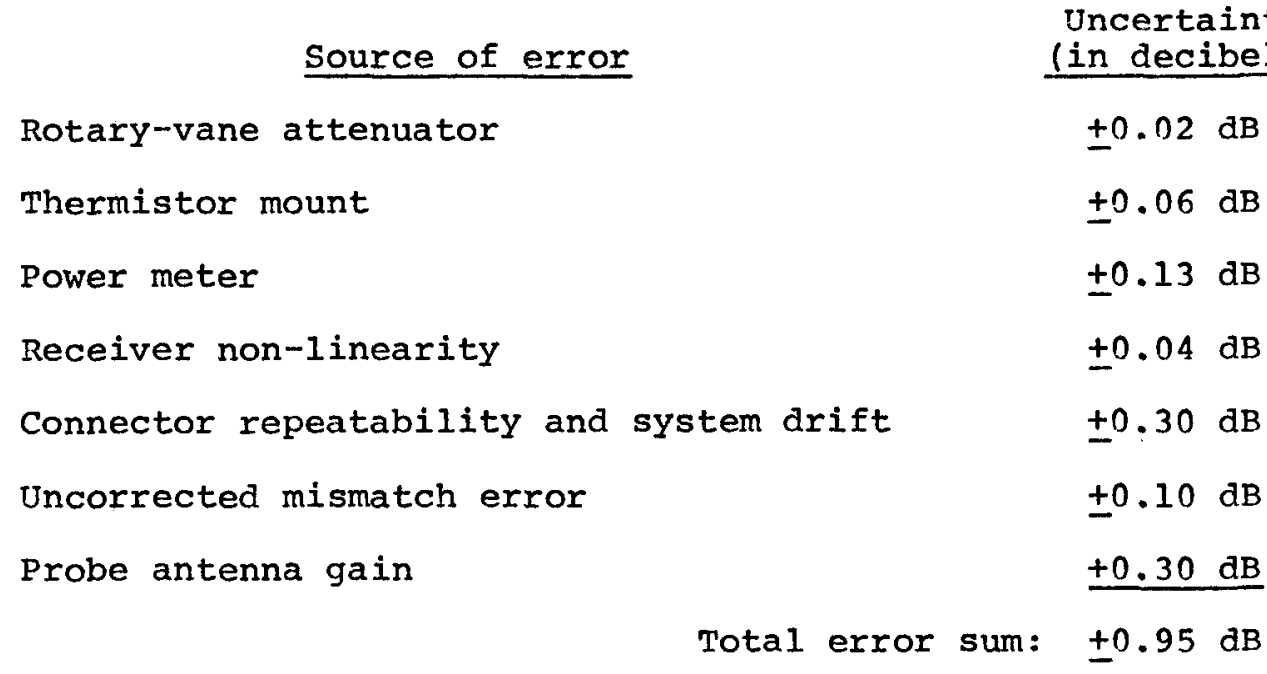

The listed errors are approximate worst-case values and, since the errors are uncorrelated, the sum represents a conservative estimate for the total error.

Although an estimated error approaching +1 dB may seem rather high, it should be noted that radiated power density is a particularly difficult parameter to measure with high accuracy because of the many variables and precise calibrations involved. In this case, the two largest sources of error were associated with the gain of the probe antenna and with connector repeatability and system drift. As has already been mentioned, the gain uncertainty could be reduced to $\pm 0.10 \mathrm{~dB}$ by careful calibration, and the repeatability could probably be improved to 0.10 to $0.15 \mathrm{~dB}$ through the use of precision connectors. These improvements would result in an overall error of approximately $+0.5 \mathrm{~dB}$, which is about the best one could expect. However, considering the variability that exists among radar units of the same type and the variable effects of the immediate operational radar environment on the radiated field strength, the approximate $+0.3 \mathrm{~dB}$ improvement in accuracy did not justify the use of the more expensive and time-consuming techniques required to achieve it. 


\subsection{Measurement Procedures and Results}

\subsubsection{Alignment and Measurements}

The mounting arrangement is shown in figure 4. A ring mount was constructed which clamped to the radar being measured. The ring mount was attached to a tilt plate which was, in turn, attached to a translation plate. The translation plate was bolted to the model mount. A handgun is shown mounted in figure 4, but the same basic arrangement was used for all the radars tested. Care was taken to assure that the radar aperture was always well in front of the metal mounting ring to minimize perturbation of the pattern by the mount.

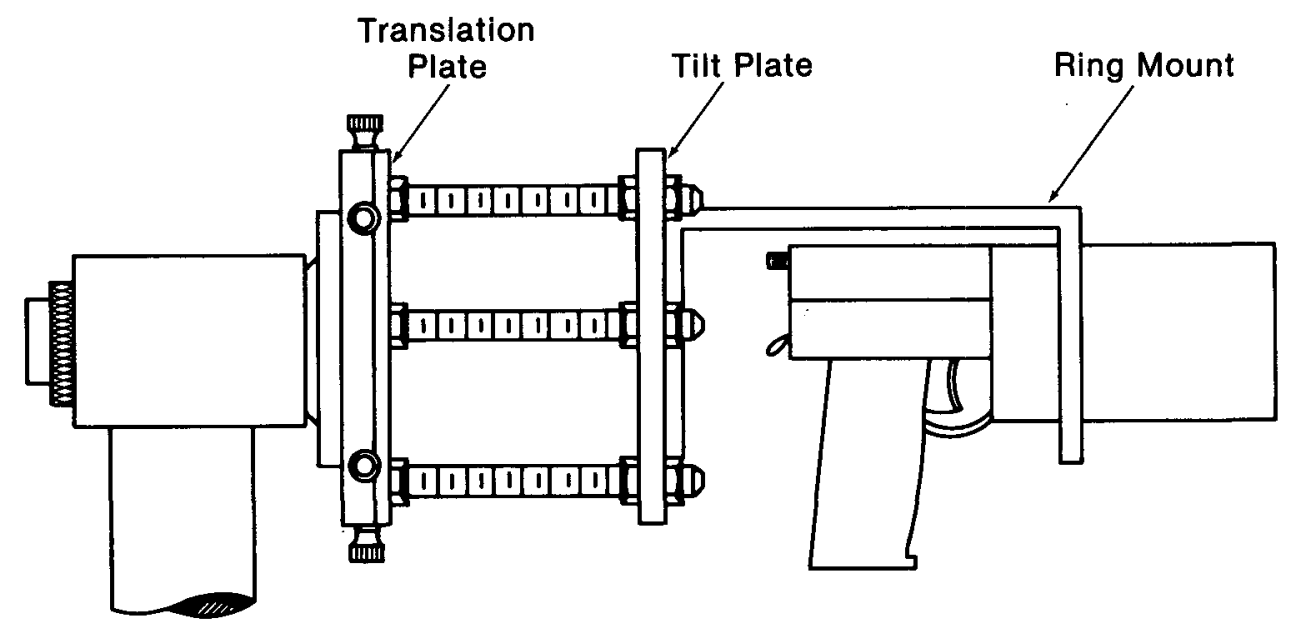

Figure 4. Mounting arrangement used to support radars so that they could be properly aligned for radiated power density measurements.

Although mechanical, optical, and electrical techniques for antenna alignment were employed, the final test involved only electrical measurements of the fields emitted by the test antenna. Proven methods were used for the precise alignment of each radar. The objective was to assure that the radar axis coincided with the $\phi$ rotation axis of the model mount and that for $\theta=0$, the axes of the probe, radar, and model mount were all coincident with the $z$-axis of the coordinate system of figure 1 . Once this was accomplished, the z-position of the radar was adjusted slightly by moving the model mount with respect to the azimuth rotator until rotation in $\theta$ produced minimal phase variations. This adjustment was done to place the rotation axis at the phase center of the radar.

After the alignment was completed, a set of data was obtained by rotating the radar $360^{\circ}$ about the $\theta$ axis, recording the field strength at $5^{\circ}$ intervals in $\theta$, and repeating the process for $10^{\circ}$ increments in $\phi$ until the entire sphere was scanned. This procedure yielded data along the $10^{\circ}$ meridians of a sphere. 
The total power density is the sum of the power densities associated with two orthogonal field components. Therefore, at each measurement distance, two complete scans must be performed, one for each component. Since the probes were linearly polarized, they were oriented to respond to the vertical component for one scan and then rotated $90^{\circ}$ to respond to the horizontal component for the second scan. The entire process was carried out at four distances for each radar, the distances being $1,3,6$, and $12 \mathrm{ft}$ $(30,91,183$, and $366 \mathrm{~cm})$ for the $\mathrm{x}$-Band radars and $1,3,6$, and $10 \mathrm{ft}$ (30, 91, 183, and $305 \mathrm{~cm}$ ) for the $\mathrm{k}-\mathrm{Band}$ radars. The largest $\mathrm{k}-\mathrm{Band}$ distance was restricted to $10 \mathrm{ft}(305 \mathrm{~cm})$ because the probe assembly was longer than the $x$-Band probe and the overall distance available was limited by the length of the rails on which the rotator was mounted. At the shortest distance, 12 in $(30 \mathrm{~cm})$, the rotation about the $\theta$ axis was limited to the range $-135^{\circ}$ to $+135^{\circ}$ in order to avoid hitting the probe antenna with the rear of the model tower.

\section{4 .2 Results}

The power density values were obtained as follows. Results of the calibration procedures described in section 2.3.1 were analyzed and used to calculate the received power at the on-axis reference point, which we shall call $P_{R}^{\prime}$. The values of $P_{R}$ obtained during the scanning process were measured relative to this on-axis value. Once $\mathrm{P}_{\mathrm{R}}$ had been calculated, the received power in $\mathrm{mW}$ at each measurement point was determined and the corresponding incident power density was then calculated by eq (1), for each point. The power densities for each component were summed to give the total power density at each point. These calculations were performed using the NBS computing facilities, and one of a variety of plotting routines was selected to display the results in graphical form.

In order to determine the symmetry of typical radiation patterns, contour plots like that in figure 10 (see sec. 5) were generated for selected radars. Note that the beam possesses circular symmetry down to about $23.4 \mathrm{~dB}$ below the peak $\left(42 \mathrm{~dB}\right.$ below $\left.1 \mathrm{~mW} / \mathrm{cm}^{2}\right)$. This symmetry is typical of all the radars tested. Because of the uniformity between radar units, it was decided not to provide contour plots for each distance for 20 radars.

A graphical display which presents the power density information in a more useful form is the polar coordinate format used in figures 11 through 50. These graphs display the power density in $\mathrm{mW} / \mathrm{cm}^{2}$ or $\mathrm{dB}$ with respect to $1 \mathrm{~mW} / \mathrm{cm}^{2}$ as functions of the angle off axis and the distance from the radar. Each figure has four curves, one for each measurement distance, and figures were prepared for both the vertical (elevation) and horizontal (azimuth) pattern cuts in order to display the effects of any significant asymmetries which might exist. The vertical and horizontal planes are defined with respect to the radars when mounted in their normal upright configurations and pointed horizontally as in figure 1 . The horizontal and vertical cuts correspond to $\phi=0$ and $90^{\circ}$, respectively. In each figure the origin corresponds to a power density of $10^{-5} \mathrm{~mW} / \mathrm{cm}^{2}$. The power density in dB corresponding to a particular distance and elevation or azimuth angle (equal to $\theta$ for these principal plane cuts) is proportional to the length of the radius vector from the origin to the point selected on the particular distance curve. Therefore, the inner curve represents the smallest power density and is for the largest distance from the radar. The strongest fields are associated with the closest distance 12 in $(30 \mathrm{~cm})$ and are plotted on the outer curve. This format provides a good visual representation of the field patterns as viewed by an operator positioned behind the radar and looking in the direction the radar is aimed.

The nomenclature used to identify the radars $(x-1, k-1$, etc.) is identical to that used in task 2 so that results between tasks may be compared if desired. Fourteen $\mathrm{X}$-Band and six $\mathrm{K}-\mathrm{Band}$ radar units were tested during task $I$ and $15 \mathrm{x}-\mathrm{Band}$ and seven $\mathrm{K}-\mathrm{Band}$ radar units were tested during task 2 . 


\section{TASK 2 MEASUREMENTS}

\subsection{General Approach}

Since speed radar units are usually mounted on or inside an automobile, a complete investigation of microwave radiation levels requires that measurements be made inside the automobile under normal operating conditions. By this means it is possible to observe any field enhancement effects produced by the automobile enclosure. Each of the 22 radar units tested was mounted in the positions in which it is normally used, and calibrated field probes were used to measure the power density $\left(\mathrm{mW} / \mathrm{cm}^{2}\right)$ throughout the interior of the car, paying particular attention to regions where the head and groin would be located.

\subsection{Probes Used for the Vehicular Measurements}

Two different probes were used for these measurements. An NBS Model EDM-IC Electric Energy Density Meter was used for the measurements involving the $\mathrm{X}$-Band $(10.525 \mathrm{GHz})$ radars. This NBS probe does not operate above $\mathrm{X}-$ Band, so a commerical Electromagnetic Radiation Monitor was used for the $\mathrm{K}-$ Band $(24.15 \mathrm{GHz})$ measurements. The sensor antennas in both probes consisted of three orthogonal dipoles in order to achieve isotropic response patterns. The measurements are, therefore, quite insensitive to the orientation of the probe with respect to the field being measured, as long as the probe handle is not pointed toward the radiation source. The NBS probe uses diodes for the detecting elements, while the commerical unit employs thermocouples. Consequently, the NBS probe has greater sensitivity; its threshold response being $0.001 \mathrm{mw} / \mathrm{cm}^{2}$. With the commerical meter, the minimum detectable power density was $0.01 \mathrm{~mW} / \mathrm{cm}^{2}$. Both probes make use of high-resistance leads between the sensor and metering unit to eliminate pickup by the leads which would generate an error signal.

The meters were calibrated by the free-space standard-field method which is illustrated in figure 5. The power density, $w$, at a point on the transmitting axis at a distance d from the standard gain horn is given by

$$
\mathrm{W}=\frac{\mathrm{P}_{T^{G}}}{4 \pi \mathrm{d}^{2}},
$$

where $P_{T}$ is the net power delivered to the horn and $G$ is the effective gain of the horn. The gain was determined in advance [2] and $P_{T}$ and $d$ were measured as part of the calibration procedure. The incident power $\mathrm{P}_{i}$ and reflected power $\mathrm{P}_{r}$ were monitored with the coupler sidearms, and $\mathrm{P}_{\mathrm{T}}=\mathrm{P}_{i}-\mathrm{P}_{\mathrm{r}}$. When $W$ had been determined at a particular point, the probe being calibrated was placed at this same point in the known field and a probe correction factor was obtained from the ratio of the actual power density to the indicated power density.

The error in the basic calibration was estimated to be $+0.5 d B$ (128). However, in actual use, additional uncertainties arose due to such things as multipath effects, perturbation of the field by the operator, and the fact that the probe was calibrated in a plane-wave field but was used in a more complex field configuration. Taking all of these factors into consideration resulted in an estimated overall measurement uncertainty of +1.0 dB (258). Although it may seem rather high, a $+1.0 \mathrm{~dB}$ uncertainty is very good for electromagnetic field measurements perfformed in such a complicated electromagnetic environment. 


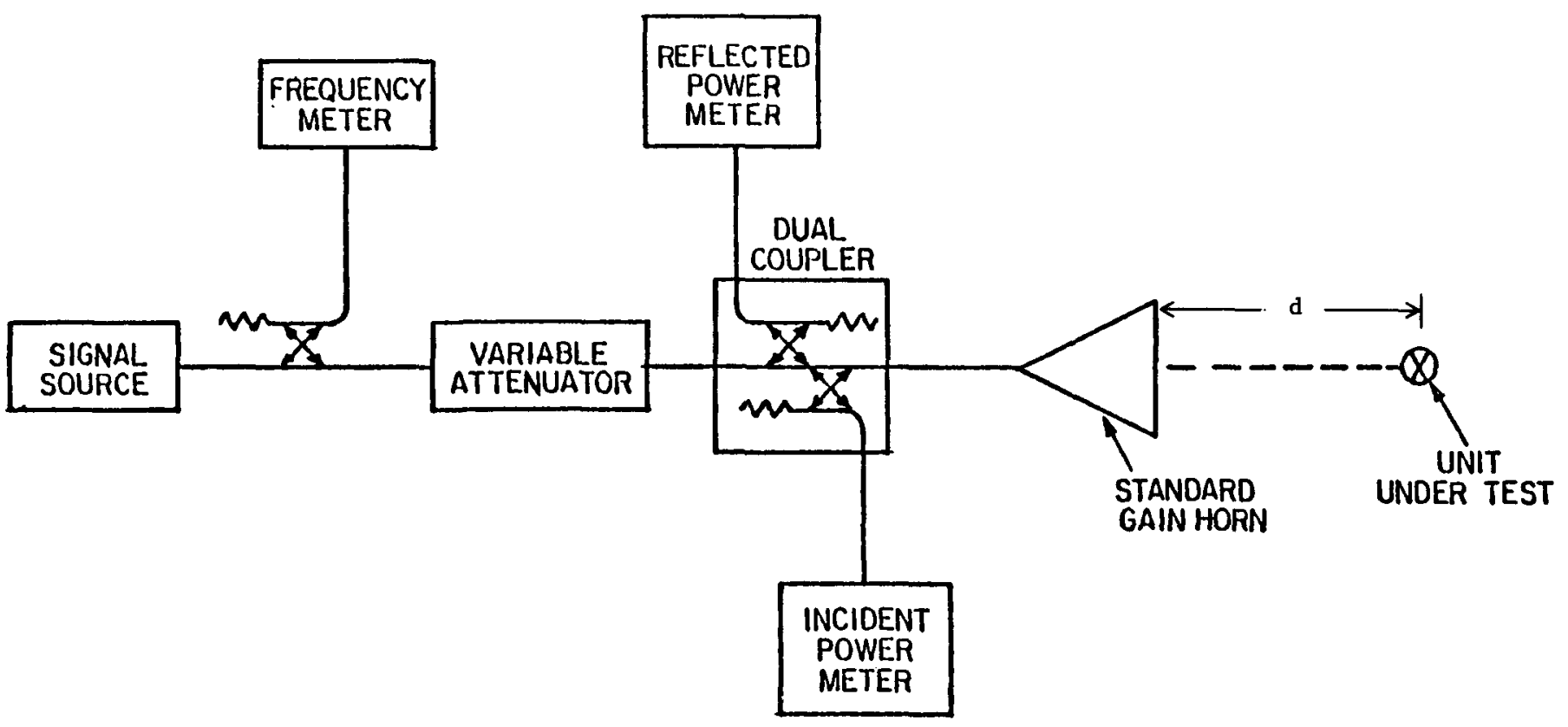

Figure 5. Diagram of the basic experimental arrangement required for the free-space standard-field method of calibrating microwave hazard meters. 


\subsection{Measurement Procedures and Results}

Prior to making measurements inside the automobile, the power density in the main beam, close to the aperture, was determined by holding the probe directly in front of the aperture as shown in figure 6 . These results are listed in column 2 of table 1 . The maximum power density radiated to the sides and rear of each unit was also determined by moving the probe over the surface of the unit as shown in figure 7 and observing the maximum indication. These values are listed in column 3 of table 1 .

Following the above tests, the radars were mounted in, on, or hand-held in a four-door sedan in the various operating positions indicated by the numbers in figure 8 . In positions 1 and 2 , the radars were hand-held and aimed through the windshield. Position 5 is the common dashboard mount with the radar aimed forward ( $f i g .9 a$ ), and $5 R$ is the same arrangement with the radar aimed to the rear through the back window (fig. 9b). In positions 6 and 7 the radars were hand-held and aimed out the left and right front side windows, respectively. For position 3 , the radar was attached to the inside of the right rear window and aimed forward through the windshield while, in position 4, the radar was attached outside the left rear window and aimed forward. In position 8 , the radar was aimed to the rear through the back window.

Each radar unit was mounted in each of the positions in which it was designed to operate, as indicated in column 4 of table 1 . With the radar in each position, the appropriate hazard probe was used to survey the field intensity throughout the interior of the automobile. The maximum power densities observed in the general regions occupied by the driver and three passengers (locations $A$ through $D$ of $f i g .8$ ) are given in table 1 , columns 5-8. These recorded values represent the maximum levels observed, that is, there were no values of higher radiation intensity in locations other than those whose power density values are listed in table 1.

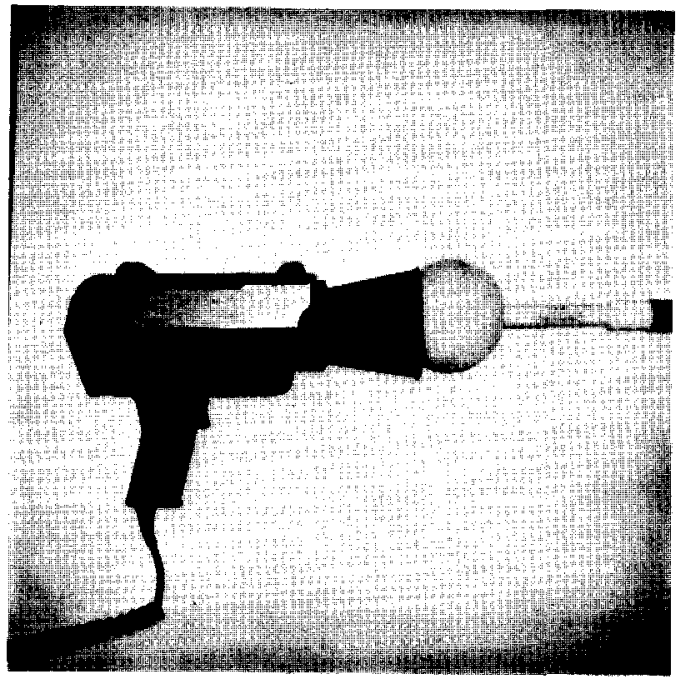

Figure 6. Measurement of main-beam power density in the aperture region.

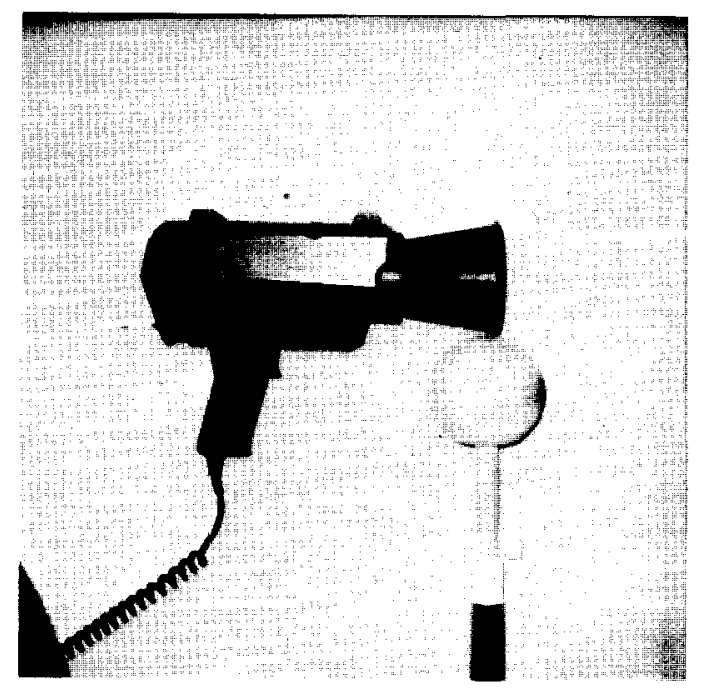

Figure 7. Measurement of radiation in the side- and backlobe regions. 
Table 1. Results of vehicular power density measurements.

This table contains results of measurements of field intensities produced by the various radar units inside an automobile. The radar code numbers are given in the first column, with the K-Band units (24.15 GHz) designated by $\mathrm{K}-1$ to $\mathrm{K}-7$ and the $\mathrm{X}$-Band units $(10.525 \mathrm{GHz})$ by $\mathrm{X}-1$ to $\mathrm{X}-15$. Column 2 gives the power density in the aperture, and column 3 the maximum power density in the back hemisphere. The mounting positions of column 4 correspond to the numbered positions of figure 8 as described in the text. The interior vehicular data are given in columns 5 to 8 . Blank entries in these columns mean that the field intensities were too low to read with the meters used for these tests; i.e., the fields were $<0.01 \mathrm{~mW} / \mathrm{cm}^{2}$ for $\mathrm{K}-\mathrm{Band}$ and $<0.001 \mathrm{~mW} / \mathrm{cm}^{2}$ for $\mathrm{X}-\mathrm{Band}$.

\begin{tabular}{|c|c|c|c|c|c|c|c|}
\hline \multirow{2}{*}{$\begin{array}{l}\text { Radar } \\
\text { code } \\
\text { number }\end{array}$} & \multirow{2}{*}{$\begin{array}{l}\text { Aperture } \\
\text { power } \\
\text { density } \\
\left(\mathrm{mW} / \mathrm{cm}^{2}\right)\end{array}$} & \multirow{2}{*}{$\begin{array}{c}\text { Maximum } \\
\text { back-lobe } \\
\text { power } \\
\text { density } \\
\left(\mathrm{mW} / \mathrm{cm}^{2}\right)\end{array}$} & \multirow{2}{*}{$\begin{array}{l}\text { Radar } \\
\text { mounting } \\
\text { position }\end{array}$} & \multicolumn{4}{|c|}{$\begin{array}{c}\text { Maximum power density at positions } \\
A, B, C \text {, and } D \text { of figure } 8 \\
\left(\mathrm{~mW} / \mathrm{cm}^{2}\right)\end{array}$} \\
\hline & & & & $\mathrm{A}$ & $\mathrm{B}$ & $\mathrm{C}$ & $\mathrm{D}$ \\
\hline$K-1$ & 1.97 & $<0.01$ & $\begin{array}{l}5 \\
8\end{array}$ & & & & \\
\hline \multirow[t]{2}{*}{$\mathrm{K}-2$} & 2.40 & 0.02 & $\begin{array}{l}1 \\
2\end{array}$ & & & & \\
\hline & & & $\begin{array}{l}5 \\
5 R^{a} \\
8\end{array}$ & 0.01 & 0.01 & & \\
\hline$K-3$ & 2.27 & $<0.01$ & $\begin{array}{l}1 \\
2 \\
5\end{array}$ & & & & \\
\hline $\mathrm{K}-4$ & 1.83 & $<0.01$ & $\begin{array}{l}1 \\
2 \\
5\end{array}$ & & & & \\
\hline$K-5$ & 0.25 & $<0.01$ & $\begin{array}{l}1 \\
2 \\
5 \\
5 \mathrm{R}\end{array}$ & & & & \\
\hline$\pi-6$ & 2.78 & 0.02 & $\begin{array}{l}1 \\
2 \\
5\end{array}$ & & & & \\
\hline $\mathrm{K}-7$ & 1.64 & $<0.01$ & $\begin{array}{l}1 \\
2 \\
5\end{array}$ & & & & \\
\hline \multirow[t]{2}{*}{$x-1$} & 0.55 & $<0.001$ & $\begin{array}{l}1 \\
2\end{array}$ & & & & \\
\hline & & & $\begin{array}{l}3 \\
4\end{array}$ & 0.137 & $\begin{array}{l}0.001 \\
0.001\end{array}$ & 0.002 & 0.002 \\
\hline \multirow[t]{2}{*}{$x-2$} & 0.73 & 0.001 & $\begin{array}{l}1 \\
2\end{array}$ & 0.001 & 0.001 & & \\
\hline & & & $\begin{array}{l}3 \\
4\end{array}$ & 0.36 & $\begin{array}{l}0.003 \\
0.002\end{array}$ & 0.001 & 0.001 \\
\hline$x-3$ & 2.82 & 0.018 & $\begin{array}{l}1 \\
2 \\
5\end{array}$ & $\begin{array}{l}0.002 \\
0.001 \\
0.002\end{array}$ & $\begin{array}{l}0.003 \\
0.021 \\
0.001\end{array}$ & $\begin{array}{l}0.001 \\
0.001\end{array}$ & $\begin{array}{l}0.001 \\
0.001\end{array}$ \\
\hline$x-4$ & 2.55 & 0.018 & $\begin{array}{l}1 \\
2 \\
5\end{array}$ & $\begin{array}{l}0.002 \\
0.001 \\
0.001\end{array}$ & $\begin{array}{l}0.001 \\
0.003 \\
0.001\end{array}$ & 0.001 & $\begin{array}{l}0.001 \\
0.001 \\
0.001\end{array}$ \\
\hline$x-5$ & 0.36 & 0.001 & $\begin{array}{l}1 \\
2 \\
5\end{array}$ & & & & \\
\hline
\end{tabular}


Table 1. Results of vehicular power density measurements (Continued)

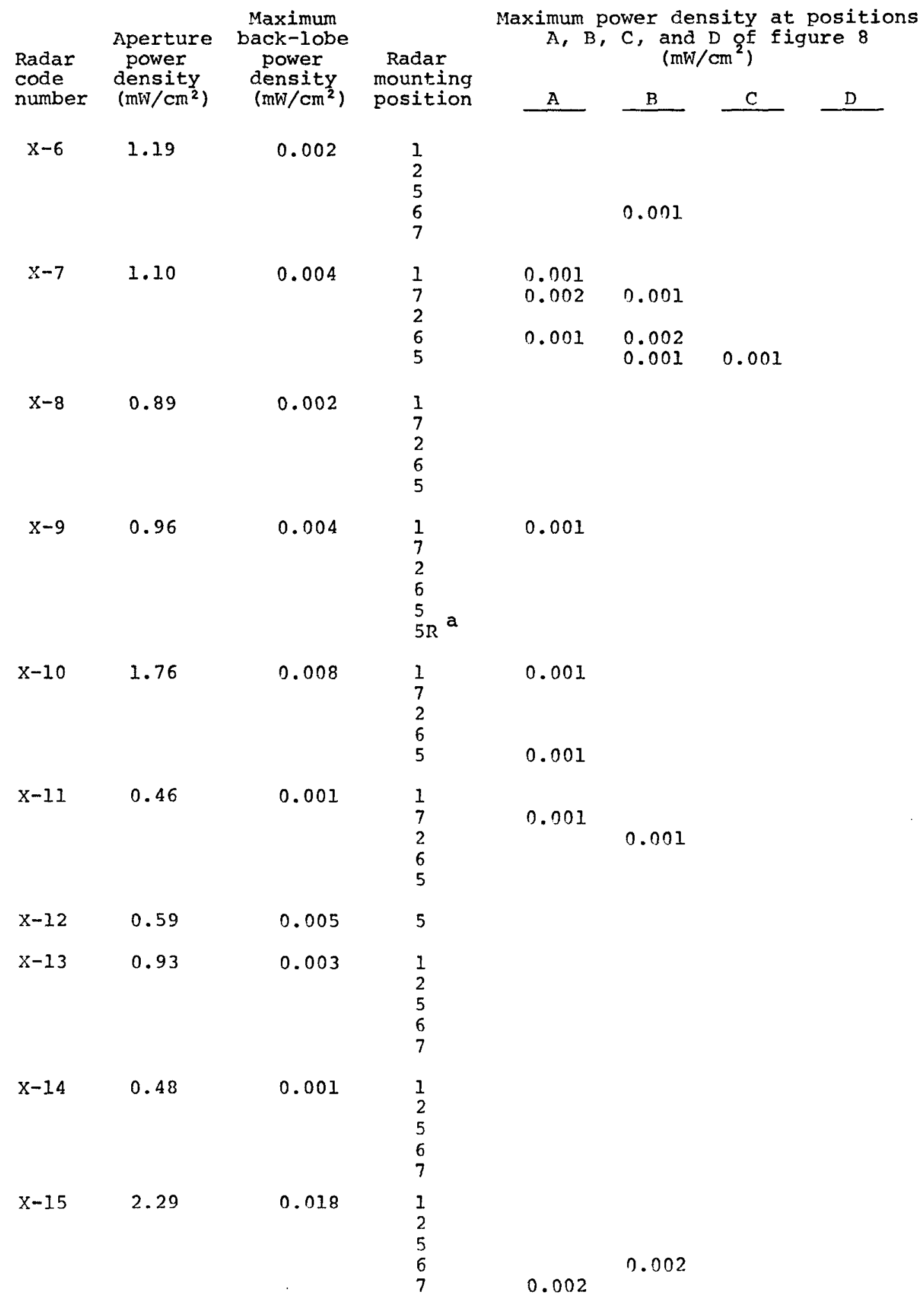

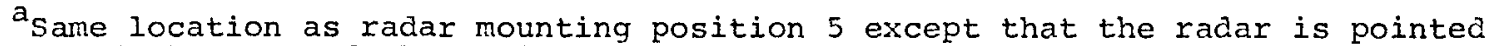
toward the rear of the vehicle.
} 


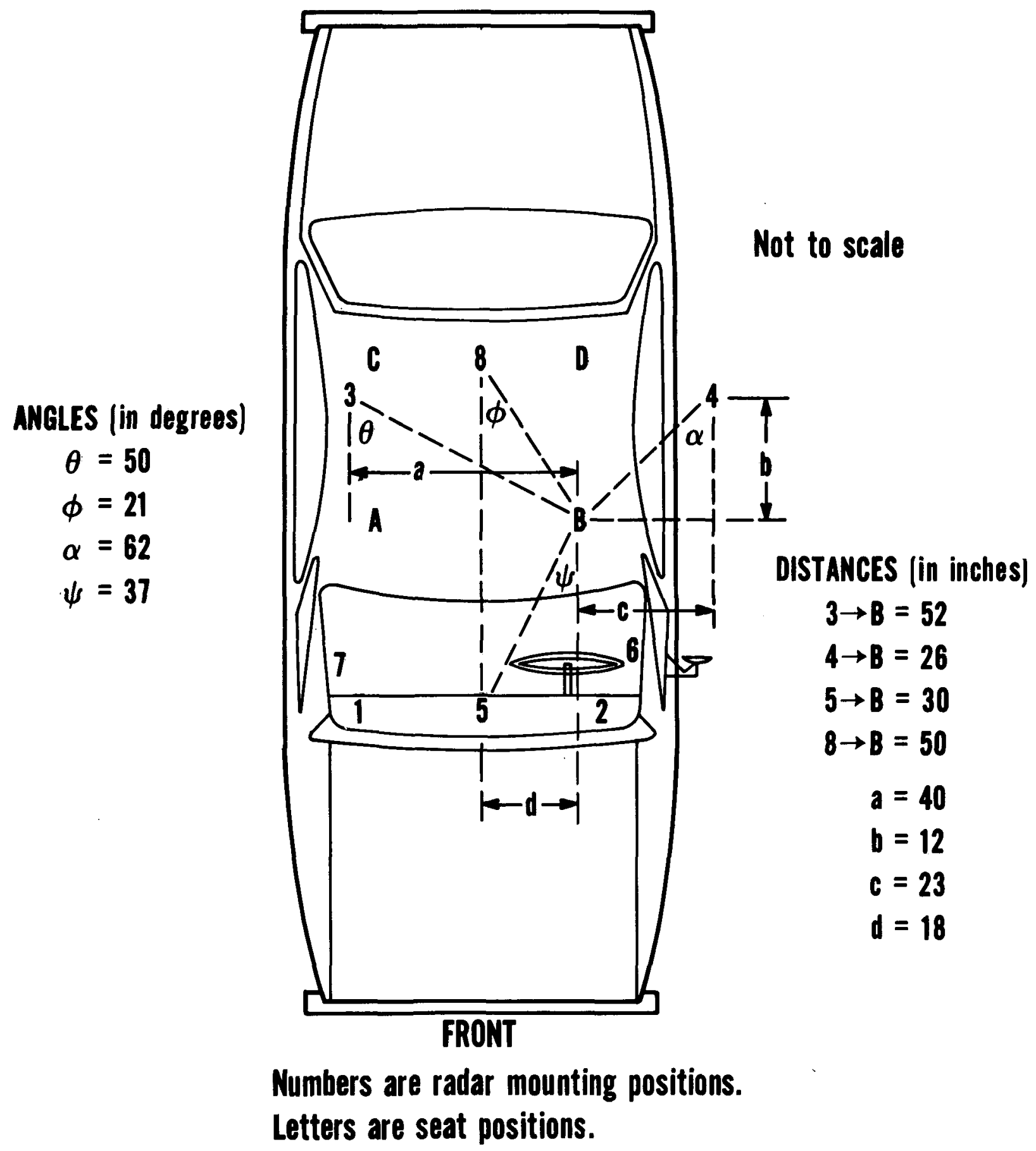

Figure 8. Diagram showing the location of radar mounting positions $(1-8)$, seat locations (A-D), and distances between selected radar positions and seat locations used in describing field intensity distributions inside the automobile. 


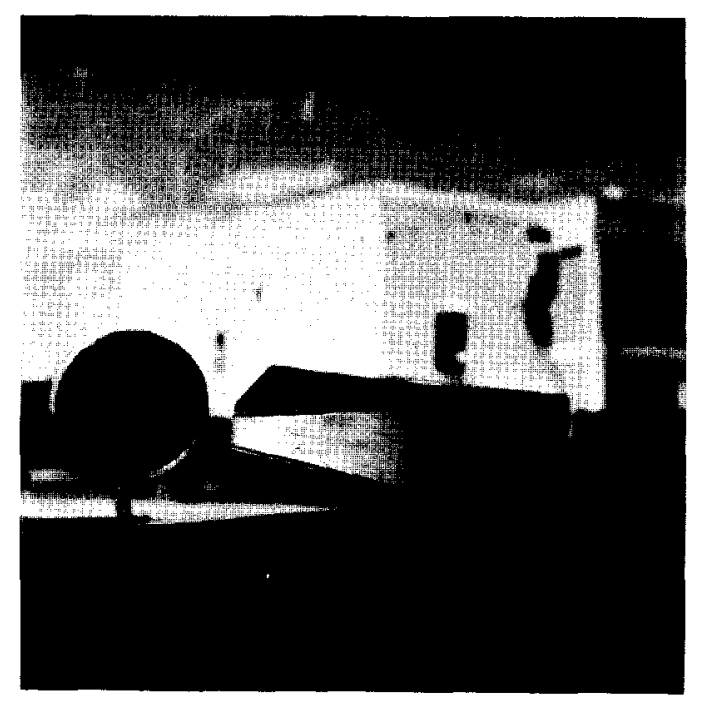

a)

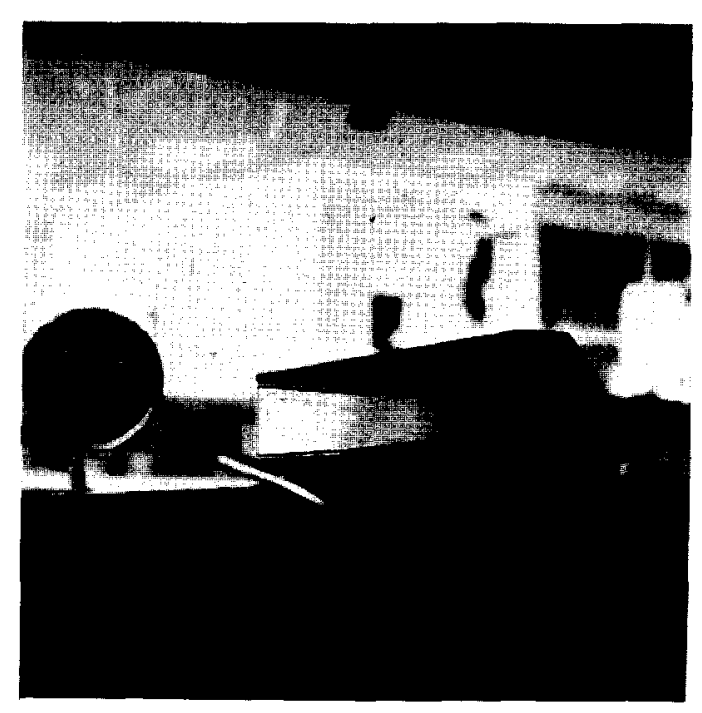

b)

Figure 9. Typical dashboard mounting arrangement:

a) shows the radar pointing forward, and b) shows the radar aimed to the rear through the back window.

\section{DISCUSSION OF MEASUREMENT RESULTS FOR TASKS I AND 2}

It is not the purpose of this report to state what levels of electromagnetic fields constitute a health hazard. Such issues are left to those organizations and committees that have been established to perform ard interpret research on the biological effects of electromagnetic waves and to set exposure limits based on the results of such research.

From the graphs of figures 11 through 50 one can obtain the expected power density in any desired region of space. For example, from the horizontal cut for $\mathrm{x}-1$ ( $\mathrm{fig} .11$ ), it is evident that, for distances greater than $\frac{1}{2} 2$ in $(30 \mathrm{~cm})$ and for all angles, the power density is less than 0.2 $\mathrm{mW} / \mathrm{cm}^{2} \quad\left(\begin{array}{ll}-7 & \mathrm{~dB}\end{array}\right)$. Another way of using the curves is to determine regions where a specified power density such as $0.1 \mathrm{~mW} / \mathrm{cm}^{2}$ is not exceeded. From figure 11, it is clear that the power density is less than $0.1 \mathrm{~mW} / \mathrm{cm}^{2}(-10$ dB) at all angles for distances greater than about 36 in $(91 \mathrm{~cm})$ and also for distances greater than 12 in $(30 \mathrm{~cm})$ if the angle is greater than approximately $\pm 10^{\circ}$ off axis. Similar determinations can be done for the other radars us̄ing the appropriate graphs.

Section 1910.97 of the Occupational Safety and Health Act (OSHA) contains a Radiation Protection Guide (RPG) which applies to exposure to electromagnetic radiation at various frequencies. $\lambda t$ frequencies of $\frac{10}{2} \mathrm{MHz}$ to $100 \mathrm{GHz}$, the RPG allows exposure up to a power density of $10 \mathrm{~mW} / \mathrm{cm}^{2}$ over any $0.1-\mathrm{h}$ period, or up to a power density of $10 \mathrm{~mW} / \mathrm{cm}^{2}$ averaged over any $0.1-\mathrm{h}$ period or more. Concurrently, a voluntary Radio Frequency Protection Guide of $5 \mathrm{~mW} / \mathrm{cm}^{2}$ for the $1500 \mathrm{MHz}$ to $100 \mathrm{GHz}$ frequency range is under consideration for adoption by the American National Standards Institute. Whether the power density exposure limit remains at $10 \mathrm{~mW} / \mathrm{cm}^{2}$ or is lowered to $5 \mathrm{~mW} / \mathrm{cm}^{2}$, the power densities measured at a 12 in $(30 \mathrm{~cm})$ distance from the radars did not exceed either limit, even if operated continuously. The 
$\mathrm{K}-\mathrm{Band}$ radars tended toward higher powers and, since the antennas had more gain than the $\mathrm{X}$-Band antennas, it was not surprising to observe that the power densities were generally higher for most $k$-Band units. 2 In fact, all except $\mathrm{K}-5$ had on-axis power densities of approximately $1 \mathrm{~mW} / \mathrm{cm}^{2}$ at the 12 in $(30 \mathrm{~cm})$ distance. For comparison, the U.S.S.R. defines safe exposure limits at $10 \mu \mathrm{W} / \mathrm{cm}^{2}$ for a whole working day or exposure for not more than 15 or $20 \mathrm{~min}$ a day at $1 \mathrm{~mW} / \mathrm{cm}^{2}$ while wearing goggles [3].

The aperture power density for most of the units, measured in task 2 (col. 2 of table 1) is a significant fraction (25 to $50 \%$ ) of the existing or proposed maximum permissible exposure levels. Based on the back-lobe data (col. 3 of table 1), one can conclude that all units are well-designed and packaged to provide shielding from leakage and back radiation. There was not a single case of reverse-hemisphere radiation of sufficient intensity to cause concern. In most cases, the power densities were $\frac{1}{1000}$, or less, of the exposure limit presently specified in the OSHA guide.

The data in columns 5 to 8 of table 1 indicate that the field levels inside the car do not exceed $0.002 \mathrm{~mW} / \mathrm{cm}^{2}$ for most radar positions. The major exception occurs in the data for $x-1$ and $x-2$ which show relatively strong fields at location $A$ when the radar is mounted in position 3 . This is to be expected since location $A$, the front seat passenger position, is directly in the main beam for this situation. Note, however, that the field strength recorded at the driver location is still low.

\section{POWER DENSITY GRAPHIC DISPLAYS}

The radiation pattern contour plot and power density polar coordinate plots discussed earlier (figs. $11-50$ ) are grouped in this section for the convenience of the reader. 


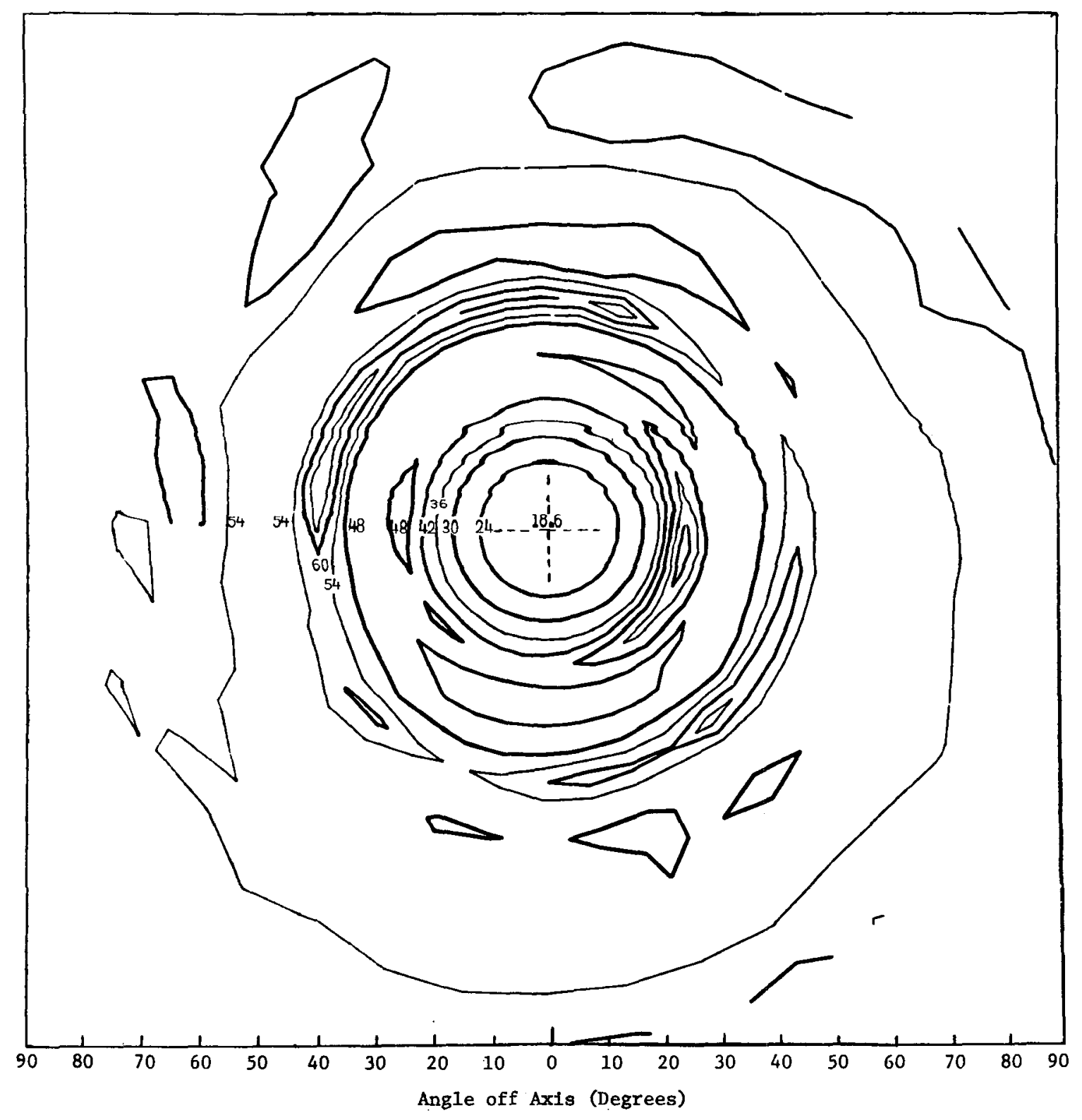

Figure 10. Power density contours for Radar X-4 at a distance of $2.1 \mathrm{~m}$ (82.5 in) from the antenna aperture. The view directly toward the radar. Numerical values of the contour lines indicate the number of decibels below $1 \mathrm{~mW} / \mathrm{cm}$. The peak, on-axis value is $-18.6 \mathrm{~dB}(0.014$ $\mathrm{mW} / \mathrm{cm}^{2}$, and the contour interval is $6 \mathrm{~dB}$. The angular distance off axis is proportional to the radial distance from the center of the figure. 


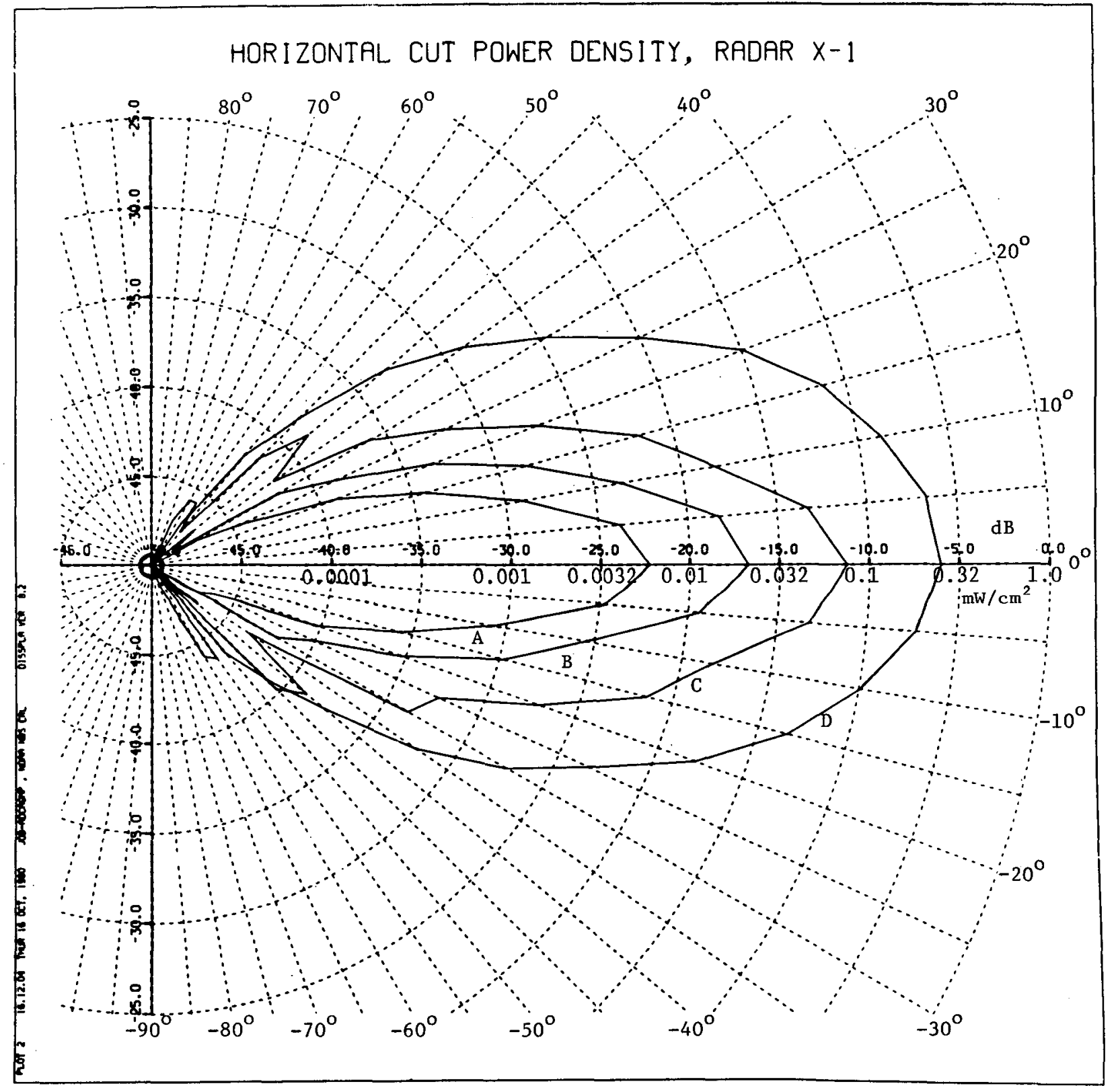

Distances From Radar (Inches): $\mathrm{A}=144, \mathrm{~B}=72, \mathrm{C}=36, \mathrm{D}=12$

Figure 11. Horizontal power patterns for Radar X-1 obtained at four distances from the aperture, Each curve displays the total gower density in $\mathrm{mw} / \mathrm{cm}^{2}$, or $\mathrm{dB}$ with respect to $1 \mathrm{~mW} / \mathrm{cm}^{2}$, as a function of the azimuth angle in degrees. Zero degrees coincides with the direction of the main beam. 


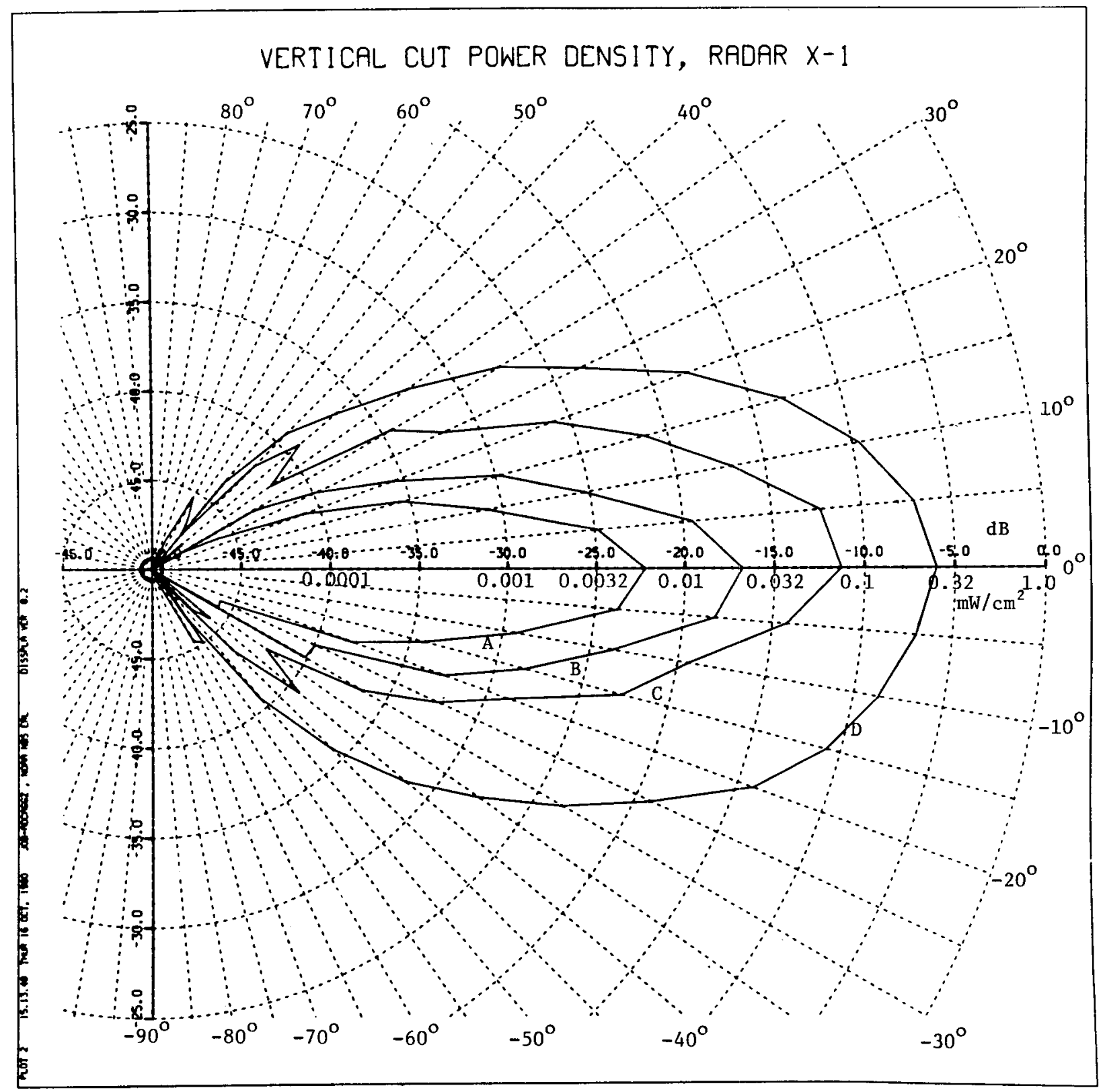

Distances From Radar (Inches): $A=144, B=72, C=36, D=12$

Figure 12. Vertical power patterns for Radar X-1 obtained at four distances from the aperture. Each curve displays the total power density in $\mathrm{mw} / \mathrm{cm}^{2}$, or $\mathrm{dB}$ with respect to $1 \mathrm{~mW} / \mathrm{cm}^{2}$, as a function of the elevation angle in degrees. Zero degrees coincides with the direction of the main beam. 


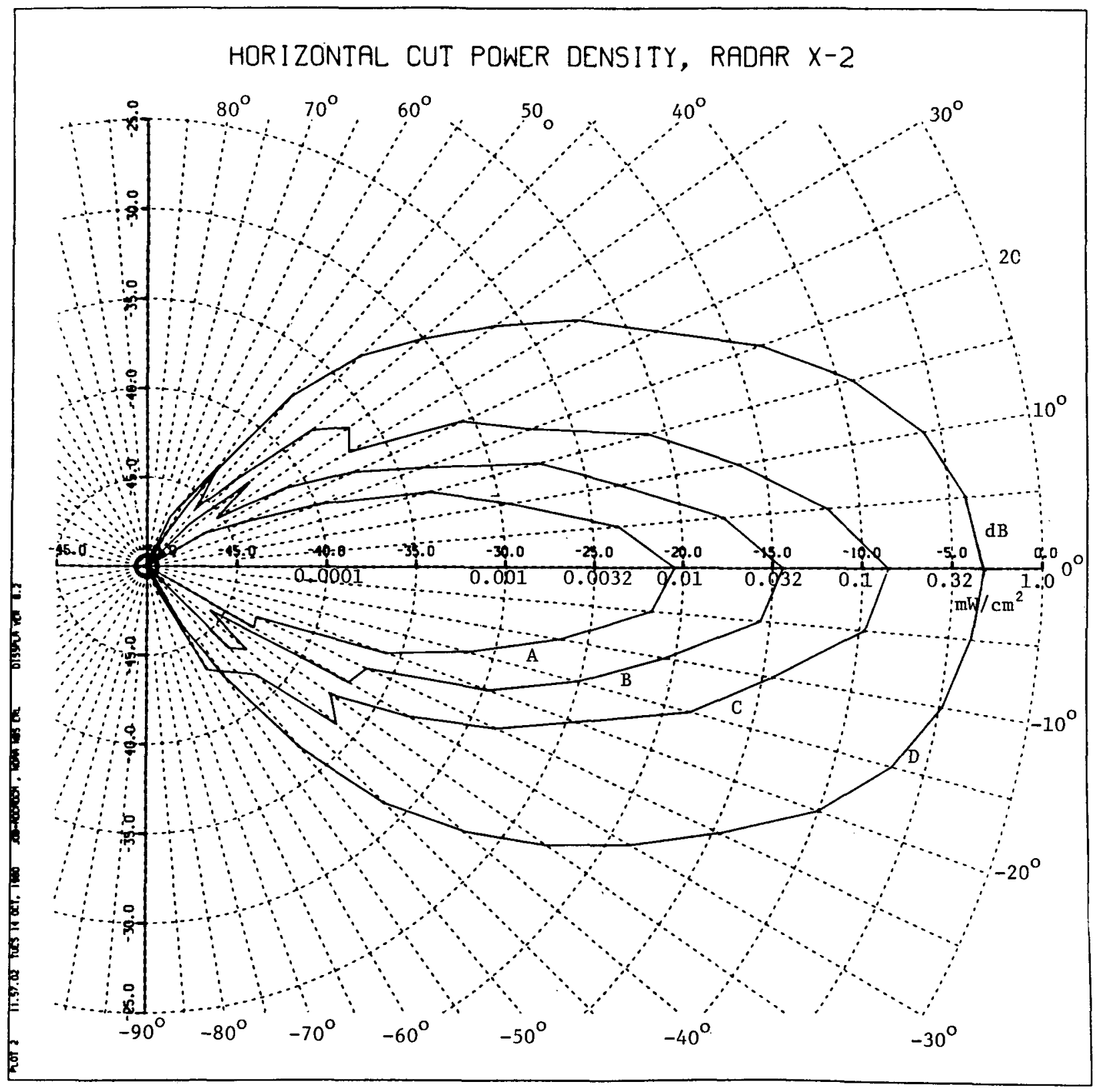

Distances From Radar (Inches): $A=144, B=72, C=36, D=12$

Figure 13. Horizontal power patterns for Radar-X-2 obtained at four distances from the aperture. Each curve displays the total power density in $\mathrm{mw} / \mathrm{cm}^{2}$, or $\mathrm{dB}$ with respect to $1 \mathrm{~mW} / \mathrm{cm}^{2}$, as a function of the azimuth angle in degrees. Zero degrees coincides with the direction of the main beam. 


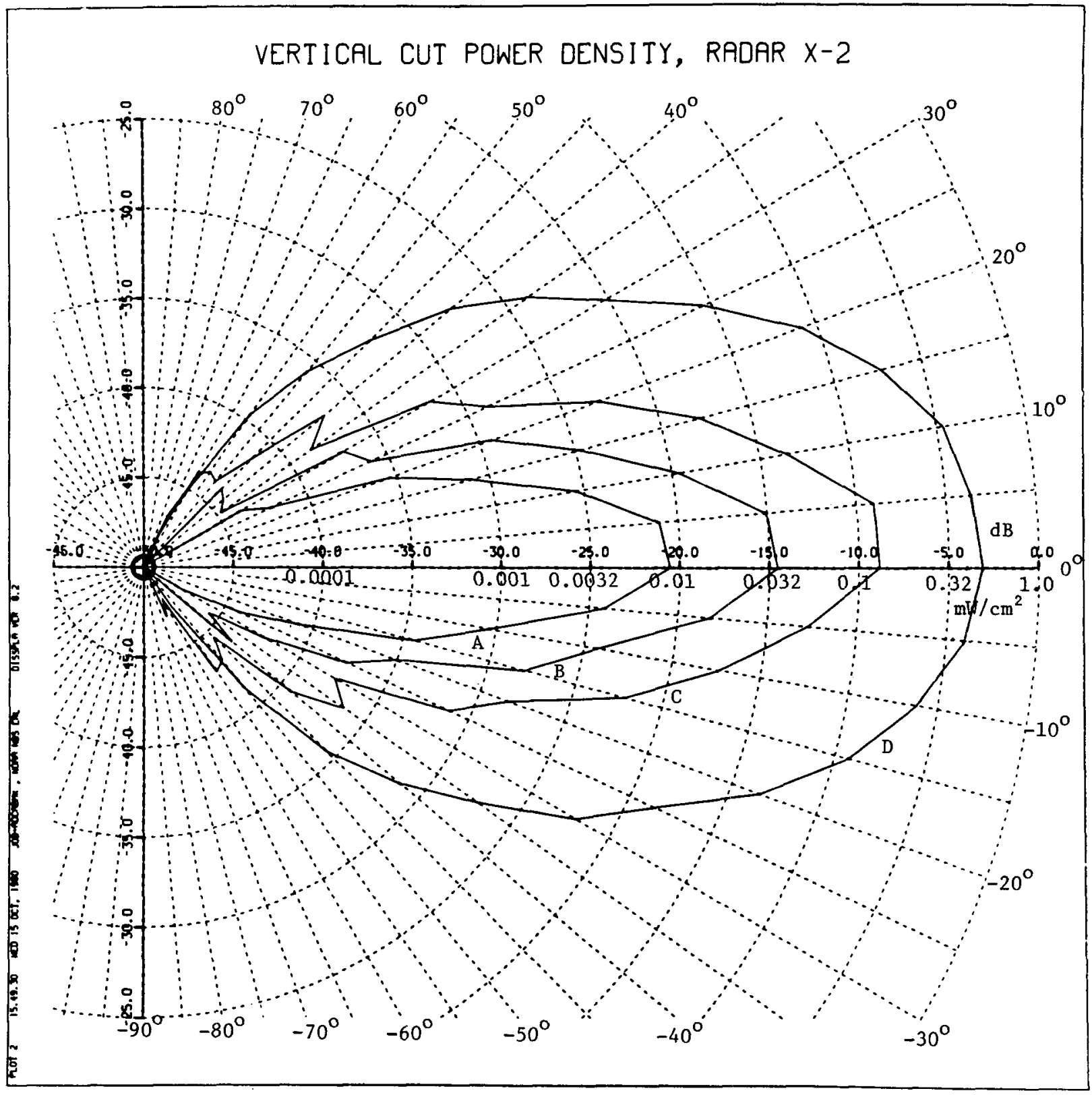

Distances From Radar (Inches): $A=144, B=72, C=36, D=12$

Figure 14. Vertical power patterns for Radar X-2 obtained at four distances from the aperture. Each curve displays the total power density in $\mathrm{mw} / \mathrm{cm}^{2}$, or $\mathrm{dB}$ with respect to $1 \mathrm{~mW} / \mathrm{cm}^{2}$, as a function of the elevation angle in degrees. Zero degrees coincides with the direction of the main beam. 


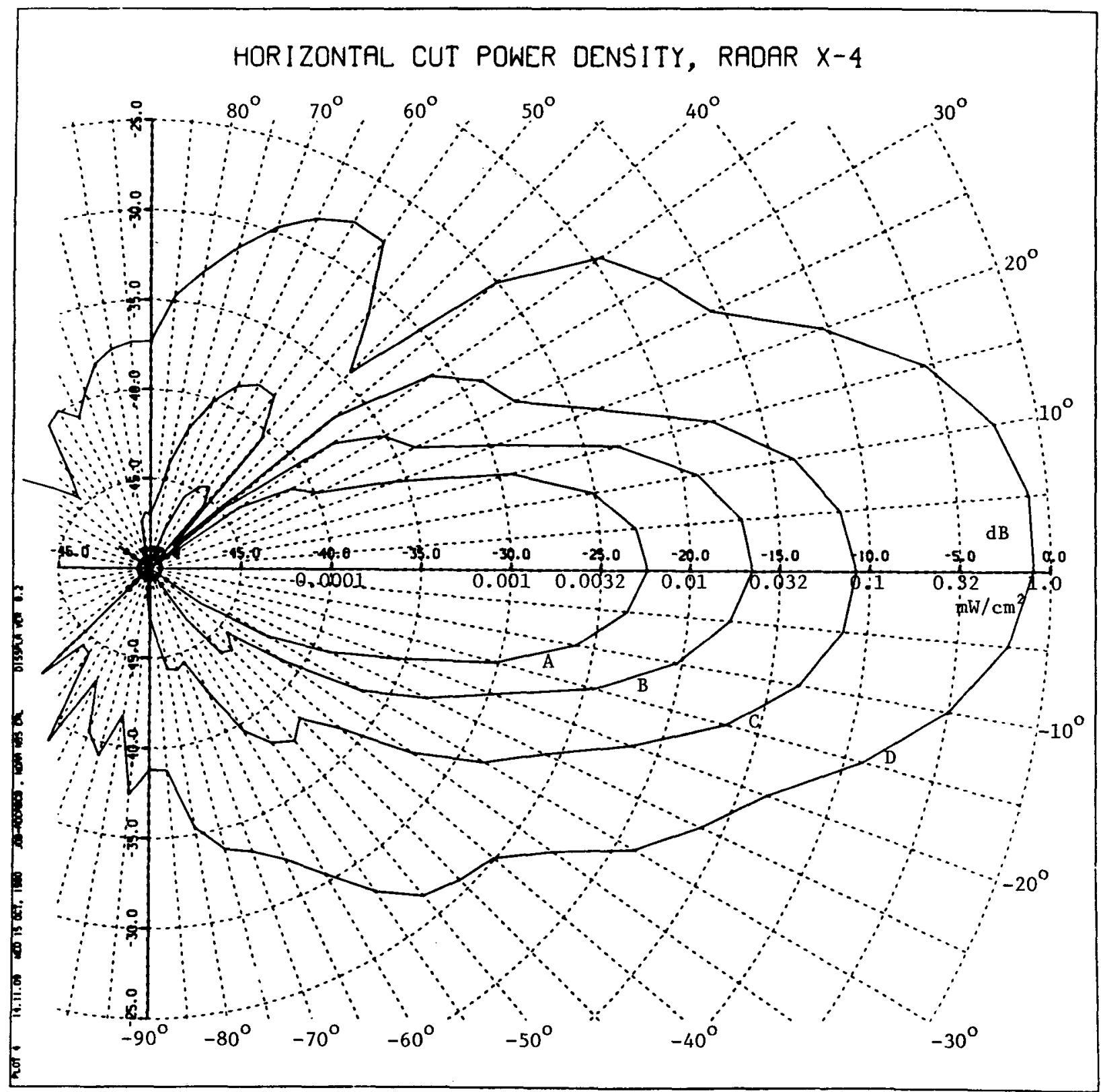

Distances From Radar (Inches): $\mathrm{A}=144, \mathrm{~B}=72, \mathrm{C}=36, \mathrm{D}=12$

Figure 15. Horizontal power patterns for Radar $x-4$ obtained at four distances from the aperture. Each curve displays the total power density in $\mathrm{mW} / \mathrm{cm}^{2}$, or $d B$ with respect to $1 \mathrm{mw} / \mathrm{cm}^{2}$, as a function of the azimuth angle in degrees. Zero degrees coincides with the direction of the main beam. 


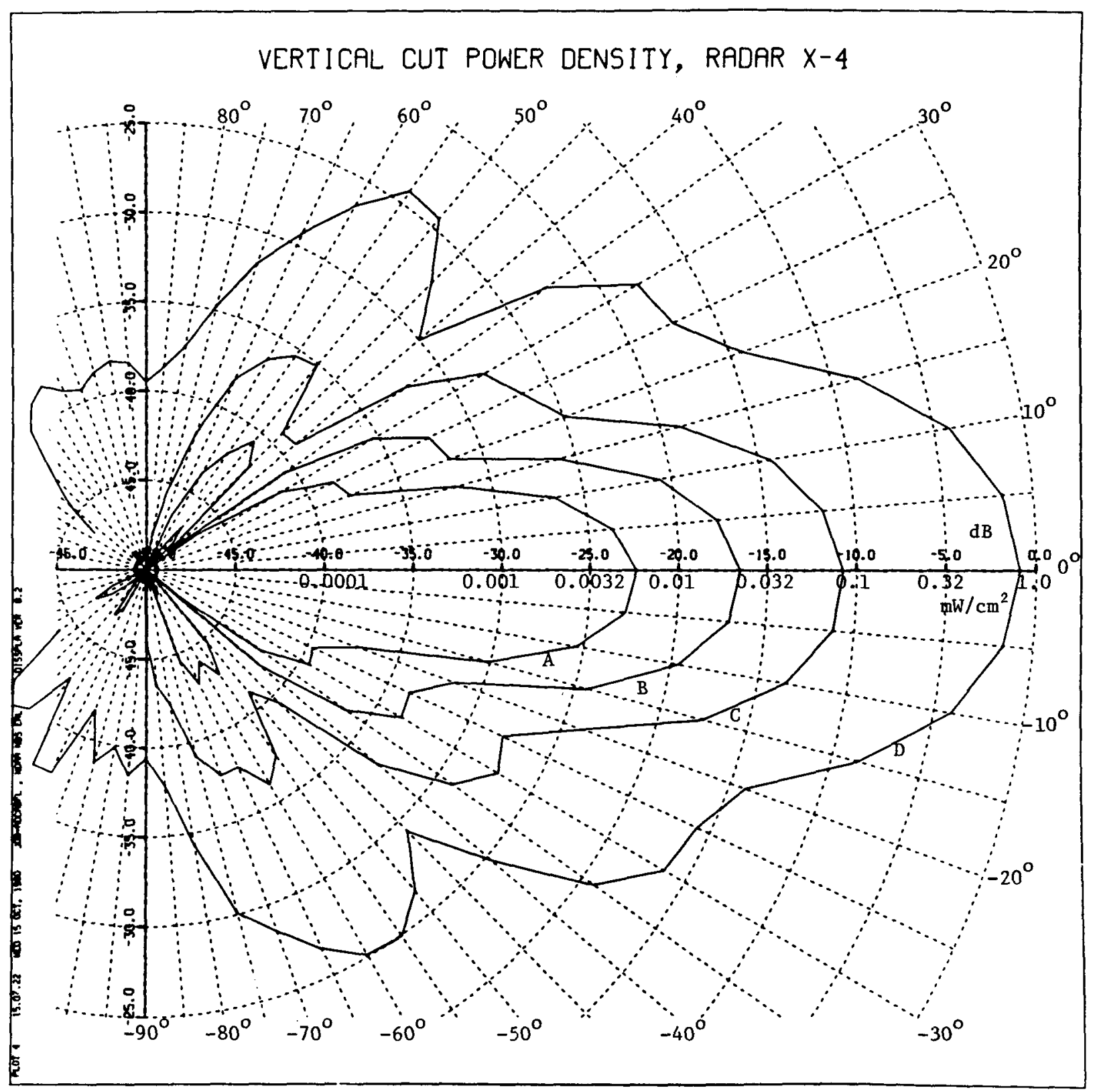

Distances From Radar (Inches): $\mathrm{A}=144, \mathrm{~B}=72, \mathrm{C}=36, \mathrm{D}=12$

Figure 16. Vertical power patterns for Radar $x-4$ obtained at four distances from the aperture. Each curve displays the total power density in $\mathrm{mW} / \mathrm{cm}^{2}$, or $\mathrm{dB}$ with respect to $1 \mathrm{mw} / \mathrm{cm}^{2}$, as a function of the elevation angle in degrees. Zero degrees coincides with the direction of the main beam. 


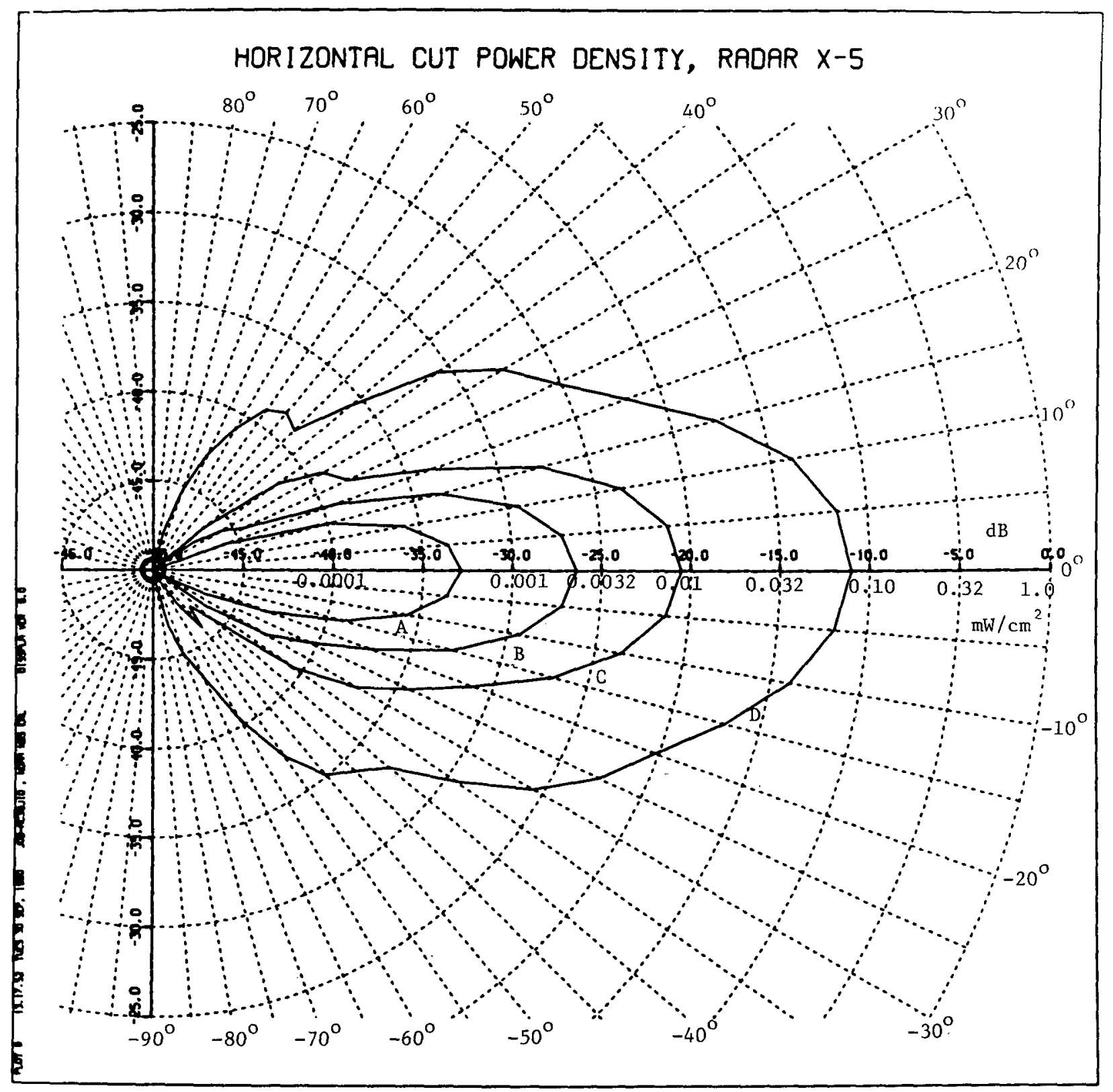

Distances From Radar (Inches): $A=144, B=72, C=36, D=12$

Figure 17. Horizontal power patterns for Radar X-5 obtained at four distances from the aperture. Each curve displays the total power density in $\mathrm{mW} / \mathrm{cm}^{2}$, or $\mathrm{dB}$ with respect to $1 \mathrm{~mW} / \mathrm{cm}^{2}$, as a function of the azimuth angle in degrees. Zero degrees with the direction of the main beam. 


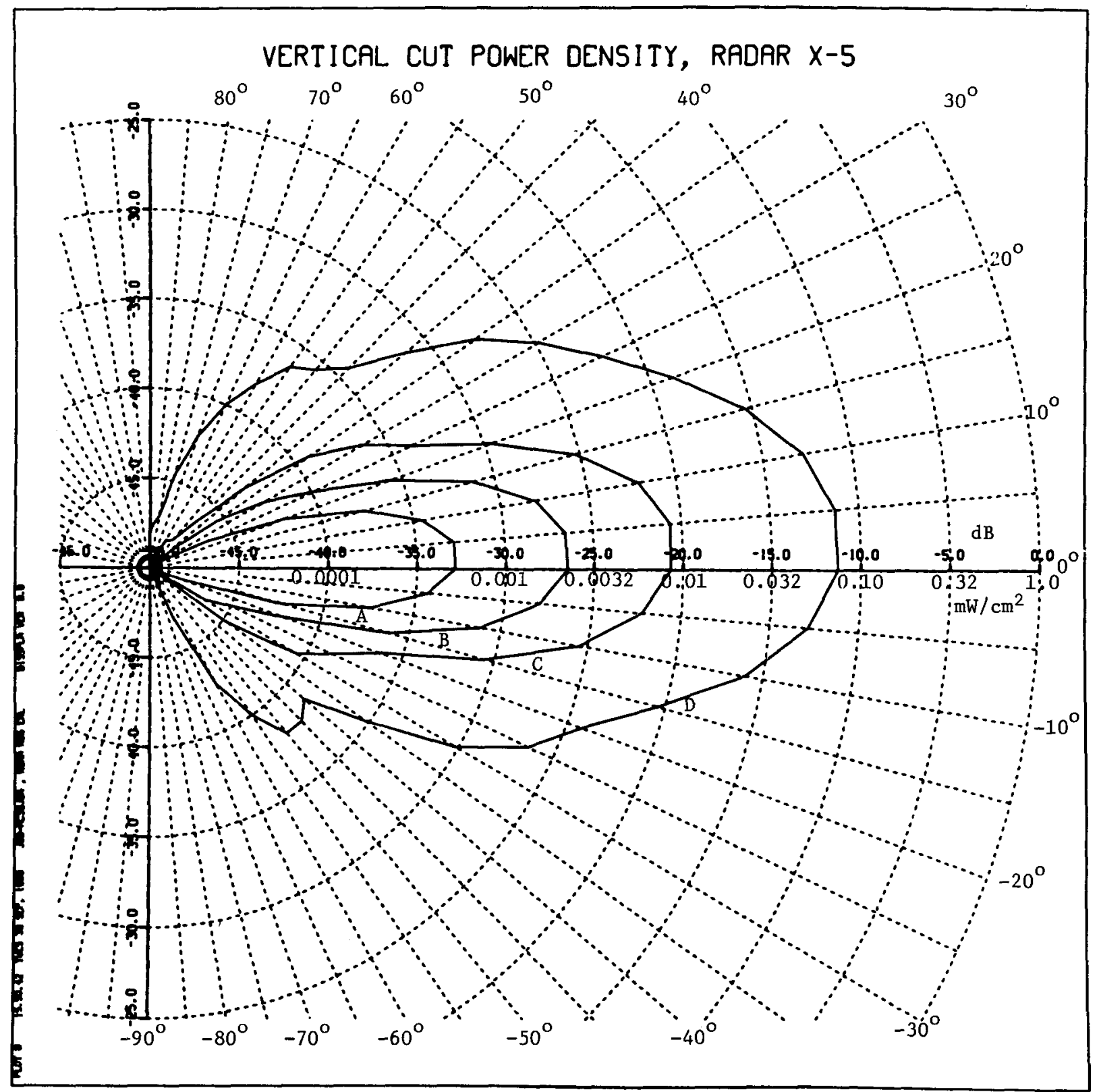

Distances From Radar (Inches): $A=144, B=72, C=36, D=12$

Figure 18. Vertical power patterns for Radar X-5 obtained at four distances from the aperture. Each curve displays the total power density in $\mathrm{mw} / \mathrm{cm}^{2}$, or $\mathrm{dB}$ with respect to $1 \mathrm{~mW} / \mathrm{cm}^{2}$, as a function of the elevation angle in degrees. Zero degrees coincides with the direction of the main beam. 


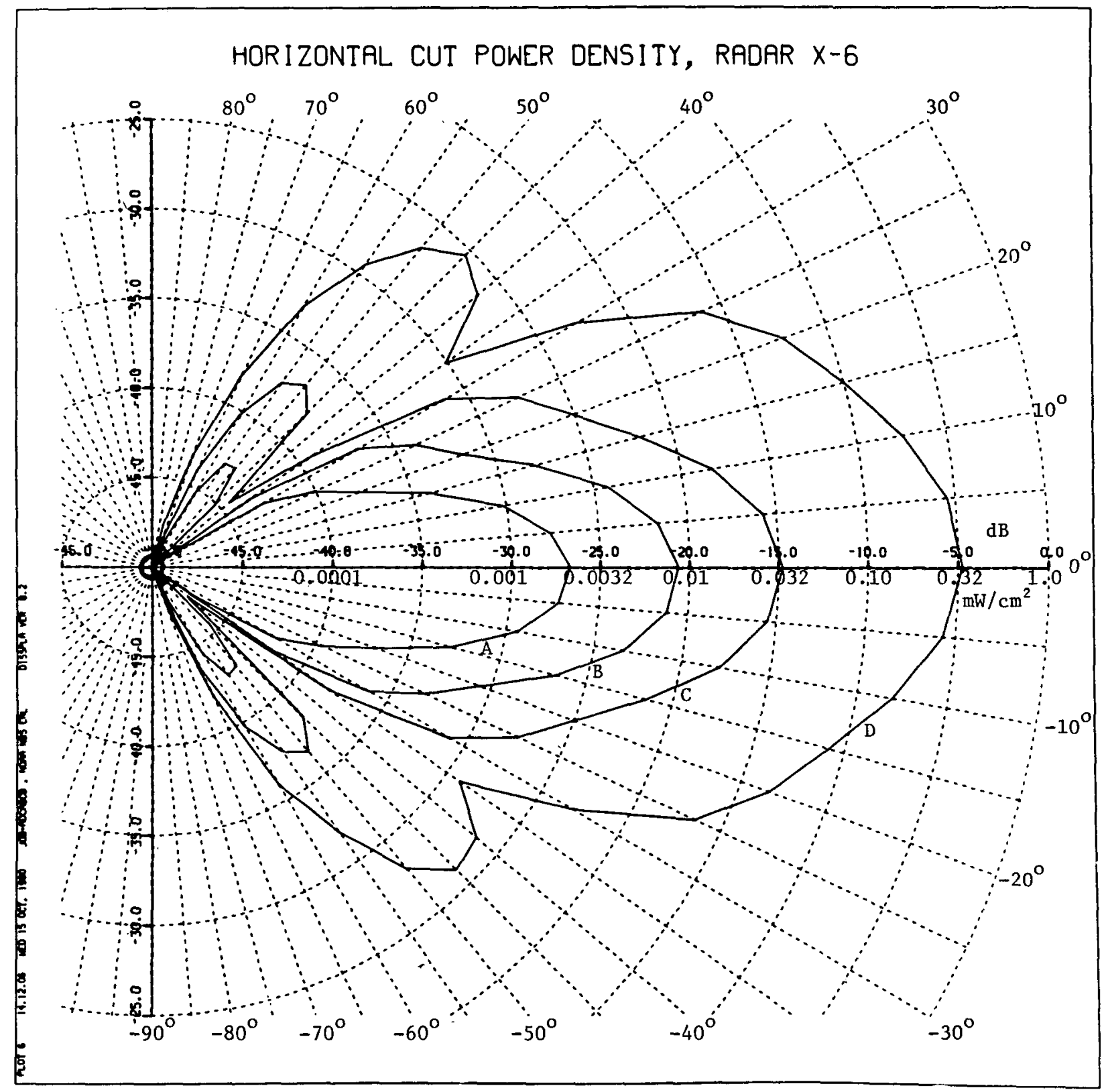

Distances From Radar (Inches): $A=144, B=72, C=36, D=12$

Figure 19. Horizontal power patterns for Radar X-6 obtained at four distances from the aperture. Each curve displays the total power density in $\mathrm{mW} / \mathrm{cm}^{2}$, or $\mathrm{dB}$ with respect to $1 \mathrm{~mW} / \mathrm{cm}^{2}$, as a function of the azimuth angle in degrees. Zero degrees coincides with the direction of the main beam. 


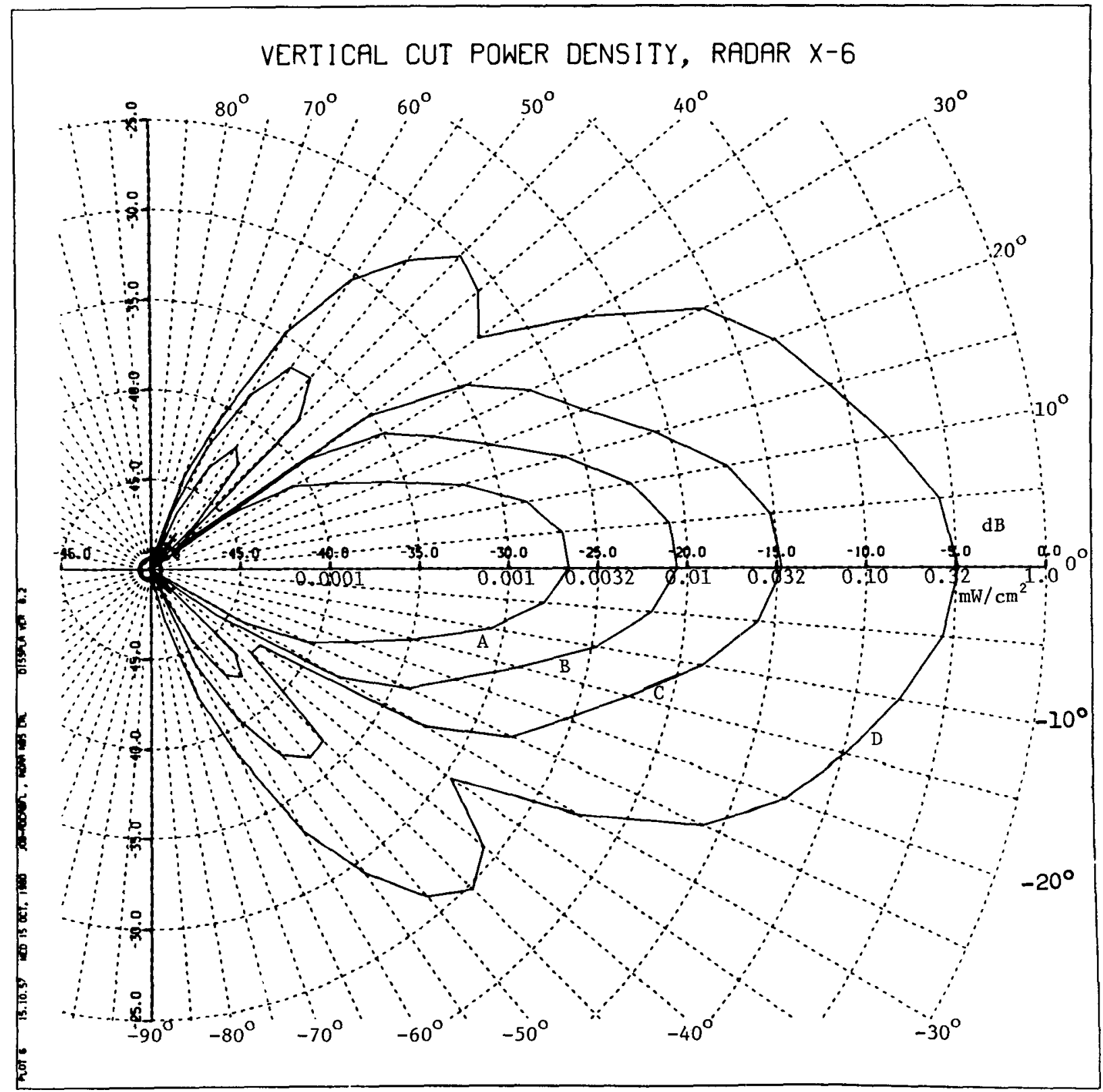

Distances From Radar (Inches): $A=144, \mathrm{~B}=72, \mathrm{C}=36, \mathrm{D}=12$

Figure 20. Vertical power patterns for Radar X-6 obtained at four distances from the aperture. Each curve displays the total power density in $\mathrm{mW} / \mathrm{cm}^{2}$, or $\mathrm{dB}$ with respect to $1 \mathrm{~mW} / \mathrm{cm}^{2}$, as a function of the elevation angle in degrees. Zero degrees coincides with the direction of the main beam. 


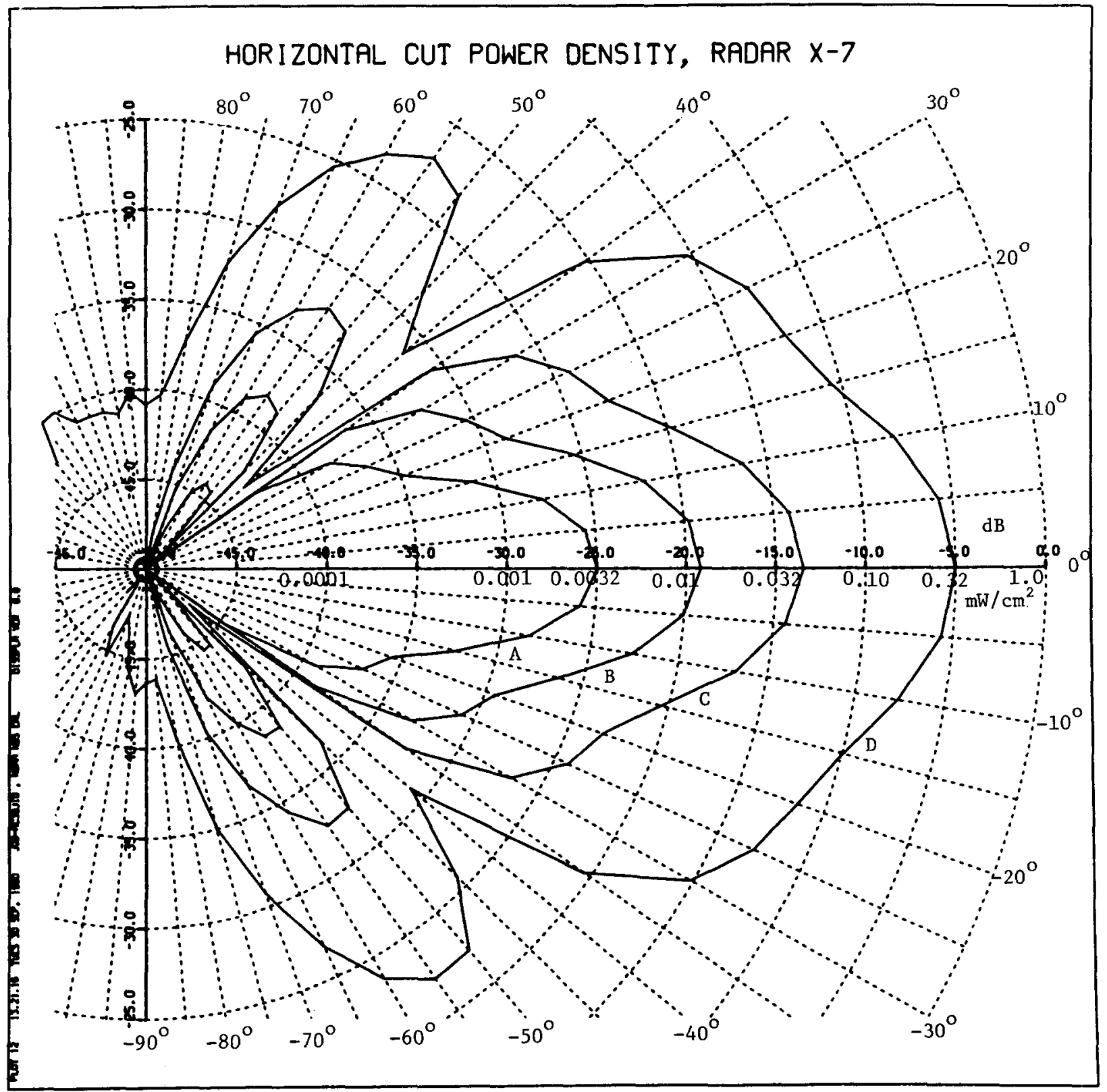

Distance From Radar (Inches): $A=144, B=72, C=36, D=12$

Figure 21. Horizontal power patterns for Radar X-7 obtained at four distances from the aperture. Each curve displays the total power density in $\mathrm{mW} / \mathrm{cm}^{2}$, or $d B$ with respect to $1 \mathrm{~mW} / \mathrm{cm}^{2}$, as a function of the azimuth angle in degrees. Zero degrees coincides with the direction of the main beam. 


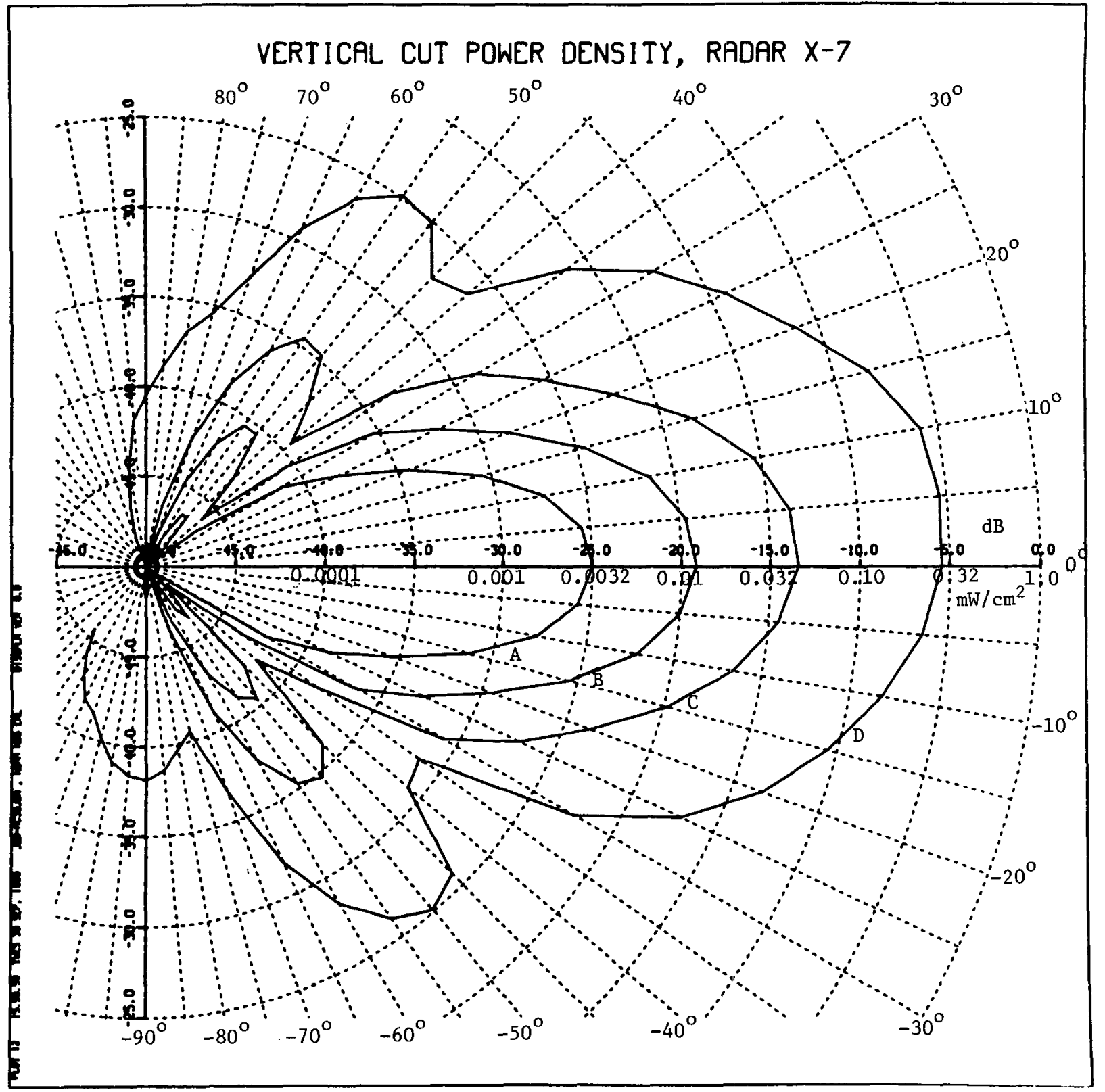

Distances From Radar (Inches): $\mathrm{A}=144, \mathrm{~B}=72, \mathrm{C}=36, \mathrm{D}=12$

Figure 22. Vertical power patterns for Radar X-7 obtained at four distances from the aperture. Each curve displays the total power density in $\mathrm{mw} / \mathrm{cm}^{2}$, or $\mathrm{dB}$ with respect to $1 \mathrm{~mW} / \mathrm{cm}^{2}$, as a function of the elevation angle in degrees. Zero degrees coincides with the direction of the main beam. 


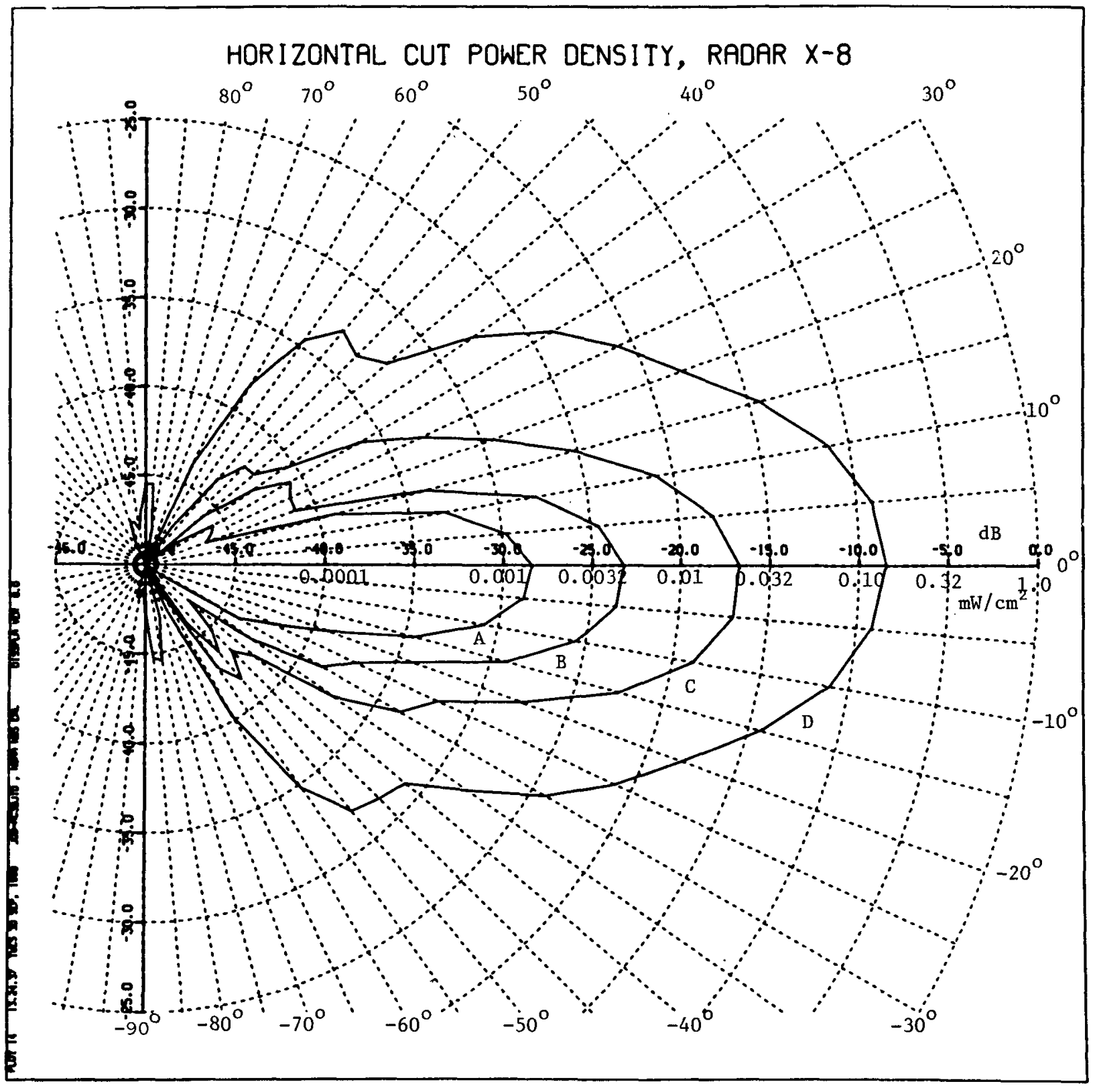

Distances From Radar (Inches): $\mathrm{A}=144, \mathrm{~B}=72, \mathrm{C}=36, \mathrm{D}=12$

Figure 23. Horizontal power patterns for Radar X-8 obtained at four distances from the aperture. Each curve displays the total power density in $\mathrm{mW} / \mathrm{cm}^{2}$, or $\mathrm{dB}$ with respect to $1 \mathrm{mw} / \mathrm{cm}^{2}$, as a function of the azimuth angle in degrees. Zero degrees coincides with the direction of the main beam. 


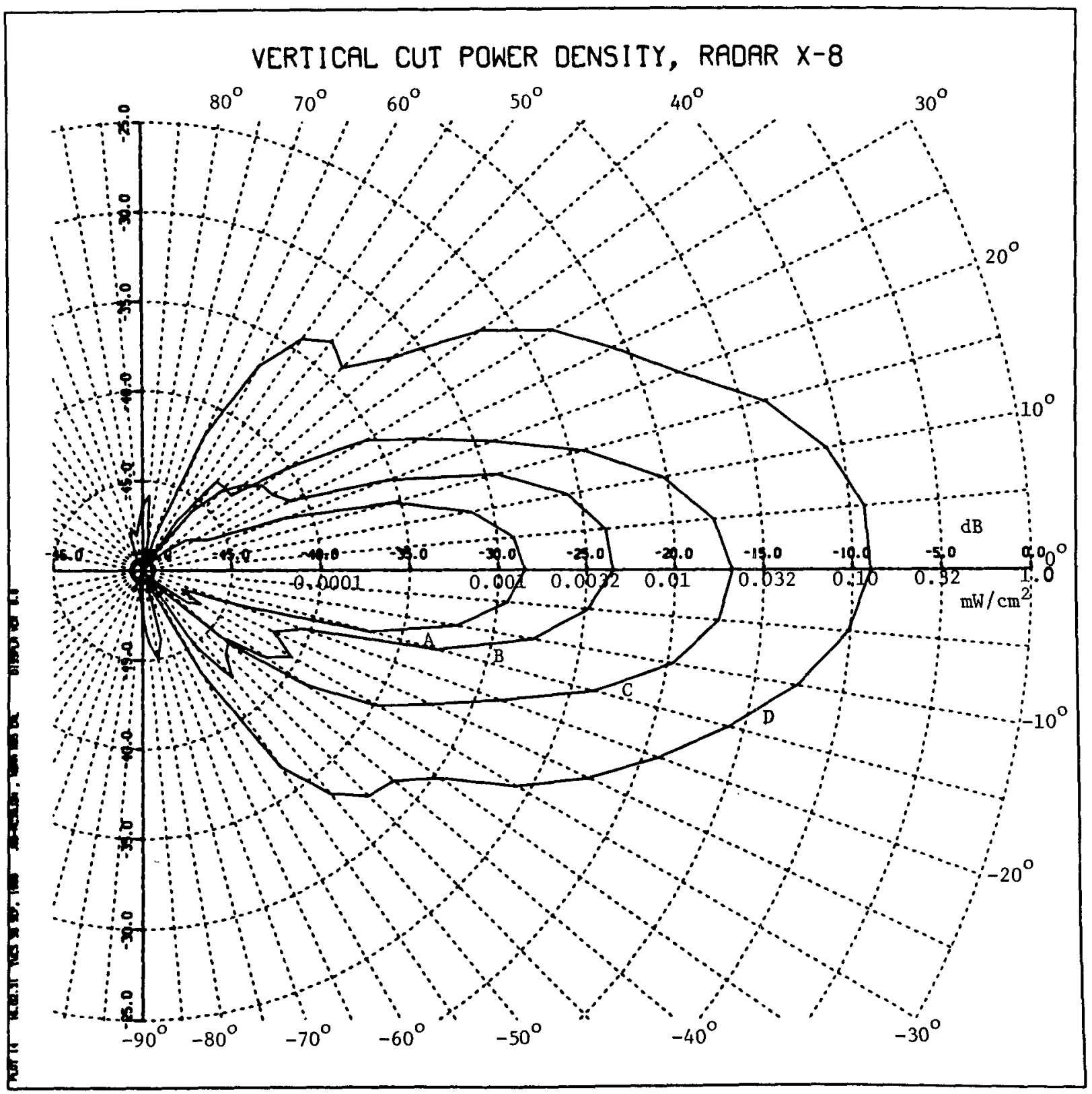

Distances From Radar (Inches): $\mathrm{A}=144, \mathrm{~B}=72, \mathrm{C}=36, \mathrm{D}=12$

Figure 24. Vertical power patterns for Radar X-8 obtained at four distances from the aperture. Each curve displays the total power density in $\mathrm{mw} / \mathrm{cm}^{2}$, or $\mathrm{dB}$ with respect to $1 \mathrm{~mW} / \mathrm{cm}^{2}$, as a function of the elevation angle in degrees. Zero degrees coincides with the direction of the main beam. 


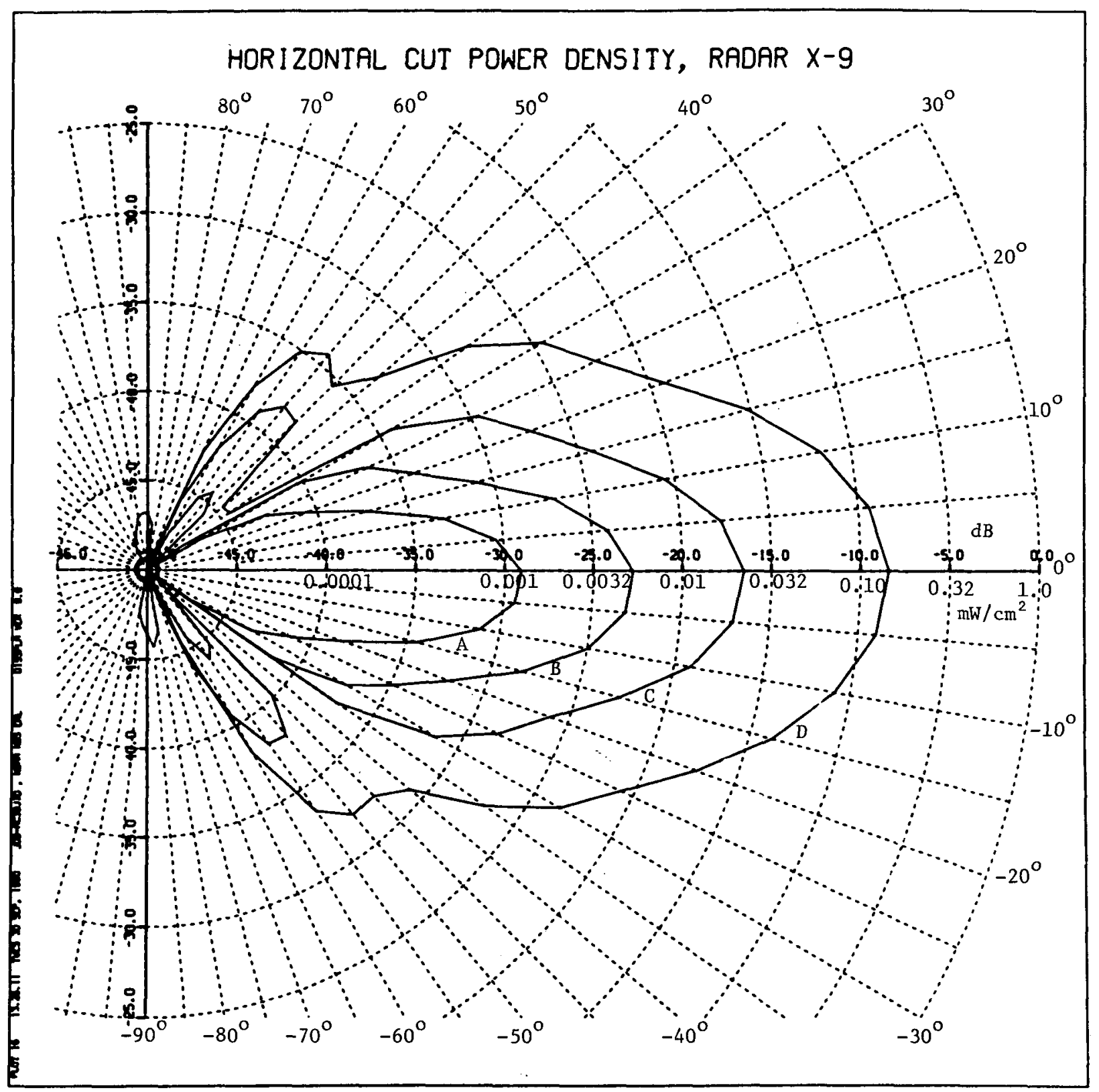

Distances From Radar (Inches): $\mathrm{A}=144, \mathrm{~B}=72, \mathrm{C}=36, \mathrm{D}=12$

Figure 25. Horizontal power patterns for Radar X-9 obtained at four distances from the aperture. Each curve displays the total power density in $\mathrm{mw} / \mathrm{cm}^{2}$, or $\mathrm{dB}$ with respect to $1 \mathrm{~mW} / \mathrm{cm}^{2}$, as a function of the azimuth angle in degrees. Zero degrees coincides with the direction of the main beam. 


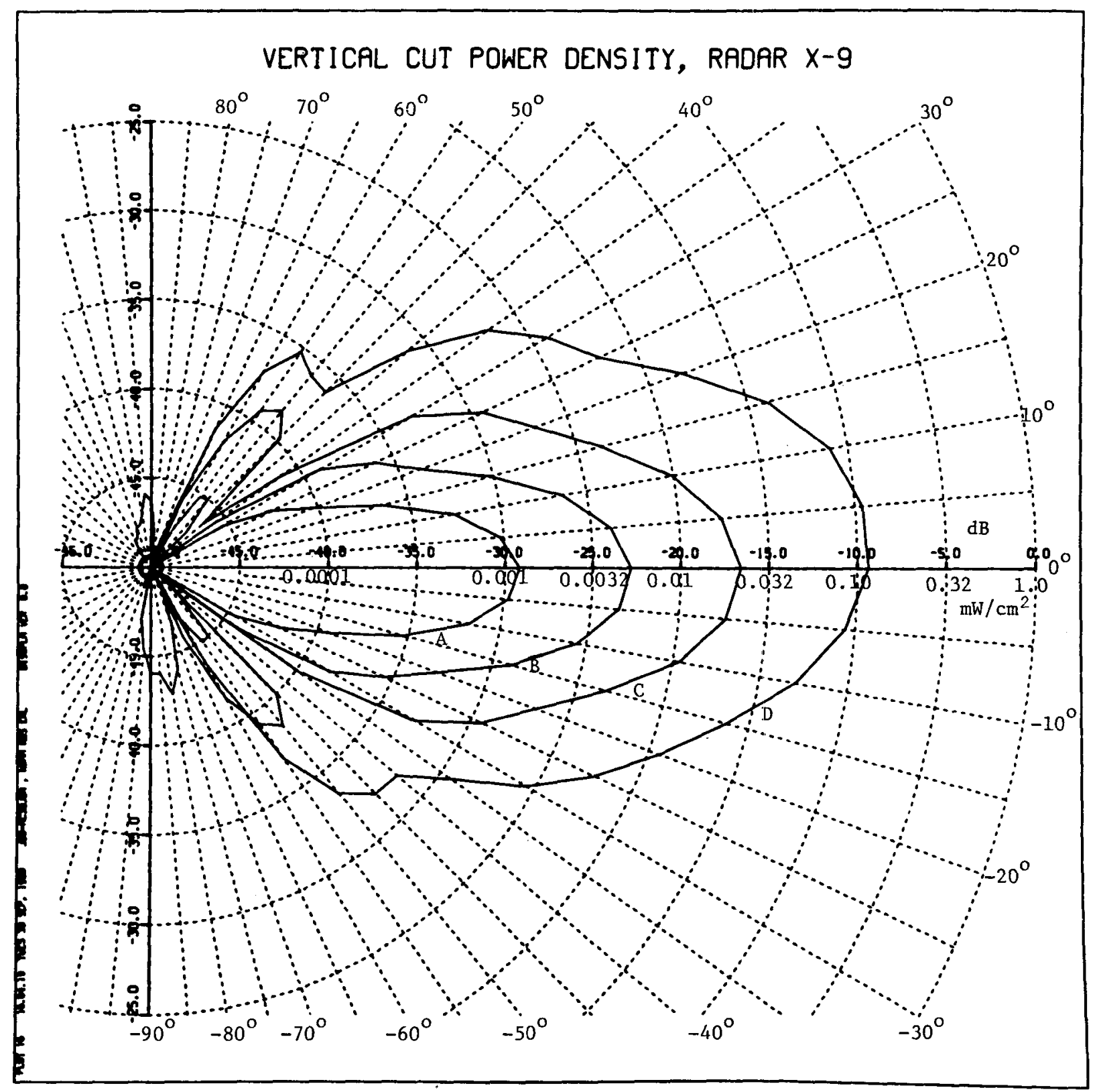

Distances From Radar (Inches): $\mathrm{A}=144, \mathrm{~B}=72, \mathrm{C}=36, \mathrm{D}=12$

Figure 26. Vertical power patterns for Radar X-9 obtained at four distances from the aperture. Each curve displays the total power density in $\mathrm{mW} / \mathrm{cm}^{2}$, or $\mathrm{dB}$ with respect to $1 \mathrm{~mW} / \mathrm{cm}^{2}$, as a function of the elevation angle in degrees. Zero degrees coincides with the direction of the main beam. 


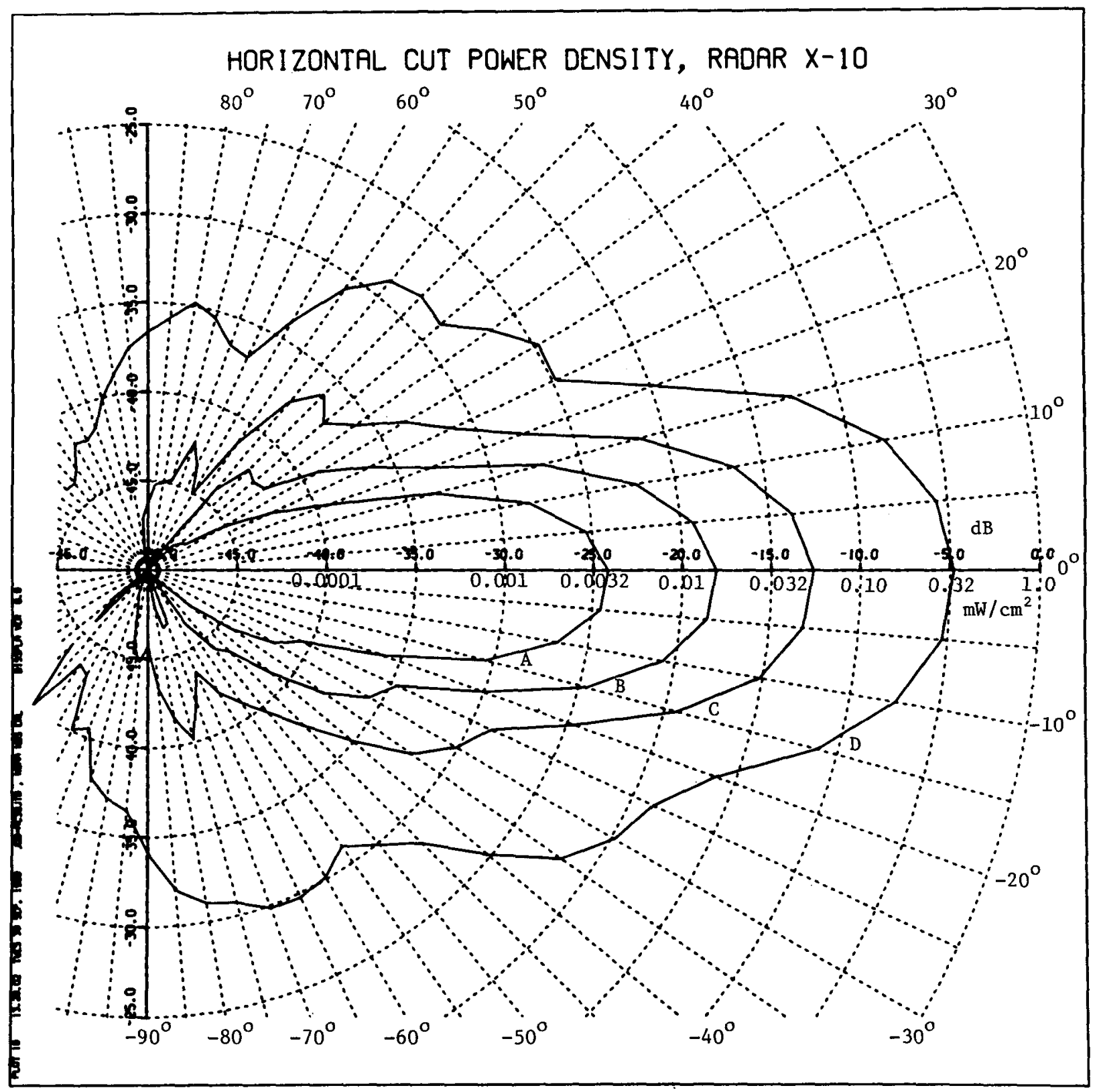

Distances From Radar (Inches): $\mathrm{A}=144, \mathrm{~B}=72, \mathrm{C}=36, \mathrm{D}=12$

Figure 27. Horizontal power patterns for Radar X-10 obtained at four distances from the aperture. Each curve displays the total power density in $\mathrm{mW} / \mathrm{cm}^{2}$, or $\mathrm{dB}$ with respect to $1 \mathrm{~mW} / \mathrm{cm}^{2}$, as a function of the azimuth angle in degrees. Zero degrees coincides with the direction of the main beam. 


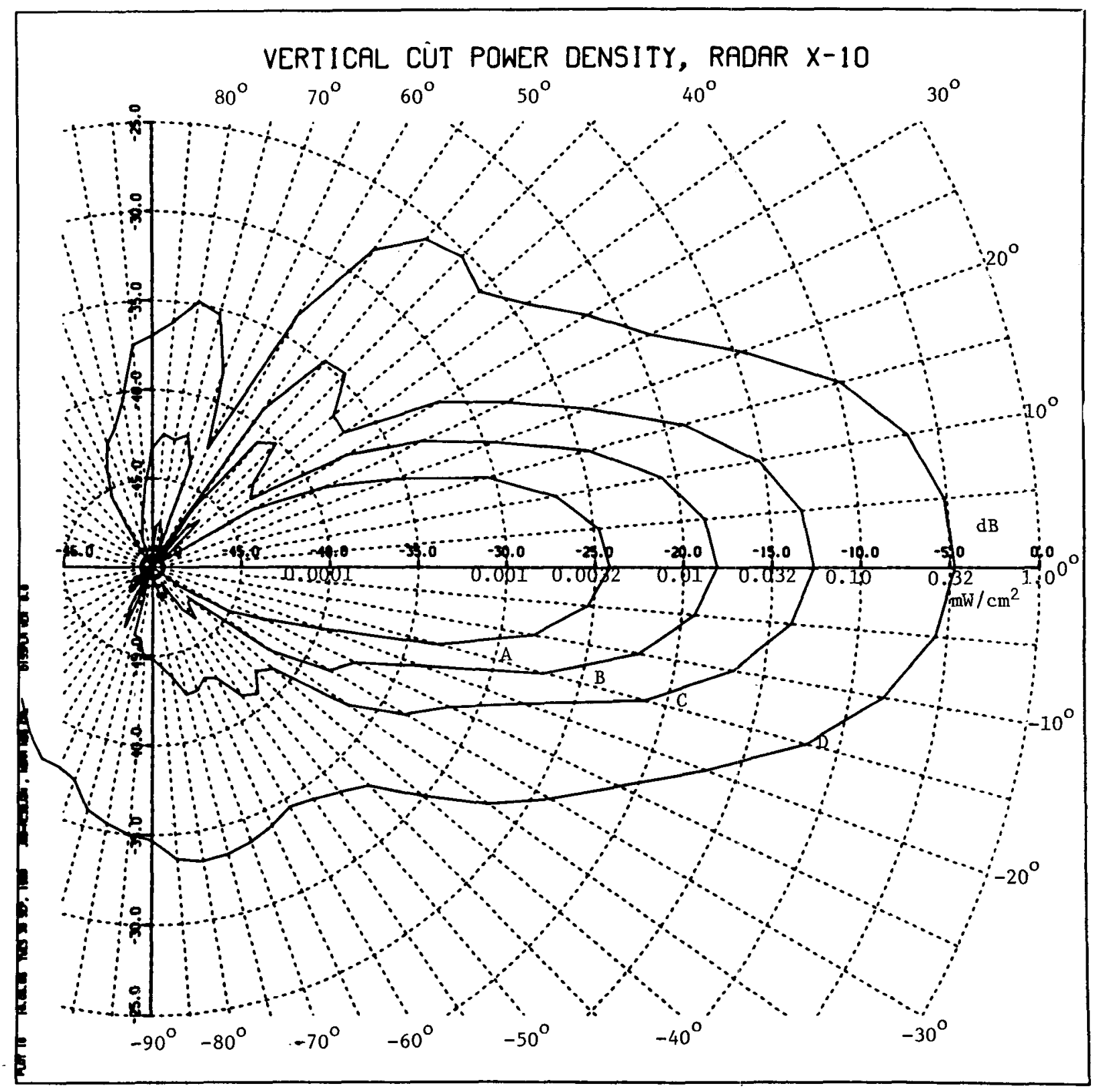

Distances From Radar (Inches): $A=144, B=72, C=36, D=12$

Figure 28. Vertical power patterns for Radar X-10 obtained at four distances from the aperture. Each curve displays the total power density in $\mathrm{mW} / \mathrm{cm}^{2}$, or $\mathrm{dB}$ with respect to $1 \mathrm{~mW} / \mathrm{cm}^{2}$, as a function of the elevation angle in degrees. Zero degrees coincides with the direction of the main beam. 


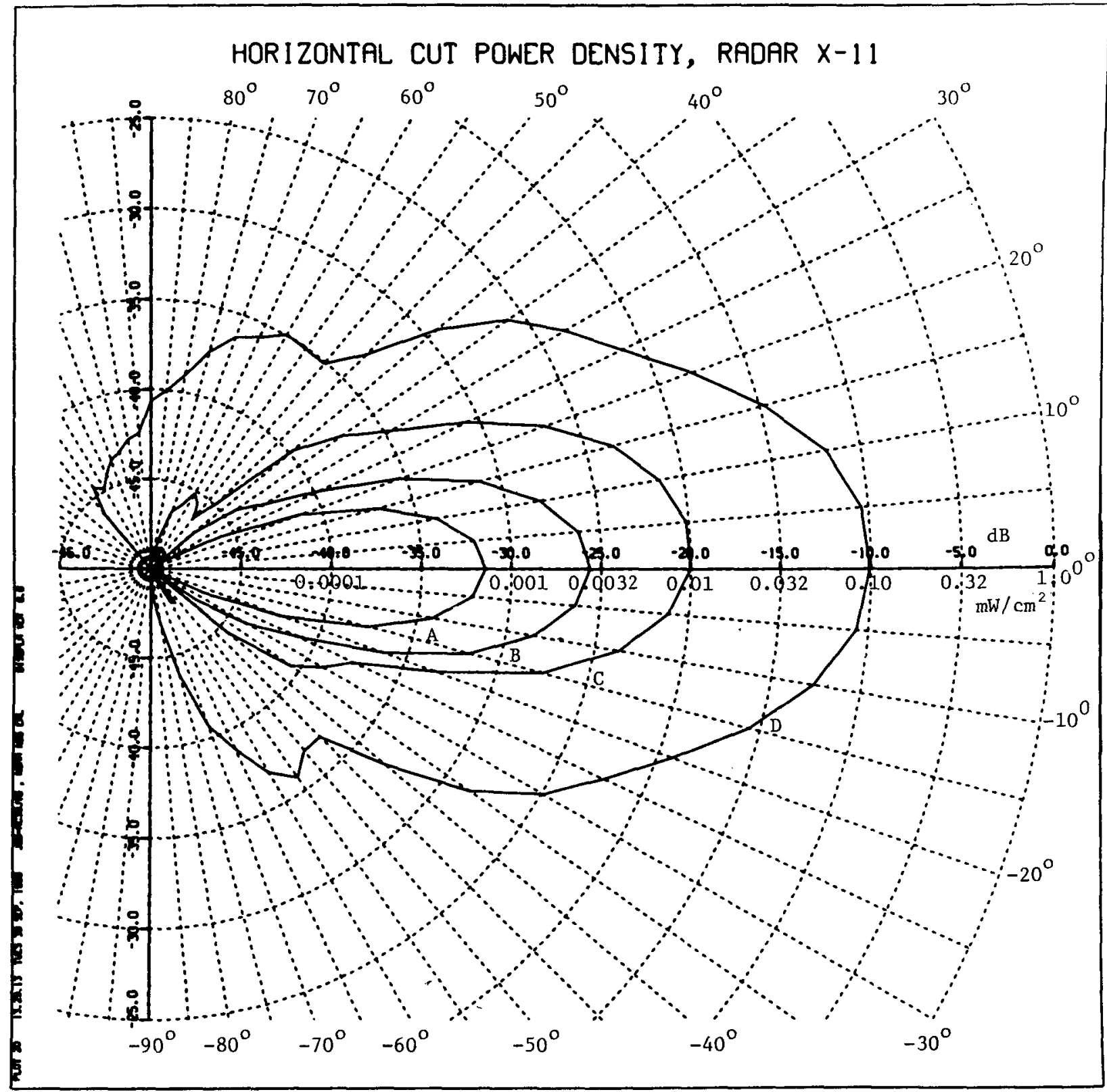

Distances From Radar (Inches): $\quad A=144, B=72, C=36, D=12$

Figure 29. Horizontal power patterns for Radar X-11 obtained at four distances from the aperture. Each curve displays the total power density in $\mathrm{mW} / \mathrm{cm}^{2}$, or $\mathrm{dB}$ with respect to $1 \mathrm{~mW} / \mathrm{cm}^{2}$, as a function of the azimuth angle in degrees. Zero degrees coincides with the direction of the main beam. 


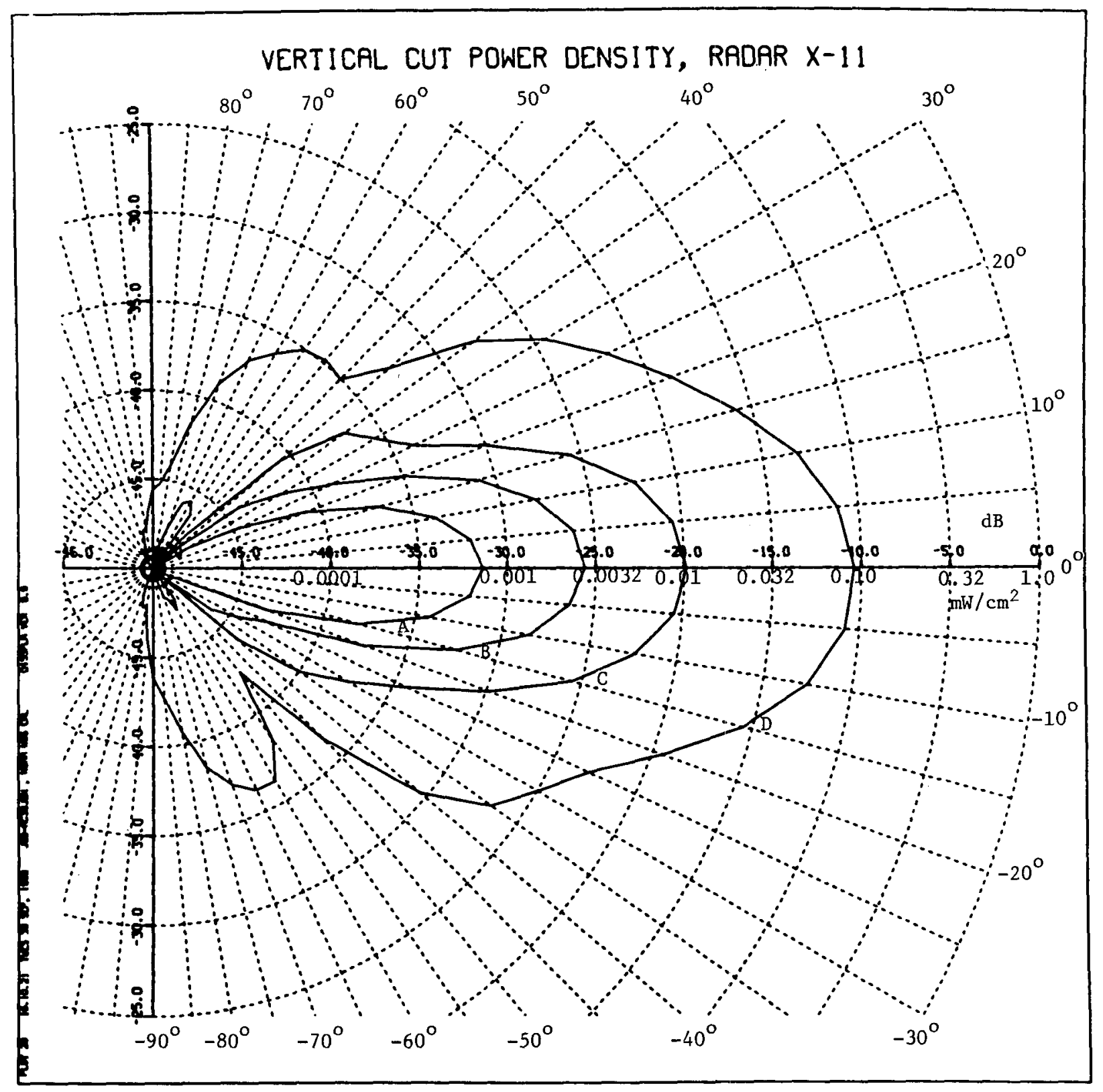

Distances From Radar (Inches): $\mathrm{A}=144, \mathrm{~B}=72, \mathrm{C}=36, \mathrm{D}=12$

Figure 30. Vertical power patterns for Radar X-11 obtained at four distances from the aperture. Each curve displays the total power density in $\mathrm{mW} / \mathrm{cm}^{2}$, or $\mathrm{dB}$ with respect to $1 \mathrm{~mW} / \mathrm{cm}^{2}$, as a function of the elevation angle in degrees. Zero degrees coincides with the direction of the main beam. 


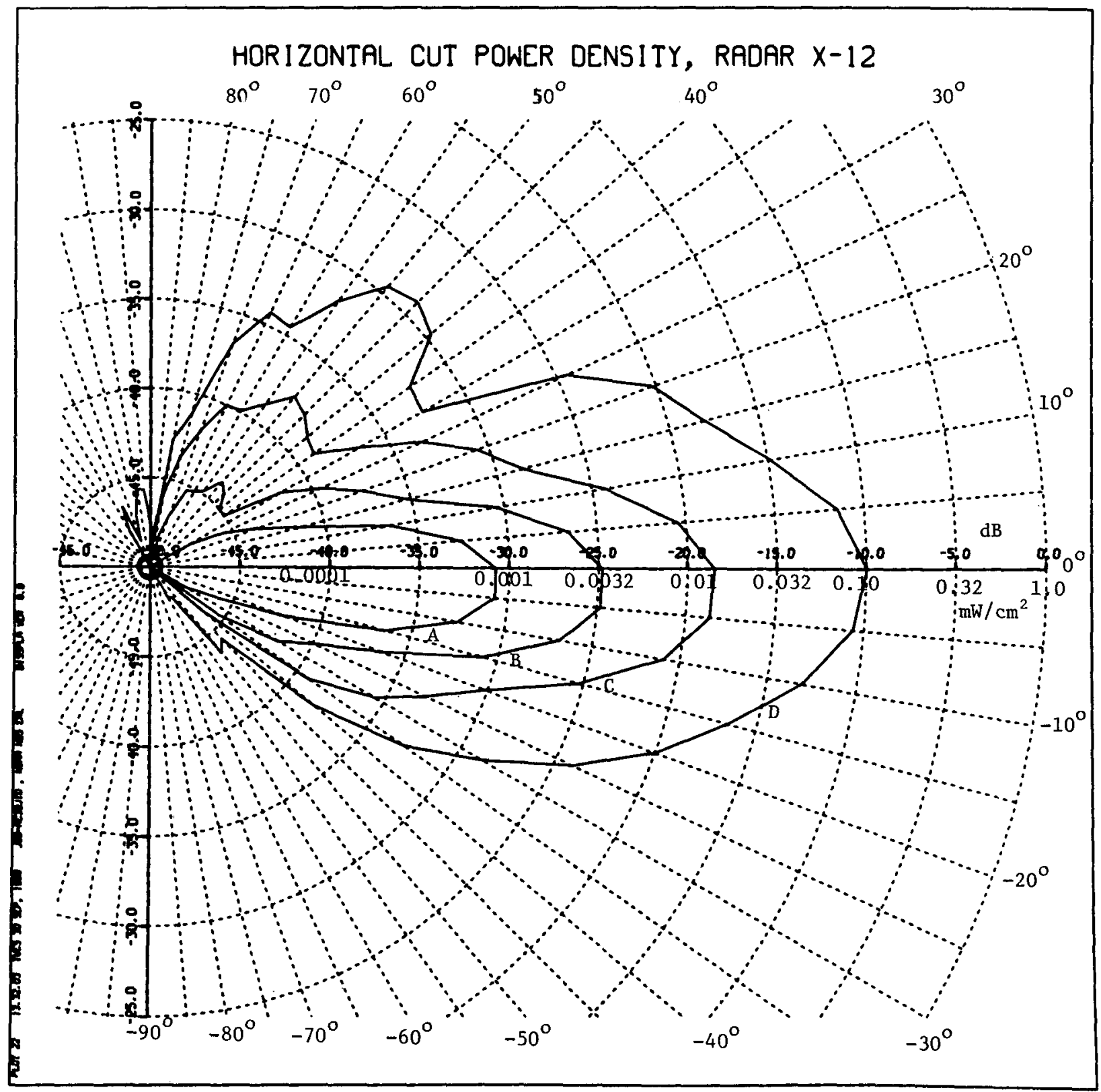

Distances From Radar (Inches): $\mathrm{A}=144, \mathrm{~B}=72, \mathrm{C}=36, \mathrm{D}=12$

Figure 31. Horizontal power patterns for Radar X-12 obtained at four distances from the aperture. Fach curve displays the total power density in $\mathrm{mW} / \mathrm{cm}^{2}$, or $\mathrm{dB}$ with respect to $1 \mathrm{~mW} / \mathrm{cm}^{2}$, as a function of the azimuth angle in degrees. Zero degrees coincides with the direction of the main beam. 


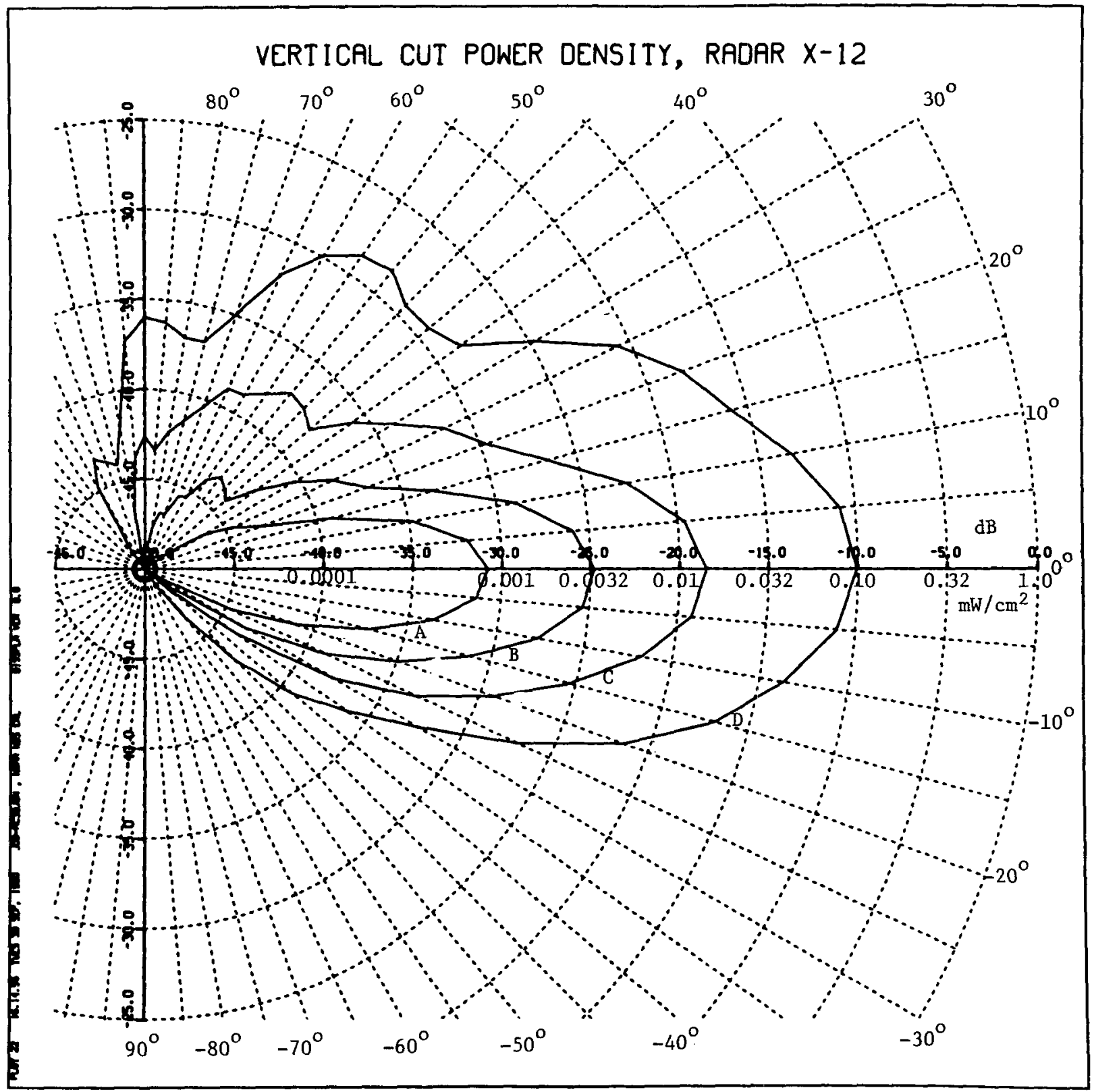

Distances From Radar (Inches): $A=144, \mathrm{~B}=72, \mathrm{C}=36, \mathrm{D}=12$

Figure 32. Vertical power patterns for Radar X-12 obtained at four distances from the aperture. Each curve displays the total power density in $\mathrm{mW} / \mathrm{cm}^{2}$, or $\mathrm{dB}$ with respect to $1 \mathrm{~mW} / \mathrm{cm}^{2}$, as a function of the elevation angle in degrees. Zero degrees coincides with the direction of the main beam. 


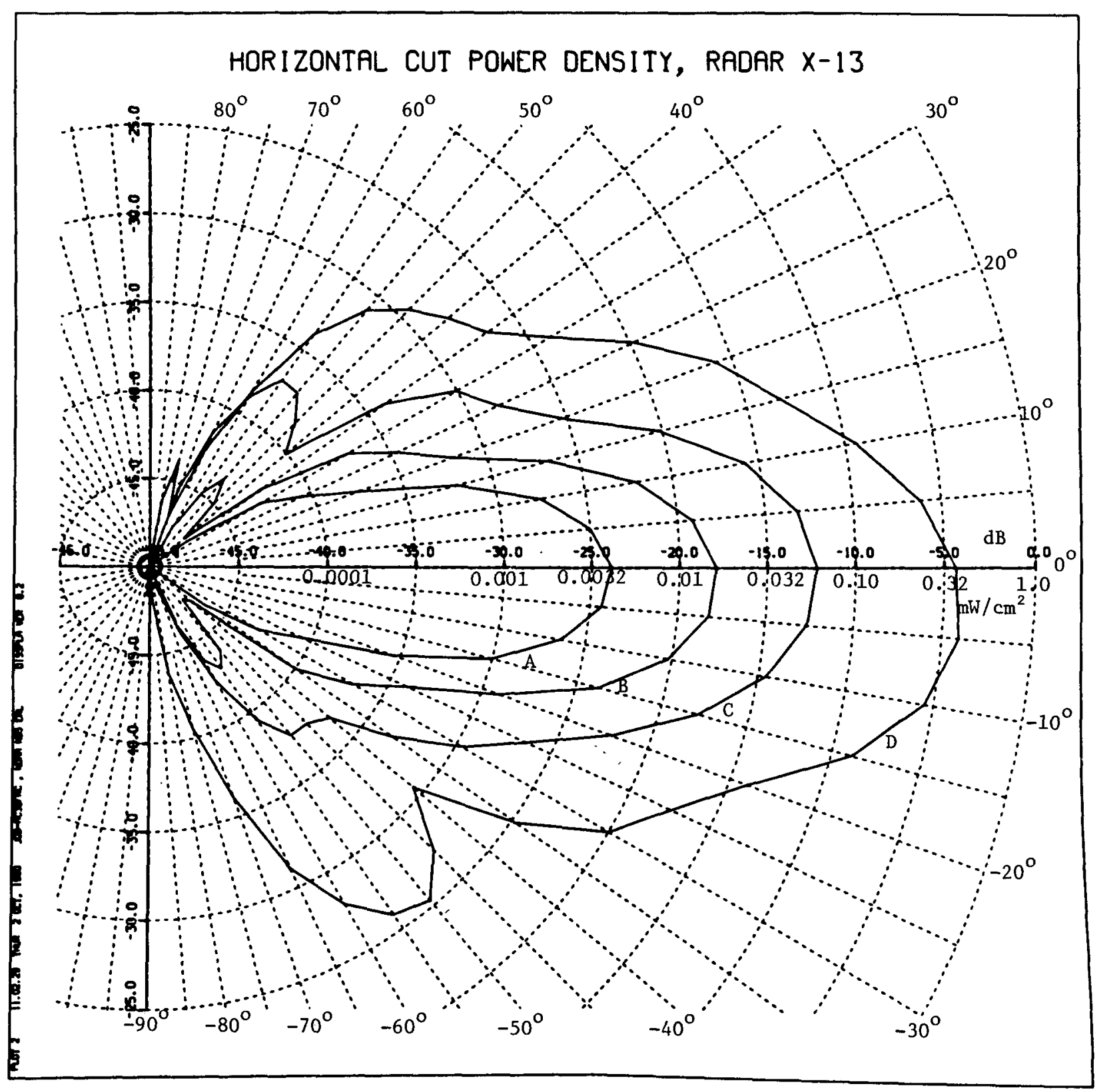

Distances From Radar (Inches): $\mathrm{A}=144, \mathrm{~B}=72, \mathrm{C}=36, \mathrm{D}=12$

Figure 33. Horizontal power patterns for Radar X-13 obtained at four distances from the aperture. Each curve displays the total power density in $\mathrm{mW} / \mathrm{cm}^{2}$, or $\mathrm{dB}$ with respect to $1 \mathrm{~mW} / \mathrm{cm}^{2}$, as a function of the azimuth angle in degrees. Zero degrees coincides with the direction of the main beam. 


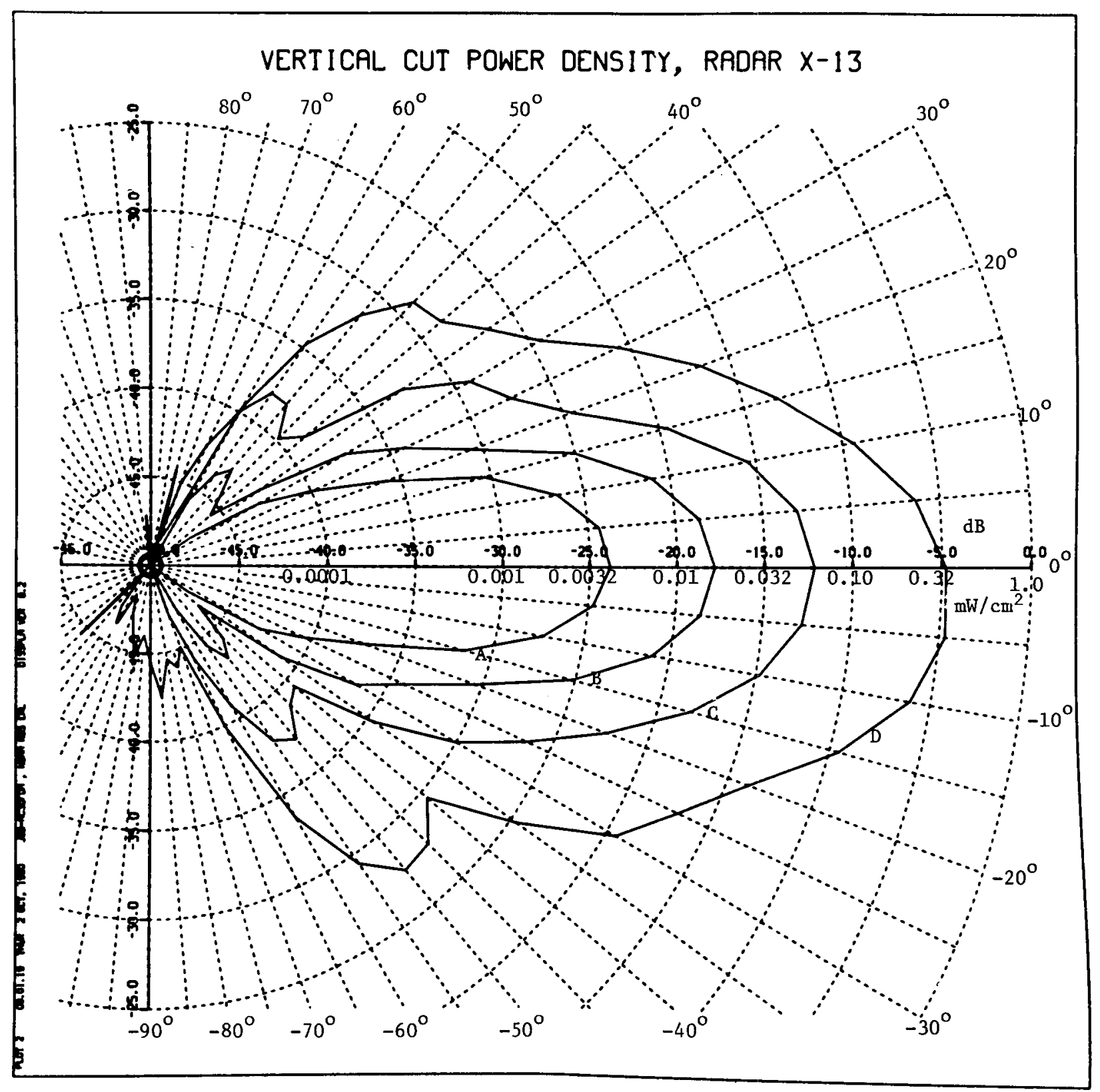

Distances From Radar (Inches): $\mathrm{A}=144, \mathrm{~B}=72, \mathrm{C}=36, \mathrm{D}=12$

Figure 34. Vertical power patterns for Radar X-13 obtained at four distances from the aperture. Each curve displays the total power density in $\mathrm{mW} / \mathrm{cm}^{2}$, or $\mathrm{dB}$ with respect to $1 \mathrm{~mW} / \mathrm{cm}^{2}$, as a function of the elevation angle in degrees. Zero degrees coincides with the direction in the main beam. 


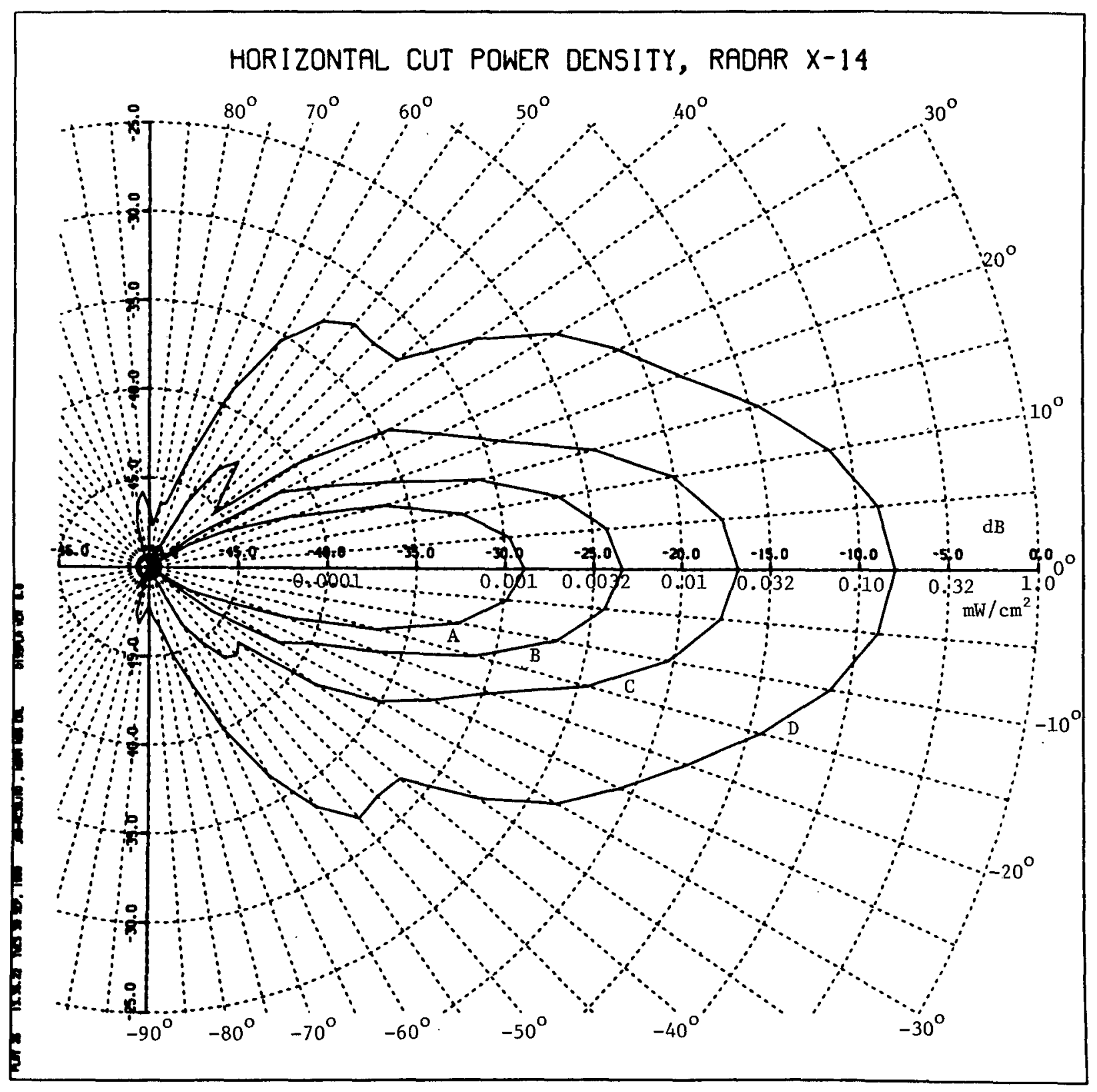

Distances From Radar (Inches): $\mathrm{A}=144, \mathrm{~B}=72, \mathrm{C}=36, \mathrm{D}=12$

Figure 35. Horizontal power patterns for Radar X-14 obtained at four distances from the aperture. Each curve displays the total power density in $\mathrm{mW} / \mathrm{cm}^{2}$, or $\mathrm{dB}$ with respect to $1 \mathrm{~mW} / \mathrm{cm}^{2}$, as a function of the azimuth angle in degrees. Zero degrees coincides with the direction of the main beam. 


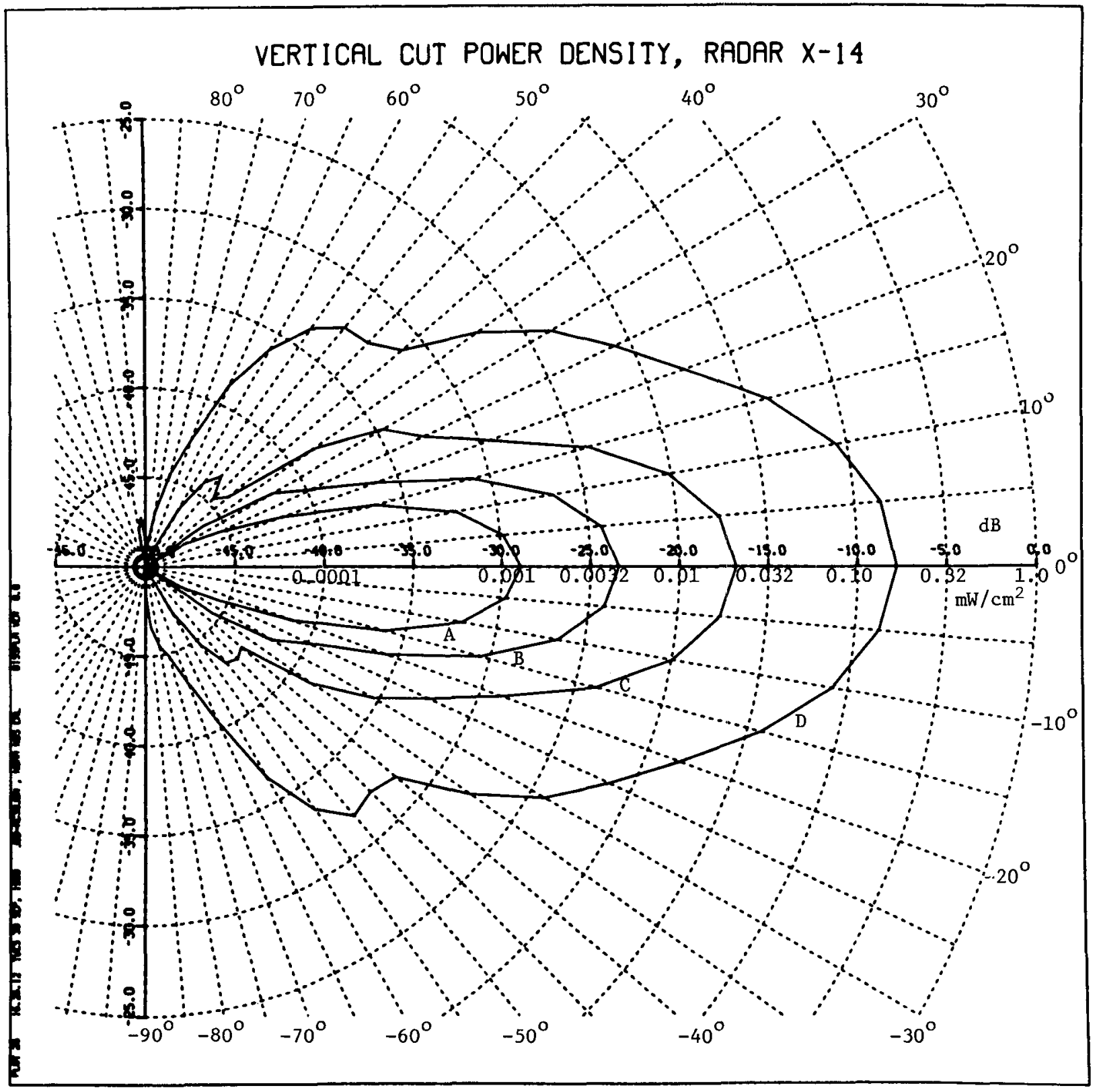

Distances From Radar (Inches): $\mathrm{A}=144, \mathrm{~B}=72, \mathrm{C}=36, \mathrm{D}=12$

Figure 36. Vertical power patterns for Radar X-14 obtained at four distances from the aperture. Each curve displays the total power density in $\mathrm{mw} / \mathrm{cm}^{2}$, or $\mathrm{dB}$ with respect to $1 \mathrm{~mW} / \mathrm{cm}^{2}$, as a function of the elevation angle in degrees. Zero degrees coincides with the direction of the main beam. 


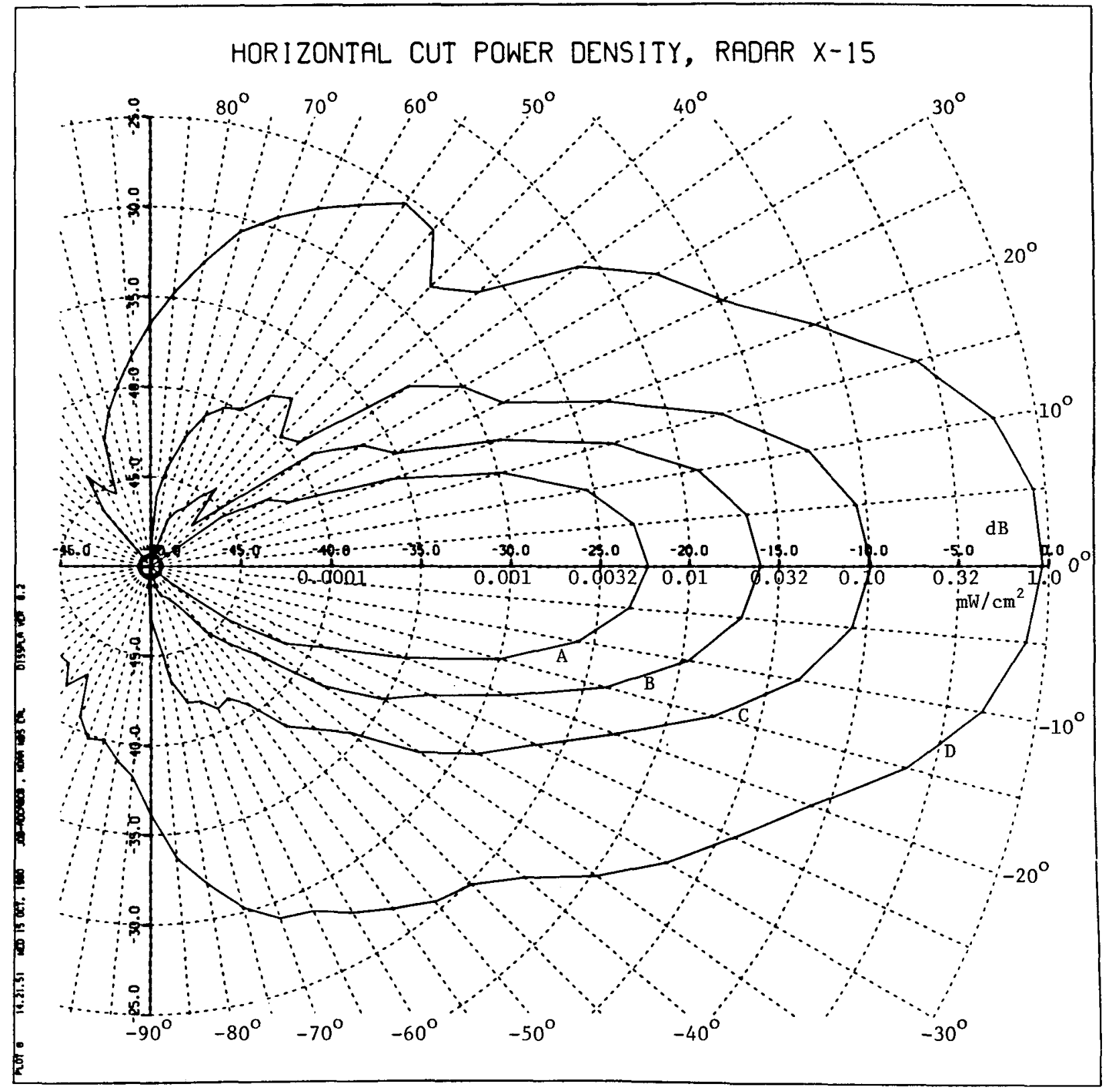

Distances From Radar (Inches): $\mathrm{A}=144, \mathrm{~B}=72, \mathrm{C}=36, \mathrm{D}=12$

Figure 37. Horizontal power patterns for Radar X-15 obtained at four distances from the aperture. Each curve displays the total power density in $\mathrm{mW} / \mathrm{cm}^{2}$, or $\mathrm{dB}$ with respect to $1 \mathrm{~mW} / \mathrm{cm}^{2}$, as a function of the azimuth angle in degrees. Zero degrees coincides with the direction of the main beam. 


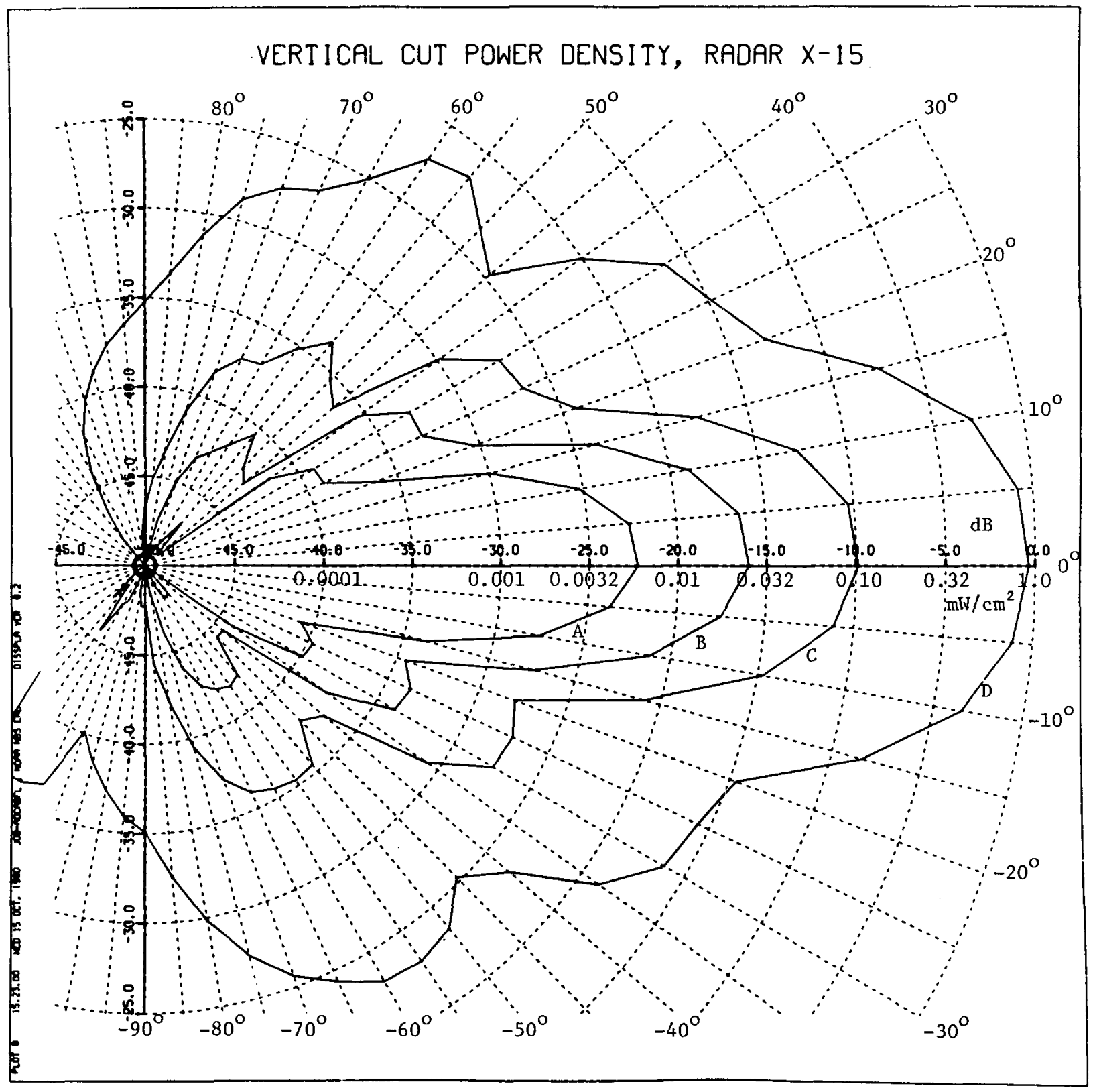

Distances From Radar (Inches): $\mathrm{A}=144, \mathrm{~B}=72, \mathrm{C}=36, \mathrm{D}=12$

Figure 38. Vertical power patterns for Radar X-15 obtained at four distances from the aperture. Each curve displays the total power density in $\mathrm{mW} / \mathrm{cm}^{2}$, or $\mathrm{dB}$ with respect to $1 \mathrm{~mW} / \mathrm{cm}^{2}$, as a function of the elevation angle in degrees. Zero degrees coincides with the direction of the main beam. 


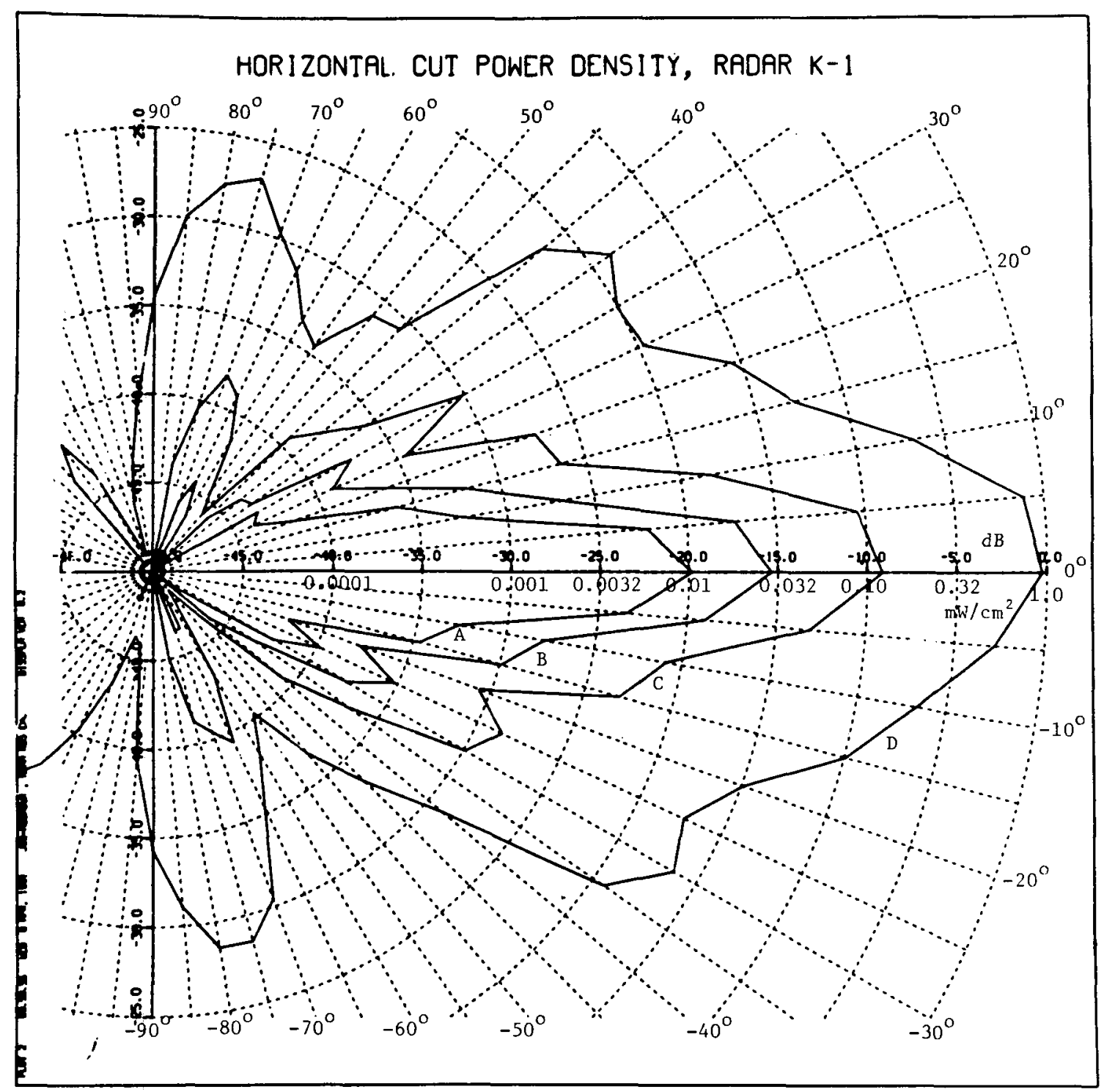

Distances From Radar (Inches): $\mathrm{A}=120, \mathrm{~B}=72, \mathrm{C}=36, \mathrm{D}=12$

Figure 39. Horizontal power patterns for Radar $K-1$ obtained at four distances from the aperture. Each curve displays the total power density in $\mathrm{mw} / \mathrm{cm}^{2}$, or $\mathrm{dB}$ with respect to $1 \mathrm{~mW} / \mathrm{cm}^{2}$, as a function of the azimuth angle in degrees. Zero degrees coincides with the direction of the main beam. 


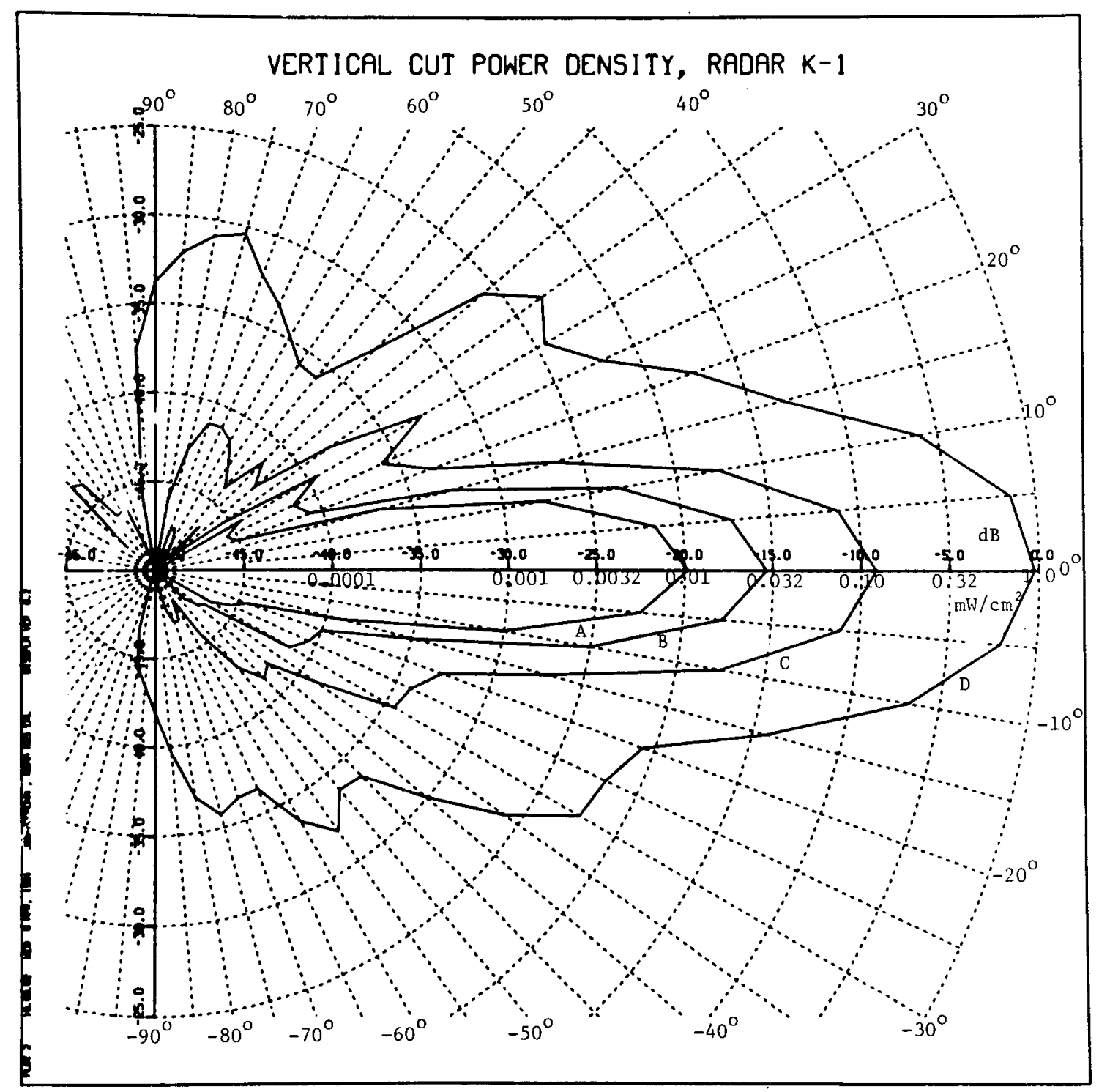

Distances From Radar (Inches): $A=120, B=72, C=36, D=12$

Figure 40. Vertical power patterns for Radar $\mathrm{K}-1$ obtained at four distances from the aperture. Each curve displays the total power density in $\mathrm{mW} / \mathrm{cm}^{2}$, or $\mathrm{dB}$ with respect to $1 \mathrm{~mW} / \mathrm{cm}^{2}$, as a function of the elevation angle in degrees. Zero degrees coincides with the direction of the main beam. 


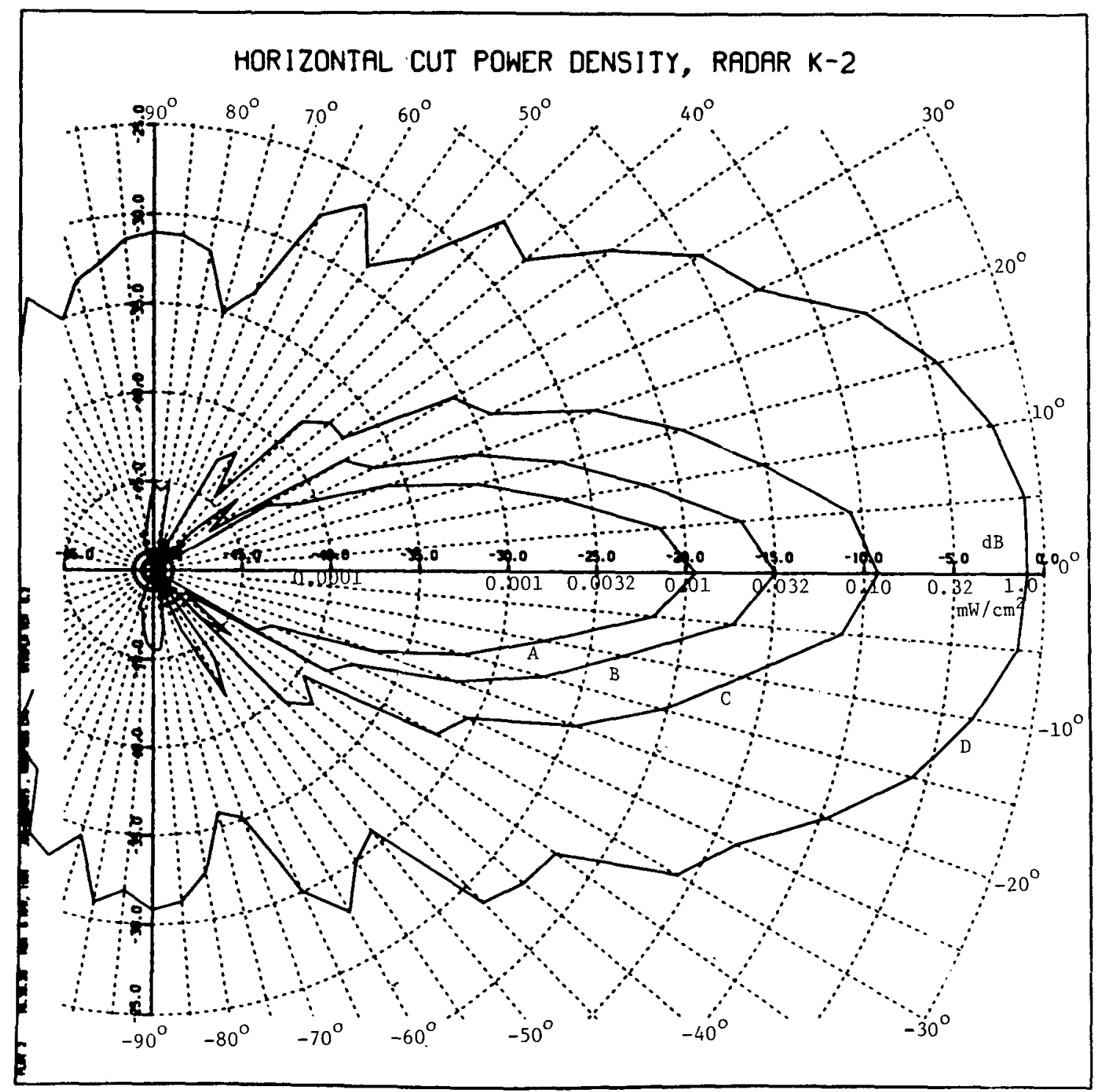

Distances From Radar (Inches): $A=120, B=72, C=36, D=12$

Figure 41. Horizontal power patterns for Radar K-2 obtained at four distances from the aperture. Each curve displays the total power density in $\mathrm{mw} / \mathrm{cm}^{2}$, or $\mathrm{dB}$ with respect to $1 \mathrm{~mW} / \mathrm{cm}^{2}$, as a function of the azimuth angle in degrees. Zero degrees coincides with the direction of the main beam. 


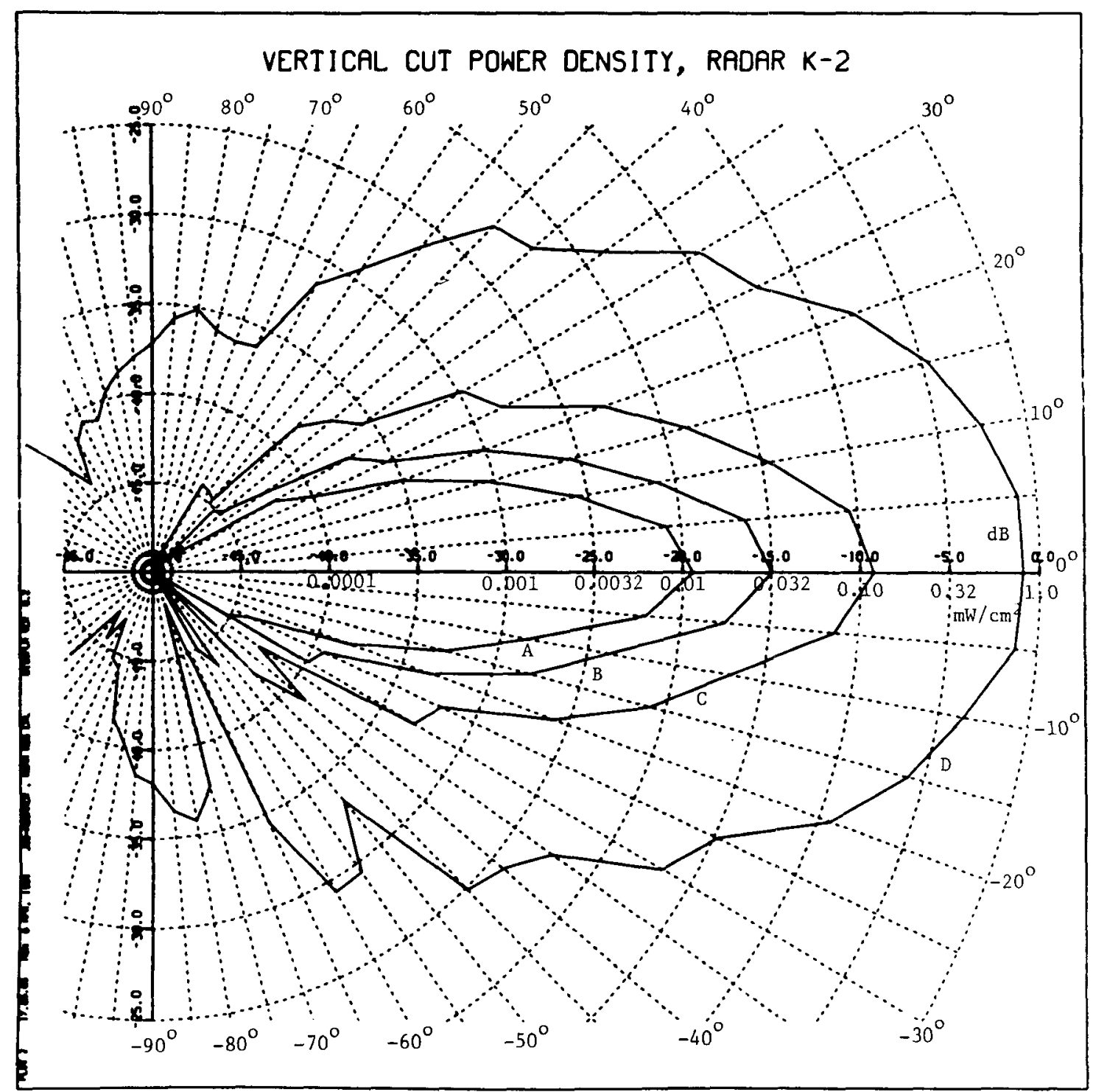

Distances From Radar (Inches): $A=120, B=72, C=36, D=12$

Figure 42. Vertical power patterns for Radar $k-2$ obtained at four distances from the aperture. Each curve displays the total power density in $\mathrm{mW} / \mathrm{cm}^{2}$, or $\mathrm{dB}$ with respect to $1 \mathrm{~mW} / \mathrm{cm}^{2}$, as a function of the elevation angle in degrees. Zero degrees coincides with the direction of the main beam. 


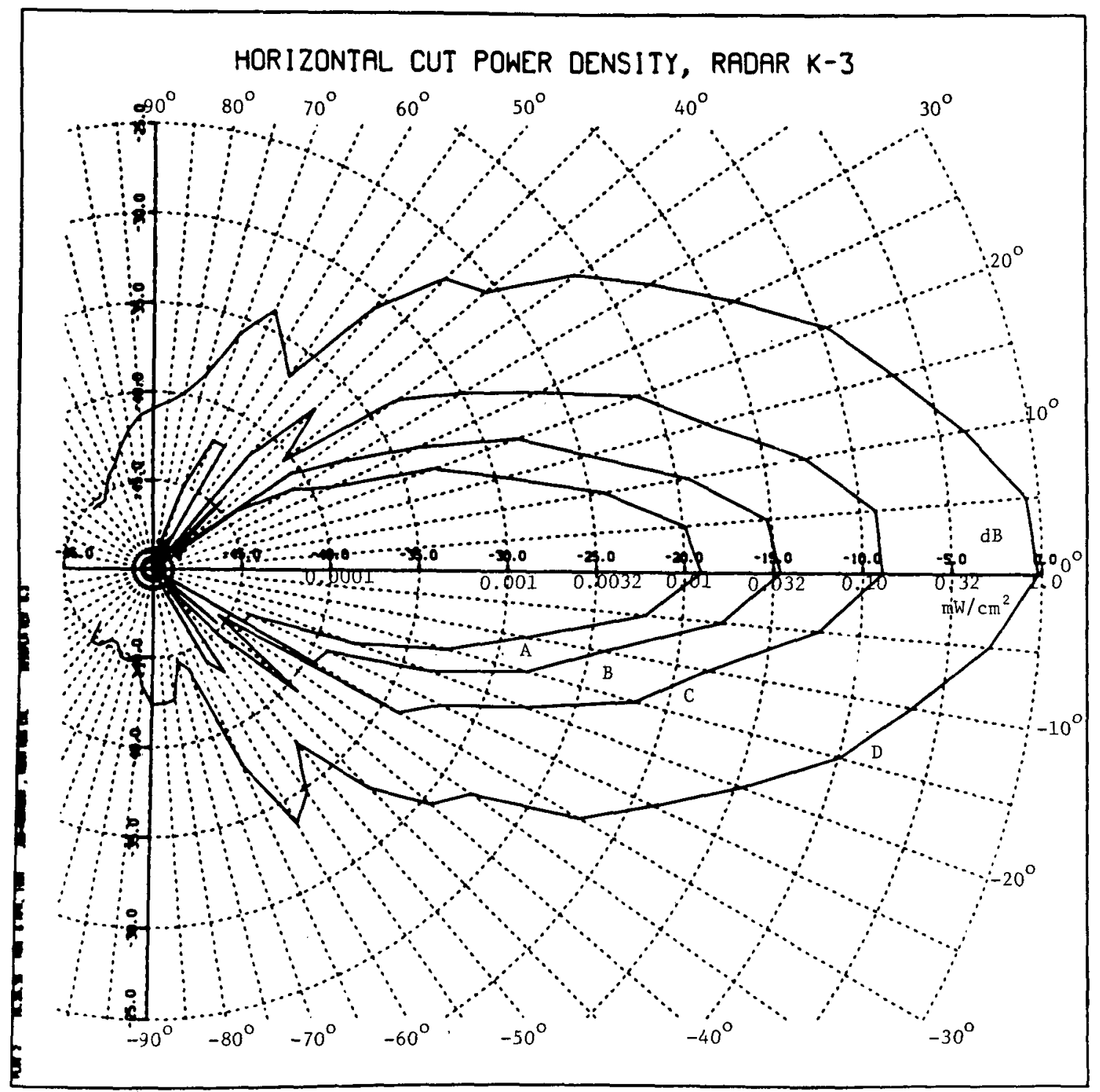

Distance From Radar (Inches): $A=120, B=72, C=36, D=12$

Figure 43. Horizontal power patterns for Radar $\mathrm{K}-3$ obtained at four distances from the aperture. Each curve displays the total power density in $\mathrm{mW} / \mathrm{cm}^{2}$, or $\mathrm{dB}$ with respect to $1 \mathrm{~mW} / \mathrm{cm}^{2}$, as a function of the azimuth angle in degrees. Zero degrees coincides with the direction of the main beam. 


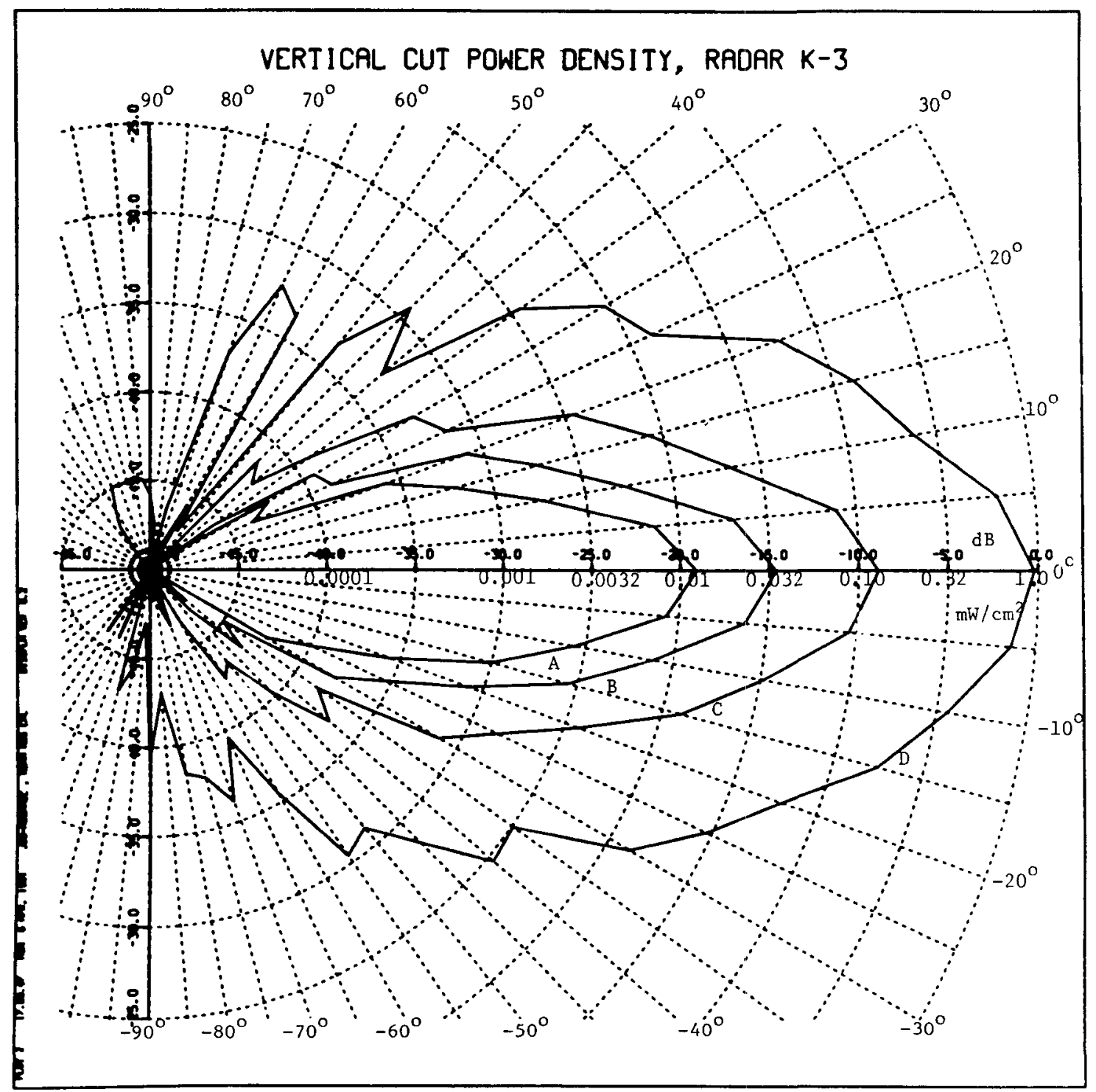

Distances From Radar (Inches): $A=120, B=72, C=36, D=12$

Figure 44. Vertical power patterns for Radar K-3 obtained at four distances from the aperture. Each curve displays the total power density in $\mathrm{mW} / \mathrm{cm}^{2}$, or $\mathrm{dB}$ with respect to $1 \mathrm{~mW} / \mathrm{cm}^{2}$, as a function of the elevation angle in degrees. Zero degrees coincides with the direction of the main beam. 


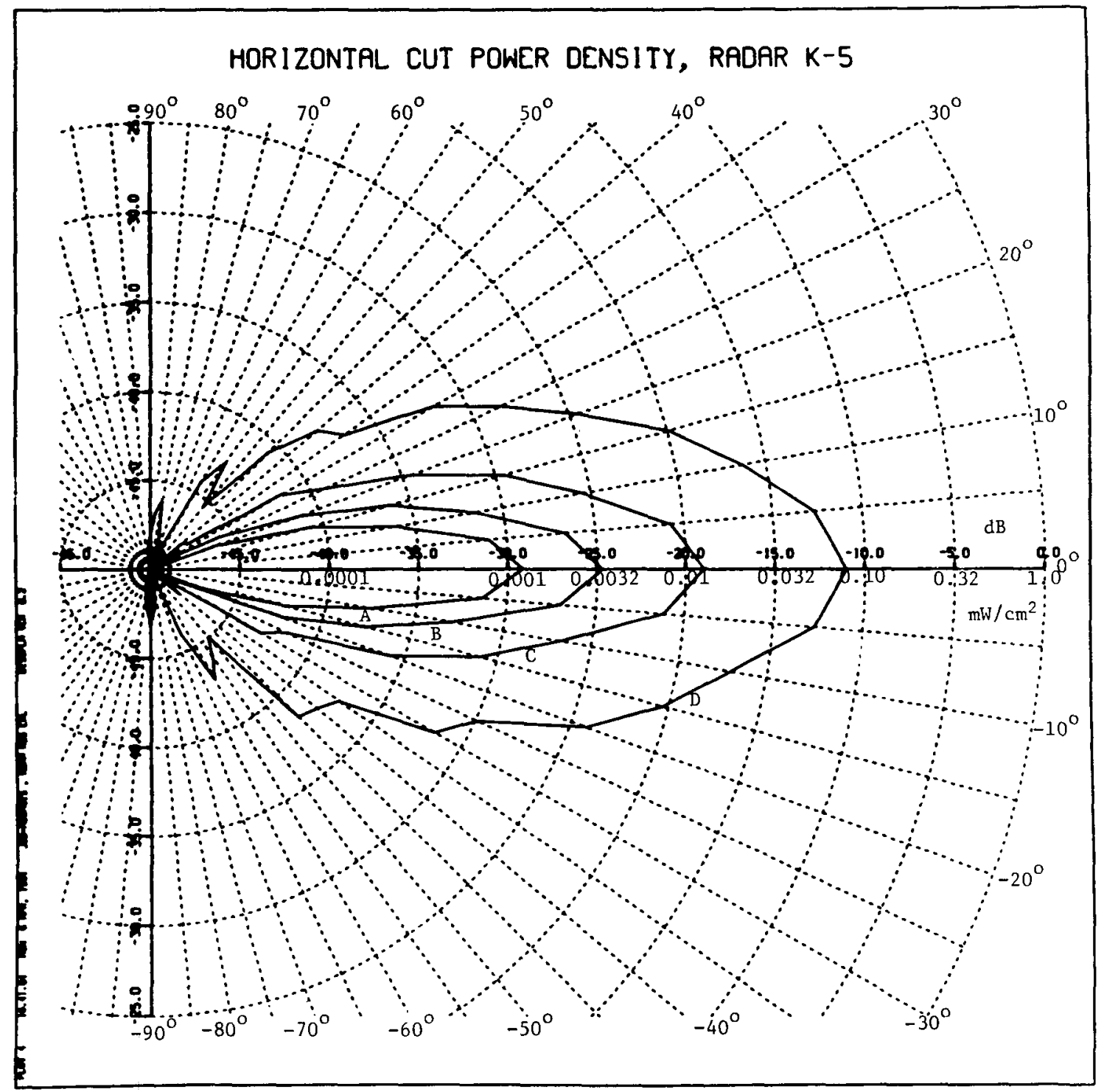

Distances From Radar (Inches): $A=120, B=72, C=36, D=12$

Figure 45. Horizontal power patterns for Radar $K-5$ obtained at four distances from the aperture. Each curve displays the total power density in $\mathrm{mW} / \mathrm{cm}^{2}$, or $\mathrm{dB}$ with respect to $1 \mathrm{~mW} / \mathrm{cm}^{2}$, as a function of the azimuth angle in degrees. Zero degrees coincides with the direction of the main beam. 


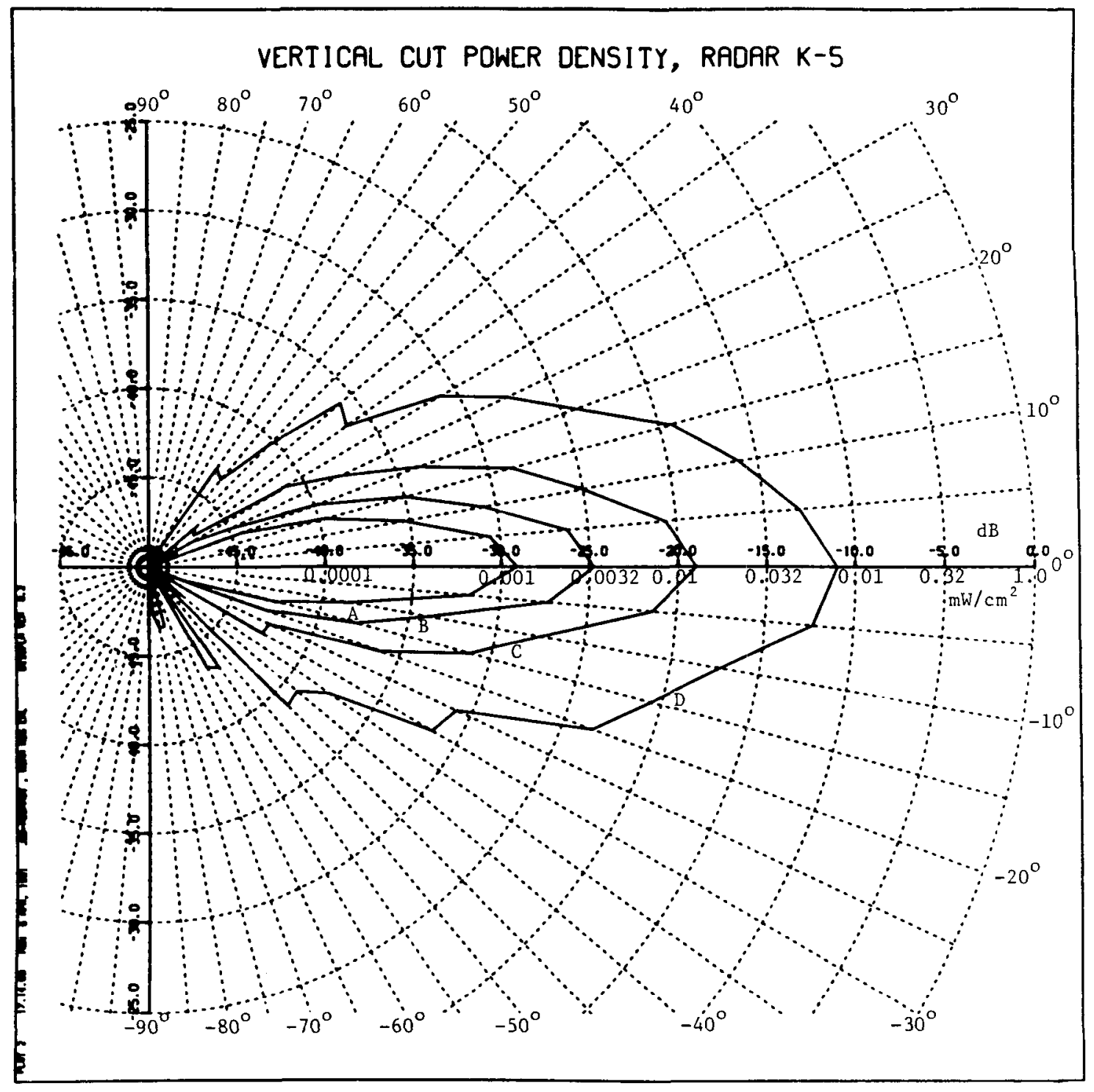

Distances From Radar (Inches): $\mathrm{A}=120, \mathrm{~B}=72, \mathrm{C}=36, \mathrm{D}=12$

Figure 46. Vertical power patterns for Radar $\mathrm{k}-5$ obtained at four distances from the aperture. Each curve displays the total power density in $\mathrm{mW} / \mathrm{cm}^{2}$, or $\mathrm{dB}$ with respect to $1 \mathrm{~mW} / \mathrm{cm}^{2}$, as a function of the elevation angle in degrees. Zero degrees coincides with the direction of the main beam. 


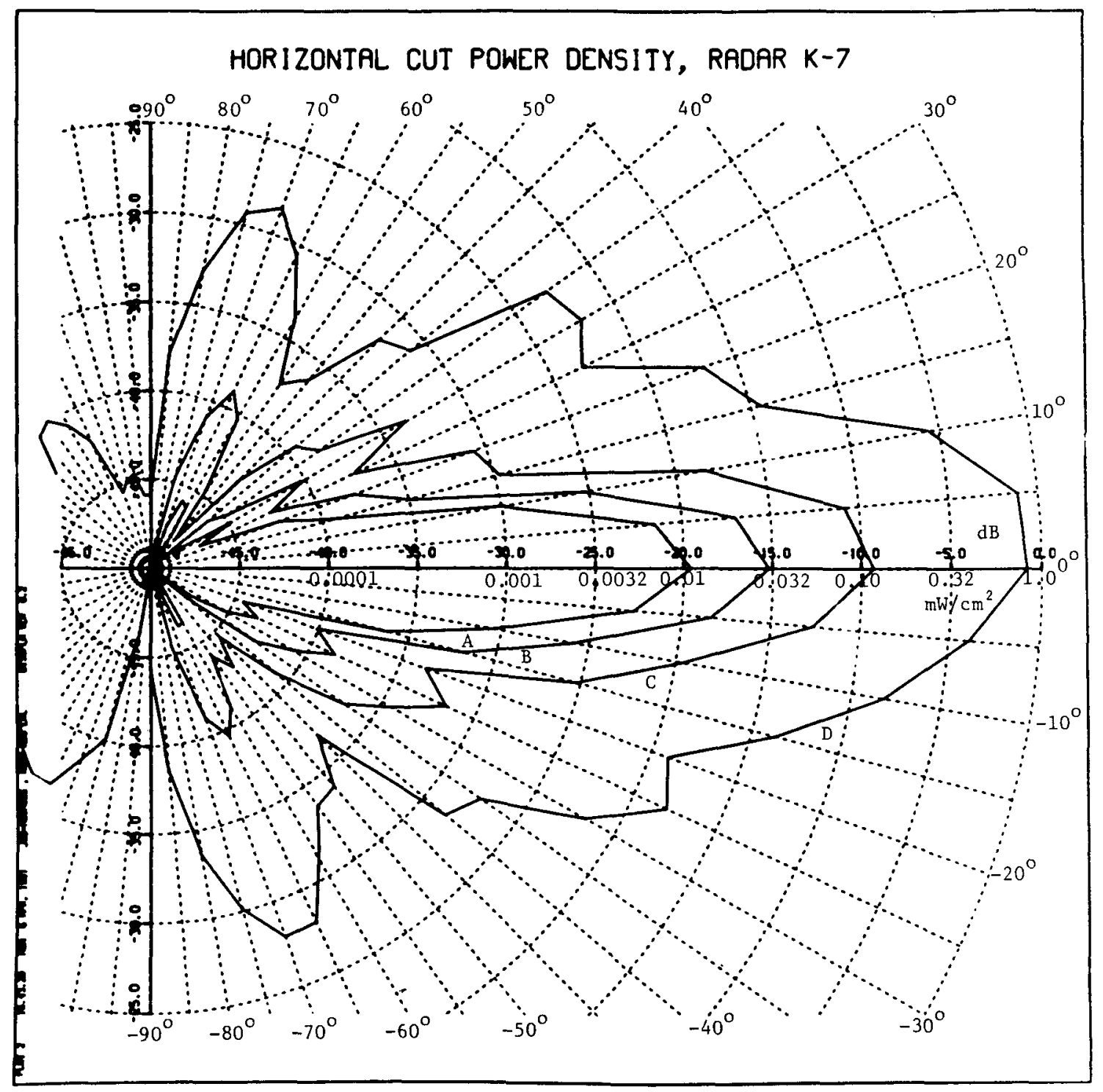

Distances From Radar (Inches): $A=120, B=72, C=36, D=12$

Figure 47. Horizontal power patterns for Radar $\mathrm{k}-7$ obtained at four distances from the aperture. Each curve displays the total power density in $\mathrm{mW} / \mathrm{cm}^{2}$, or $\mathrm{dB}$ with respect to $1 \mathrm{~mW} / \mathrm{cm}^{2}$, as a function of the azimuth angle in degrees. Zero degrees coincides with the direction of the main beam. 


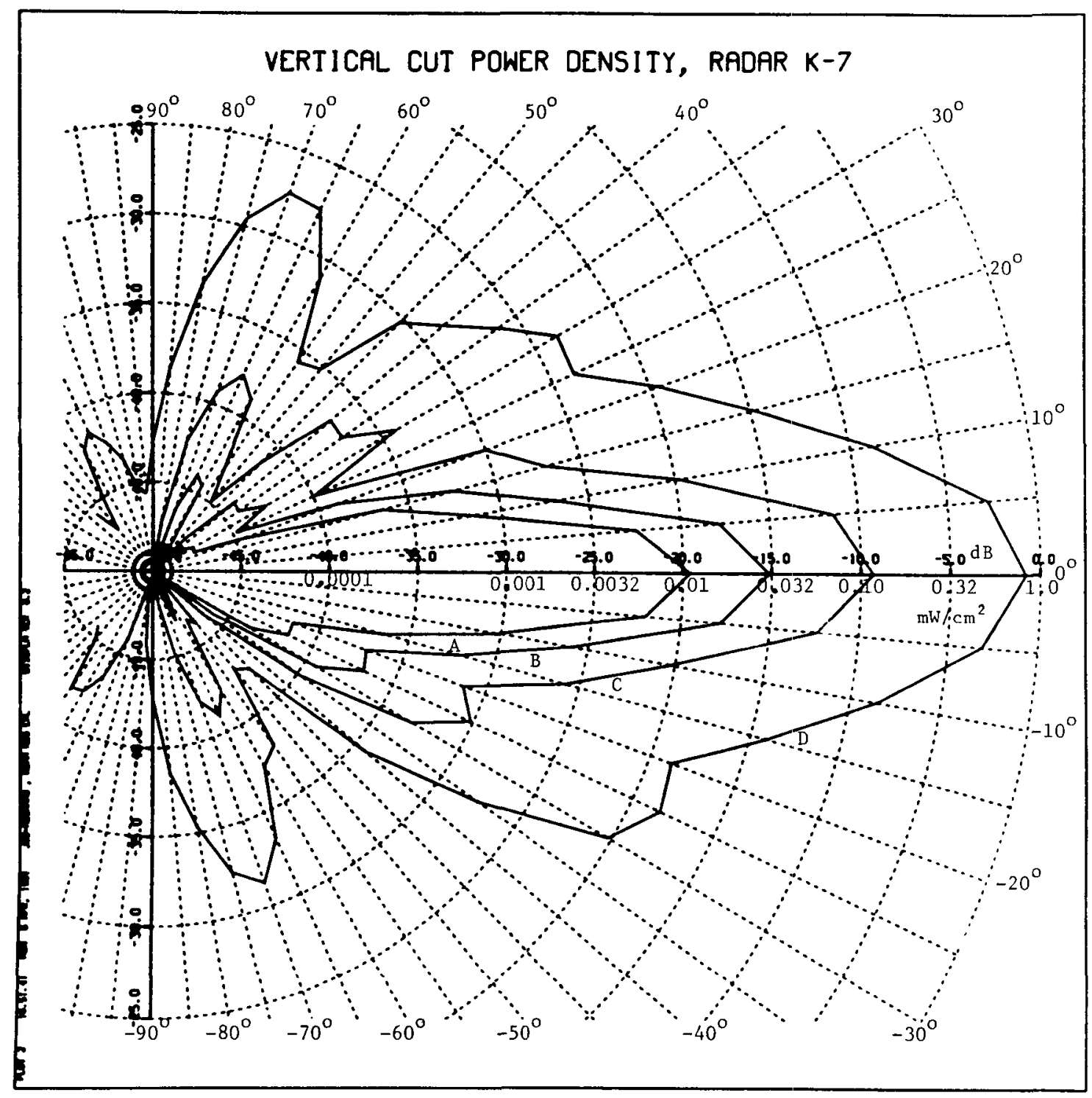

Distances From Radar (Inches): $A=120, B=72, C=36, D=12$

Figure 48. Vertical power patterns for Radar $k-7$ obtained at four distances from the aperture. Each curve displays the total power density in $\mathrm{mW} / \mathrm{cm}^{2}$, or $\mathrm{dB}$ with respect to $1 \mathrm{~mW} / \mathrm{cm}^{2}$, as a function of the elevation angle in degrees. Zero degrees coincides with the direction of the main beam. 


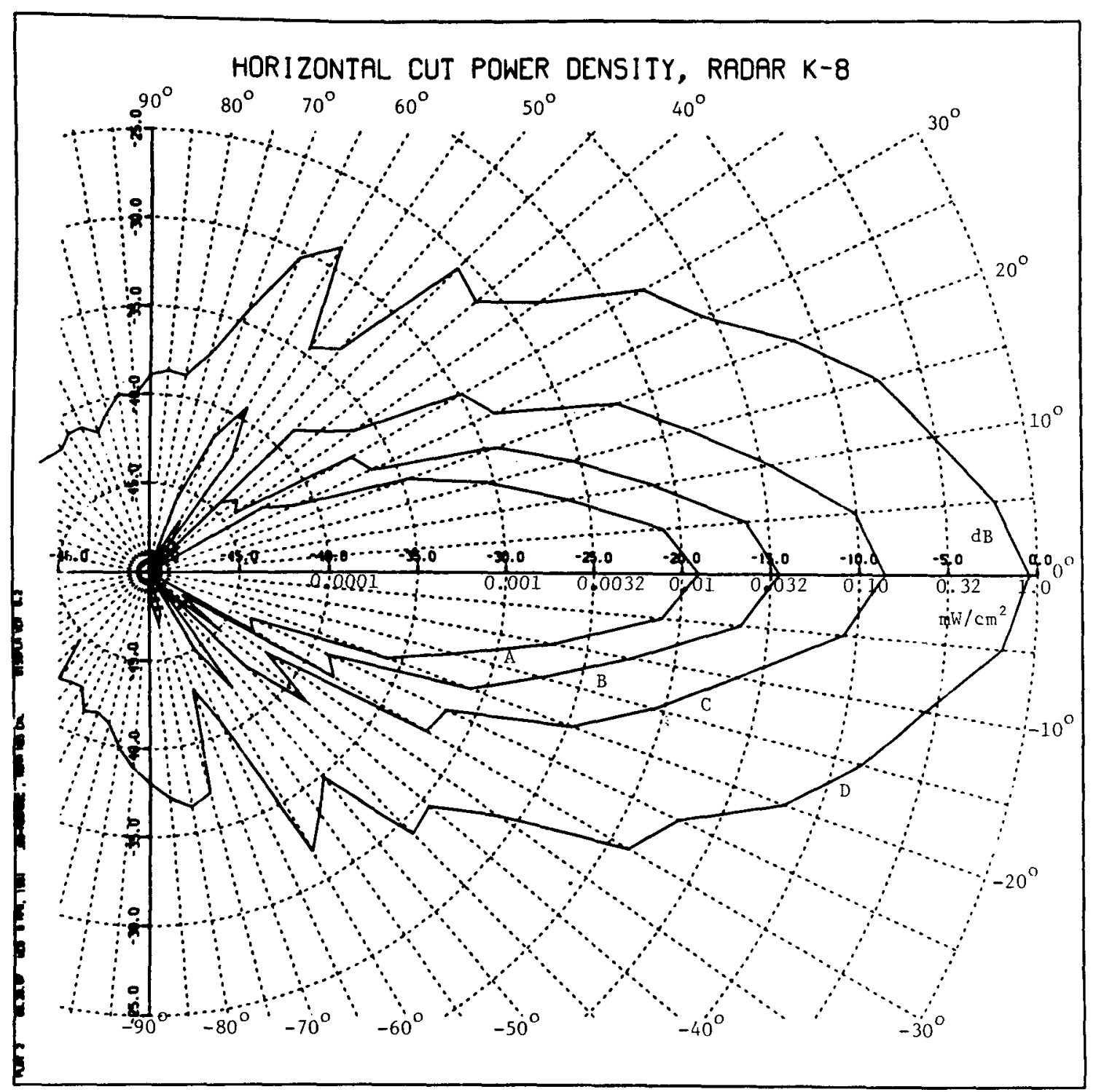

Distances From Radar (Inches): $A=120, B=72, C=36, D=12$

Figure 49. Horizontal power patterns for Radar K-8 obtained at four distances from the aperture. Each curve displays the total power density in $\mathrm{mW} / \mathrm{cm}^{2}$, or $\mathrm{dB}$ with respect to $1 \mathrm{~mW} / \mathrm{cm}^{2}$, as a function of the azimuth angle in degrees. Zero degrees coincides with the direction of the main beam. 


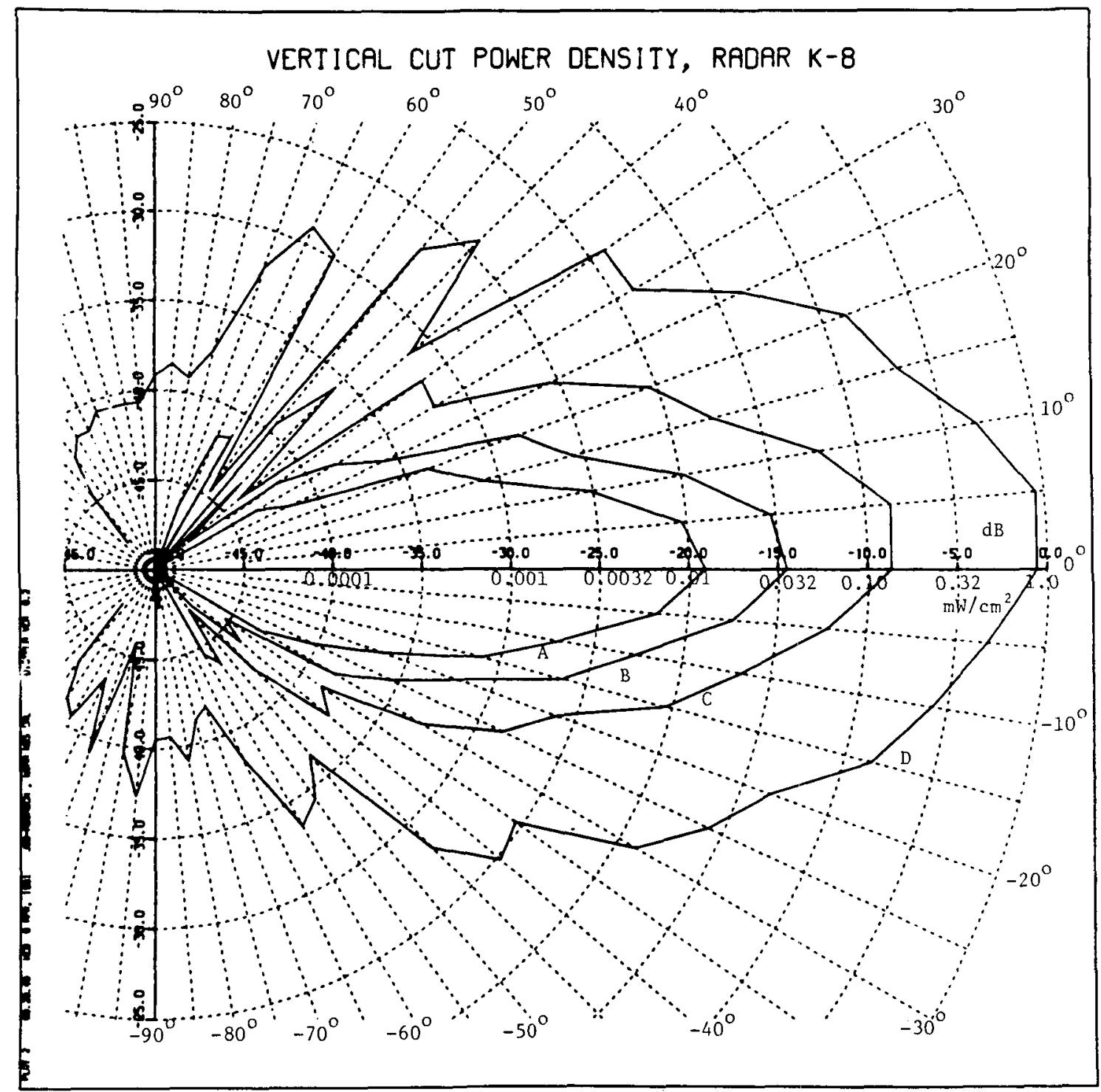

Distances From Radar (Inches): $A=120, B=72, C=36, D=12$

Figure 50. Vertical power patterns for Radar K-8 obtained at four distances from the aperture. Each curve displays the total power density in $\mathrm{mW} / \mathrm{cm}^{2}$, or $\mathrm{dB}$ with respect to $1 \mathrm{~mW} / \mathrm{cm}^{2}$, as a function of the elevation angle in degrees. Zero degrees coincides with the direction of the main beam. 


\section{Appendix A--References}

[1] Silver, S. Microwave antenna theory and design. New York, NY: McGrawHill; 1949. 1-4.

[2] Newel1, A. C.; Baird, R. C.; Wacker, P. F. Accurate measurement of antenna gain and polarization at reduced distances by an extrapolation technique. IEEE transactions on antennas and propagation. $A P-21(4)$ : 419-431; 1973 July.

[3] Baranski, S.; Czerski, P. Biological effects of microwaves. Stroudsburg, PA: Dowden, Hutchinson and Ross, Inc,; 1976. 177. 